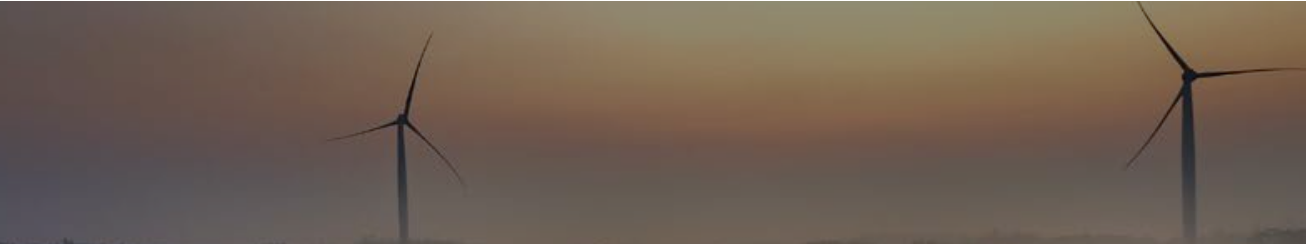

Storage Futures Study

Storage Technology Modeling Input Data Report

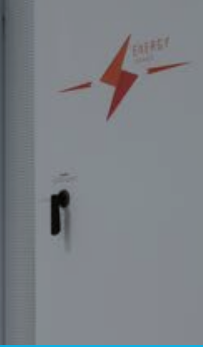




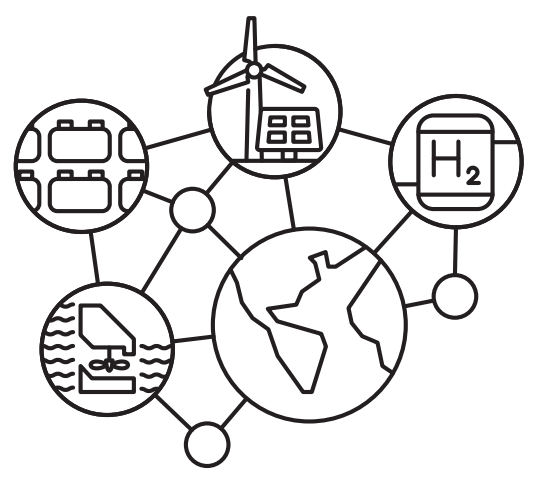

Storage Futures Study

\section{Storage Technology Modeling Input Data Report}

Chad Augustine and Nate Blair 


\section{Preface}

This report is one in a series of the National Renewable Energy Laboratory's Storage Futures Study (SFS) publications. The SFS is a multiyear research project that explores the role and impact of energy storage in the evolution and operation of the U.S. power sector. The SFS is designed to examine the potential impact of energy storage technology advancement on the deployment of utility-scale storage and the adoption of distributed storage, and the implications for future power system infrastructure investment and operations. The research findings and supporting data will be published as a series of publications. The table on the next page lists the planned publications and specific research topics they will examine under the SFS.

This report, the second in the SFS series, reviews the current characteristics of a broad range of mechanical, thermal, and electrochemical storage technologies with application to the power sector. The report provides current and future projections of cost, performance characteristics, and locational availability of specific commercial technologies already deployed, including lithium-ion battery systems and pumped-storage hydropower. These projections will inform the modeling and analysis of power system evolution scenarios planned for later reports in the series.

The SFS series provides data and analysis in support of the U.S. Department of Energy's Energy Storage Grand Challenge, a comprehensive program to accelerate the development, commercialization, and utilization of next-generation energy storage technologies and sustain American global leadership in energy storage. The Energy Storage Grand Challenge employs a use case framework to ensure storage technologies can cost-effectively meet specific needs, and it incorporates a broad range of technologies in several categories: electrochemical, electromechanical, thermal, flexible generation, flexible buildings, and power electronics.

More information, any supporting data associated with this report, links to other reports in the series, and other information about the broader study are available at https://www.nrel.gov/analysis/storage-futures.html. 


\begin{tabular}{|c|c|c|}
\hline Title & Description & Relation to this Report \\
\hline $\begin{array}{l}\text { The Four Phases of } \\
\text { Storage Deployment: } \\
\text { A Framework for the } \\
\text { Expanding Role of } \\
\text { Storage in the U.S. } \\
\text { Power System }\end{array}$ & $\begin{array}{l}\text { Explores the roles and opportunities for } \\
\text { new, cost-competitive stationary energy } \\
\text { storage with a conceptual framework } \\
\text { based on four phases of current and } \\
\text { potential future storage deployment, and } \\
\text { presents a value proposition for energy } \\
\text { storage that could result in cost-effective } \\
\text { deployments reaching hundreds of } \\
\text { gigawatts (GW) of installed capacity }\end{array}$ & $\begin{array}{l}\text { Provides broader context on } \\
\text { the implications of the cost } \\
\text { and performance } \\
\text { characteristics discussed in } \\
\text { this report, including the } \\
\text { specific grid services they } \\
\text { may enable in various phases } \\
\text { of storage deployment }\end{array}$ \\
\hline $\begin{array}{l}\text { Energy Storage } \\
\text { Technology Modeling } \\
\text { Input Data Report }\end{array}$ & $\begin{array}{l}\text { Reviews the current characteristics of a } \\
\text { broad range of mechanical, thermal, and } \\
\text { electrochemical storage technologies with } \\
\text { application to the power sector. Provides } \\
\text { current and future projections of cost, } \\
\text { performance characteristics, and locational } \\
\text { availability of specific commercial } \\
\text { technologies already deployed, including } \\
\text { lithium-ion battery systems and pumped } \\
\text { storage hydropower. }\end{array}$ & Presented in this report \\
\hline $\begin{array}{l}\text { Economic Potential of } \\
\text { Diurnal Storage in the } \\
\text { U.S. Power Sector }\end{array}$ & $\begin{array}{l}\text { Assesses the economic potential for utility- } \\
\text { scale diurnal storage and the effects that } \\
\text { storage capacity additions could have on } \\
\text { power system evolution and operations }\end{array}$ & $\begin{array}{l}\text { Analyzes utility-scale storage } \\
\text { deployment and grid } \\
\text { evolution scenarios to test the } \\
\text { various cost trajectories and } \\
\text { assumptions detailed in this } \\
\text { report. }\end{array}$ \\
\hline $\begin{array}{l}\text { Distributed Storage } \\
\text { Customer Adoption } \\
\text { Scenarios }\end{array}$ & $\begin{array}{l}\text { Assesses the customer adoption of } \\
\text { distributed diurnal storage for several } \\
\text { future scenarios and the implications for } \\
\text { the deployment of distributed generation } \\
\text { and power system evolution }\end{array}$ & $\begin{array}{l}\text { Analyzes distributed storage } \\
\text { adoption scenarios to test the } \\
\text { various cost trajectories and } \\
\text { assumptions detailed in this } \\
\text { report. }\end{array}$ \\
\hline $\begin{array}{l}\text { Grid Operational } \\
\text { Implications of } \\
\text { Widespread Storage } \\
\text { Deployment }\end{array}$ & $\begin{array}{l}\text { Assesses the operation and associated } \\
\text { value streams of energy storage for } \\
\text { several power system evolution scenarios } \\
\text { and explores the implications of seasonal } \\
\text { storage on grid operations }\end{array}$ & $\begin{array}{l}\text { Considers the operational } \\
\text { implications of storage } \\
\text { deployment and grid } \\
\text { evolution scenarios to } \\
\text { examine and expand on the } \\
\text { grid-scale scenario results } \\
\text { found with ReEDS }\end{array}$ \\
\hline $\begin{array}{l}\text { Storage Futures Study: } \\
\text { Executive Summary and } \\
\text { Synthesis of Findings }\end{array}$ & $\begin{array}{l}\text { Synthesizes and summarizes findings from } \\
\text { the entire series and related analyses and } \\
\text { reports, and identifies topics for further } \\
\text { research }\end{array}$ & $\begin{array}{l}\text { Includes a discussion of all } \\
\text { other aspects of the study } \\
\text { and provides context for the } \\
\text { results of this study }\end{array}$ \\
\hline
\end{tabular}




\section{Acknowledgments}

We would like to acknowledge the contributions of the entire Storage Futures Study team as well as our U.S. Department of Energy (DOE) Office of Strategic Analysis colleagues as core contributors to this document. Those contributors include Paul Denholm, Wesley Cole, Will Frazier, Ben Sigrin, Kevin McCabe, and Ashreeta Prasanna from the National Renewable Energy Laboratory (NREL) and Kara Podkaminer from DOE. We would also acknowledge the feedback and contributions of other NREL staff, including Chad Hunter, Evan Reznicek, Michael Penev, Greg Stark, Vignesh Ramasamy, David Feldman, and Trieu Mai, We also would like to thank the technical review committee for input, including Doug Arent (NREL/Chair), Paul Albertus, Ines Azevedo, Ryan Wiser, Susan Babinec, Aaron Bloom, Chris Namovicz, Arvind Jaggi, Keith Parks, Kiran Kumaraswamy, Granger Morgan, Cara Marcy, Vincent Sprenkle, Oliver Schmidt, David Rosner, John Gavan, and Howard Gruenspecht. Finally, additional thoughts and suggestions came from various technical experts at DOE, including Paul Spitsen, Kathryn Jackson, Neha Rustagi, Marc Melaina, Andrew Dawson, Adria Brooks, Sam Baldwin, Sarah Garman.

This work was authored by the National Renewable Energy Laboratory, operated by Alliance for Sustainable Energy, LLC, for the U.S. Department of Energy (DOE) under Contract No. DEAC36-08GO28308. Funding provided by U.S. Department of Energy Office of Energy Efficiency and Renewable Energy Solar Energy Technologies Office, U.S. Department of Energy Office of Energy Efficiency and Renewable Energy Wind Energy Technologies Office, U.S. Department of Energy Office of Energy Efficiency and Renewable Energy Water Power Technologies Office and U.S. Department of Energy Office of Energy Efficiency and Renewable Energy Office of Strategic Analysis. The views expressed in the article do not necessarily represent the views of the DOE or the U.S. Government. The U.S. Government retains and the publisher, by accepting the article for publication, acknowledges that the U.S. Government retains a nonexclusive, paid-up, irrevocable, worldwide license to publish or reproduce the published form of this work, or allow others to do so, for U.S. Government purposes. 


\section{List of Acronyms and Abbreviations}

ATB

BESS

BNEF

BOS

CAES

CSP

dGen

DOE

$\mathrm{E} / \mathrm{P}$

EPC

ESB

ESBOS

ESS

EV

FC

FERC

$\mathrm{H}_{2}$
Annual Technology Baseline

battery energy storage system(s)

Bloomberg New Energy Finance

balance of system

compressed air energy storage

concentrating solar power

Distributed Generation Market Demand (dGen) model

U.S. Department of Energy

energy/power ratio

engineering, procurement, and construction

energy storage block

energy storage balance of system

energy storage system

electric vehicle

fuel cell

Federal Energy Regulatory Commission

hydrogen (as a storage fluid)

H2 Elec-salt cavern- CT hydrogen storage using electrolyzers, salt caverns, and combustion turbines

H2 Elec-salt cavern- FC hydrogen storage using electrolyzers, salt caverns, and stationary fuel cells

$\mathrm{kW} \quad$ kilowatt

kWh kilowatt-hour

LAES

LCOGS

LFP

LIB

$\mathrm{mS}$

MW

$M W_{D C}$

$\mathrm{MWh}$

NCA

liquid air energy storage

levelized cost of generation and storage

lithium, iron, phosphate

lithium-ion battery

millisecond

megawatts

megawatts-direct current

megawatt-hour

nickel, cobalt, aluminum

nickel-manganese-cobalt

NREL

National Renewable Energy Laboratory

O\&M

PSH

PTES

operation and maintenance

pumped-storage hydropower

pumped thermal energy storage

ReEDS

NREL's Regional Energy Deployment System model

RTE

$\mathrm{S}$ round-trip efficiency

second

SFS Storage Futures Study

USD U.S. dollars

$\mathrm{W}_{\mathrm{DC}} \quad$ watts-direct current 


\section{Executive Summary}

The Storage Futures Study (SFS) is a multiyear research project to explore the role and impact of energy storage in the evolving electricity sector of the United States. The SFS is designed to examine the potential impact of energy storage technology advancement on the deployment of utility-scale storage and the adoption of distributed storage, and the implications for future power system infrastructure investment and operations. This specific report synthesizes current and projected cost performance assumptions along with location availability for storage technologies through 2050 that will be used in scenario analysis for the SFS at both the bulk power and distribution system scales. For comparison and context, this report also presents a synthesis of current cost and performance characteristics of energy storage technologies for storage durations ranging from minutes to months and including mechanical, thermal, and electrochemical storage technologies for the electricity sector. This information is intended to cover a broad range of storage technologies that are currently receiving significant attention from the investment community as well as in the media. In the report, we emphasize that energy storage technologies must be described in terms of both their power (kilowatts [kW]) capacity and energy (kilowatthours $[\mathrm{kWh}]$ ) capacity to assess their costs and potential use cases.

The technology cost and performance future projections highlighted in this work are limited to two commercial technologies that have already been deployed in the United States and thus have available data to inform forward projections: battery energy storage systems (BESS) and pumped-storage hydropower energy storage (PSH). These scenarios capture an aggressive range of future cost reductions under current market and policy conditions. They do not explicitly represent cost reductions that may occur with rapid deployment to achieve deep decarbonization. While there are uncertainties with potential supply chain constraints, costs could come down even faster than captured in this analysis under a highly decarbonized future. There are ongoing efforts to better capture the potential for accelerated cost reductions based upon accelerated deployment.

For each technology, we develop three projections: an Advanced Scenario, a Moderate Scenario, and a Conservative Scenario. The Moderate Scenario is the most likely projection based on literature and analysis, and the Advanced and Conservative Scenarios are used to test the sensitivity of technology costs to projected deployments under SFS scenarios. The PSH and utility-scale BESS projections will be used in the National Renewable Energy Laboratory's (NREL's) Regional Energy Deployment System (ReEDS) capacity expansion model to explore grid-scale energy storage, while residential and commercial and industrial BESS projections are used in the Distributed Generation Market Demand (dGen) model to study distributed energy storage.

These projections provide a benchmark for storage technologies, with a wide but plausible range of technology advancement over multiple decades. Any of the emerging technologies that reach comparable cost and performance levels could be deployed instead of BESS or PSH. Likewise, the SFS project assesses the grid impacts independent of specific storage technologies, but instead driven by the services and value that are provided. In other words, when evaluating SFS model results, the reader should focus on the energy storage costs, durations, and use cases rather than the specific technologies and should realize that a suite of technologies has the potential to provide these characteristics in the future. 


\section{Current and Projected Costs}

Current and Projected PSH Costs: To develop current and future projections for PSH costs, data from the U.S. Department of Energy's (DOE's) HydroWIRES cost modeling of U.S.averaged resources is used to frame PSH relative to a broad set of technologies (Mongird et al. 2020). Because of the interest in modeling site-specific regional data and constraints, we use the existing regional supply curve cost and performance data developed as part of the DOE HydroVision Study (DOE 2016) in the ReEDS model to assess the implications for grid evolution.

Battery Energy Storage Systems (BESS) Costs: For utility-scale, commercial/industrial, and residential BESS, we estimate current component-level costs of BESS for each market segment and apply a consistent cost projection curve for future costs. For all BESS, we assume lithiumion battery (LIB) technology is used, although do not specify the type of battery chemistry.

Current Utility-Scale BESS Costs: Current costs for utility-scale BESS are based on a bottomup cost model using the data and methodology for utility-scale BESS in Feldman et al. (2021). The bottom-up BESS model accounts for major components, including the LIB pack, inverter, and the balance of system (BOS) needed for the installation. The battery pack is a set of cells themselves and their packaging (see Figure 11). Enclosures and anything that packages a number of packs is typically captured separately in the capital cost. Using the detailed NREL cost models for LIB, we develop current costs for a 60-MW BESS with storage durations of 2, 4, 6, 8, and 10 hours, shown in terms of energy capacity $(\$ / \mathrm{kWh})$ and power capacity $(\$ / \mathrm{kW})$ in Figure ES-1 and Figure ES-2 respectively. 60-MW is used as the representative BESS project size in ReEDS based on the assumed ratio of storage for the representative 100MW PV system used in ReEDS (although here we are not looking at a hybrid system). Current installed capital costs for BESS in terms of $\$ / \mathrm{kWh}$ decrease with duration, while costs in $\$ / \mathrm{kW}$ increase. This inverse behavior is observed for all energy storage technologies and highlights the importance of distinguishing the two types of battery capacity when discussing the cost of energy storage. 


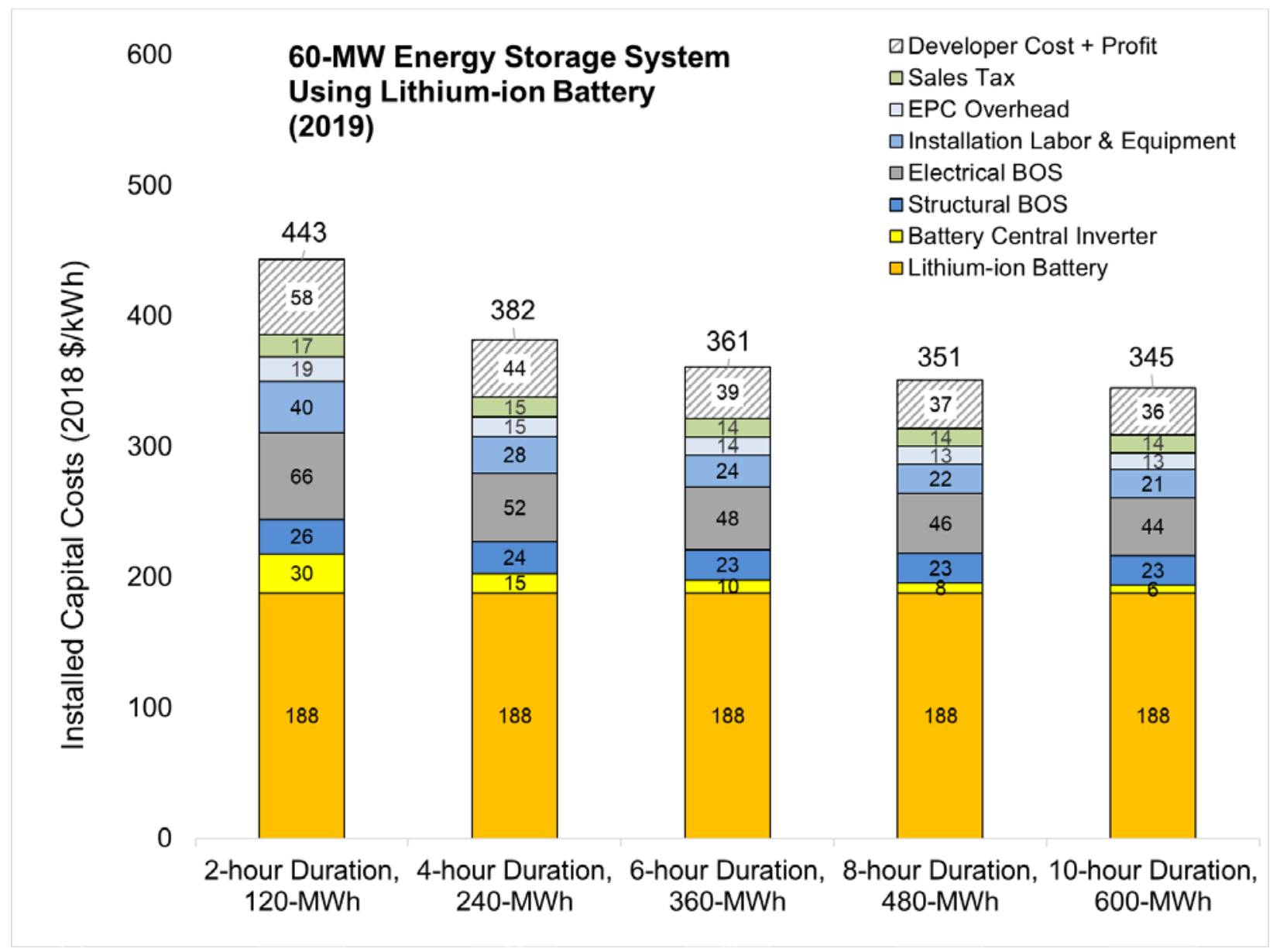

Figure ES-1. 2019 U.S. utility-scale LIB storage costs for durations of 2-10 hours (60 MW in $\$ / k W h$

$\mathrm{EPC}=$ engineering, procurement, and construction 


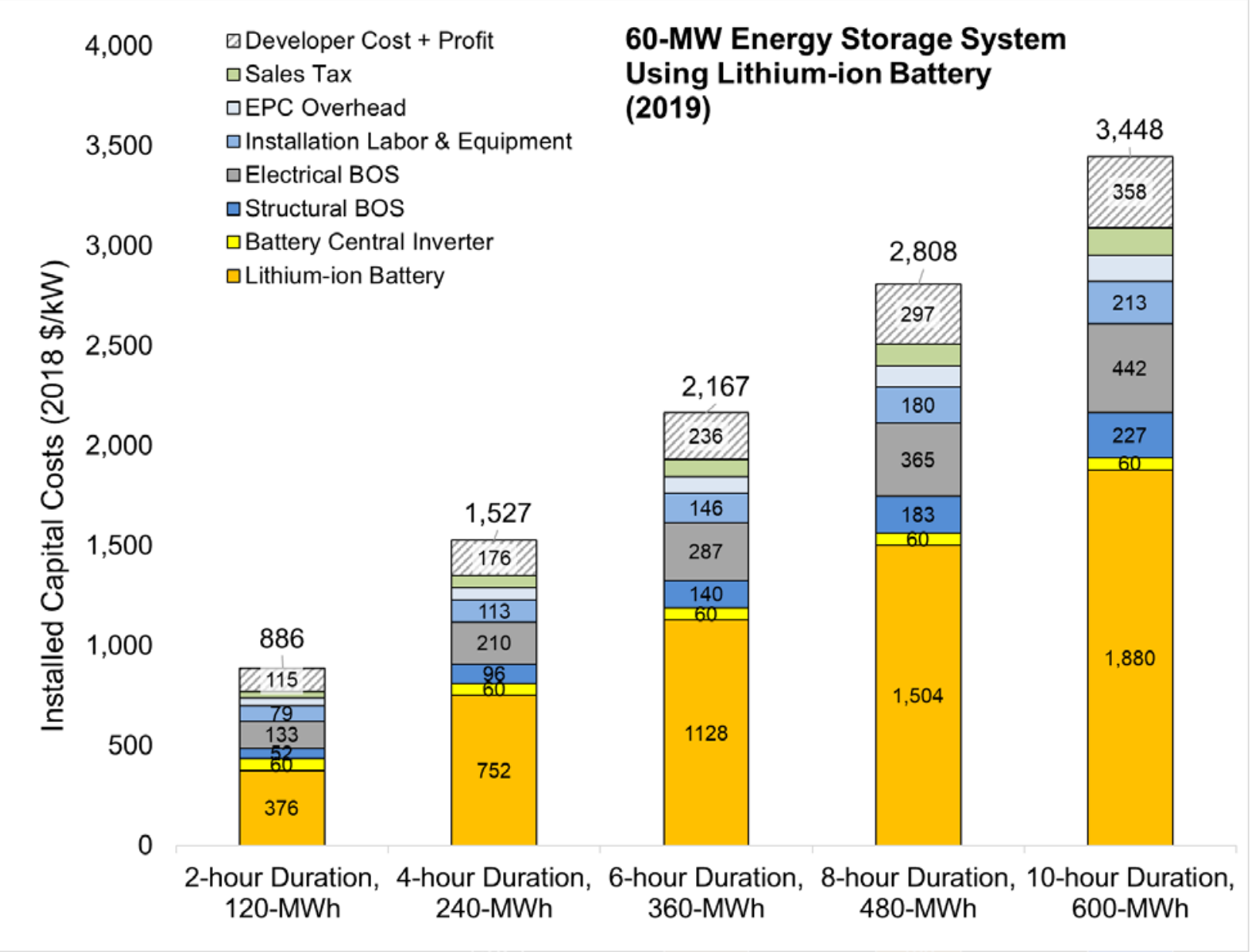

Figure ES-2. 2019 U.S. utility-scale LIB storage costs for durations of 2-10 hours (60 MW $\$ / \mathbf{k W}$

Projected Utility-Scale BESS Costs: Future cost projections for utility-scale BESS are based on a synthesis of cost projections for 4-hour duration systems in Cole and Frazier (2020) ${ }^{1}$ and the Bloomberg New Energy Finance (BNEF) cost projections for utility-scale BESS (BNEF 2019b; BNEF 2019a). The Cole and Frazier cost projections are based on a literature survey that includes results from 18 studies of BESS costs. The BNEF cost projections are based on learning rates and deployment projections for utility-scale BESS that are broken down at the system component level. Both projections extend to 2050. Projected battery costs tend to decrease much more quickly than other system components such as the inverter, BOS, installation, and soft cost components (EPRI 2018; BNEF 2019b; BNEF 2019a; Schmidt et al. 2018). Thus, projected total system costs decrease more quickly for longer-duration battery storage than shorter-duration battery storage. However, the duration aspect is not captured in the BNEF cost projections, which only consider a 4-hour system. The Cole and Frazier (2020) projections contain information for both power and duration so costs can be calculated for any storage duration, but they do not account for how the different BESS component costs (particularly, the LIB pack cost) change over time. Therefore, to account for storage costs as a function of storage duration,

\footnotetext{
${ }^{1}$ The report and comparison of 18 projections were developed for use in NREL's Annual Technology Baseline (https://atb.nrel.gov/).
} 
we apply the BNEF battery cost reduction projections to the energy (battery) portion of the 4hour storage and use the Cole and Frazier summary for the remaining component costs to develop combined projections for future years. In this way, the cost projections capture the rapid projected decline in battery costs while also accounting for component costs decreasing at different rates in the future. Figure ES-3 shows the resulting utility-scale BESS future cost projections for the Moderate Scenario for 2-10 hours in terms of both $\$ / \mathrm{kWh}$ and $\$ / \mathrm{kW}$. We also explore Advanced and Conservative BESS cost scenarios as shown in Figure 32 (page 43) and Figure 33 (page 45).

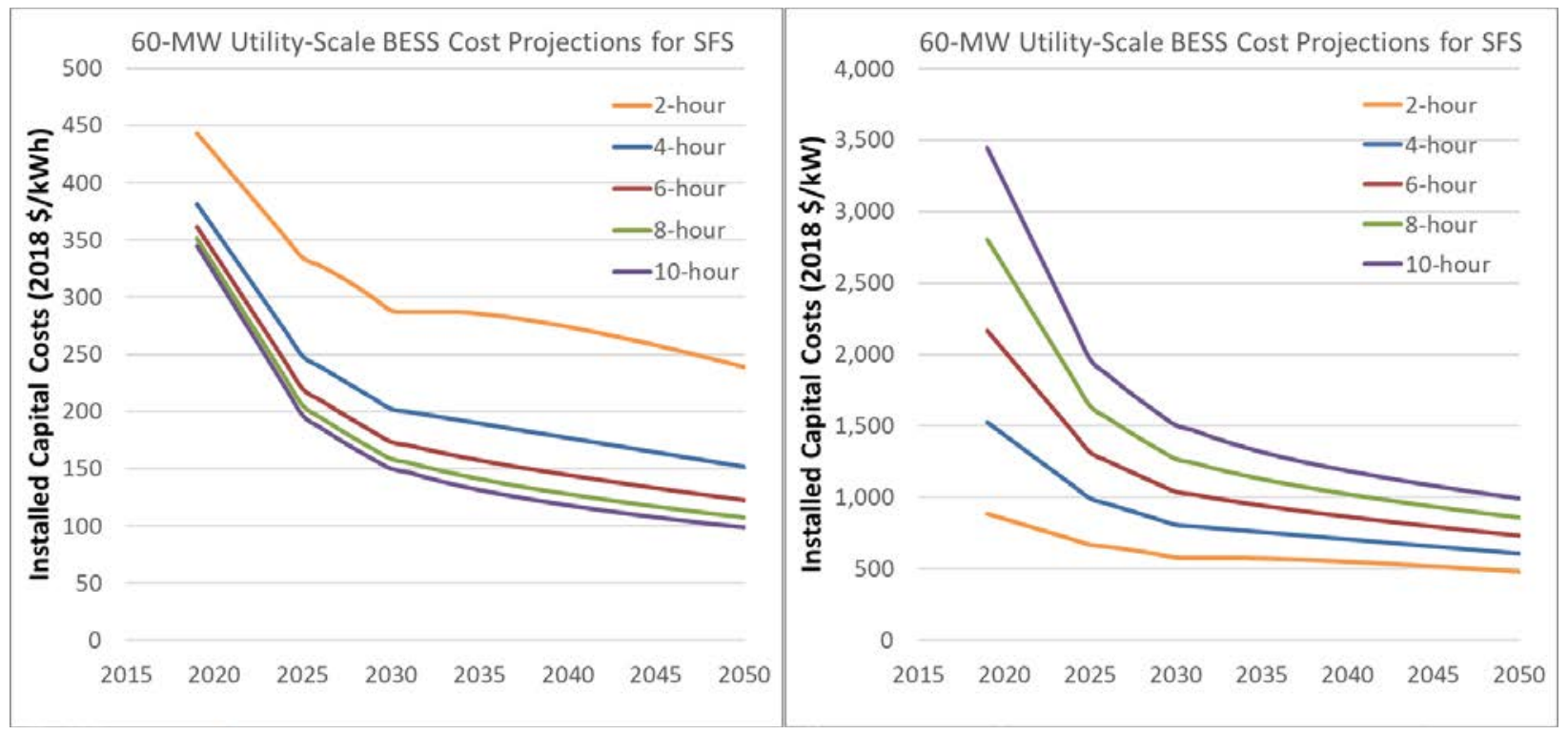

Figure ES-3. Utility-scale BESS Moderate Scenario cost projections, on a $\$ / k W h$ basis (left) and a $\$ / \mathbf{k W}$ basis (right)

Projections assume a 60-MWDC project. Note that 2019 costs correspond to Figure ES-1 and Figure ES-2.

Current Residential and Commercial/Industrial BESS: Residential and commercial/industrial BESS costs are estimated based on BESS combined with solar photovoltaic (PV) systems, or $\mathrm{PV}+\mathrm{BESS}$ system. This is done to provide the dGen model with appropriate costs for these typical hybrid systems. In addition, rather than prescribe a system size, we allow the model to choose the optimum system size and storage duration. Current costs for residential and commercial/industrial BESS and PV+BESS are based on NREL's bottom-up BESS cost models using the data and methodology for commercial/industrial PV systems and BESS in Feldman et al. (2021) (see Figure ES-4 and Figure ES-5). We run the models over a range of system sizes and storage durations and then develop a correlation for costs by fitting curves to the results. Because of the method of optimization used to select PV and battery sizes within the dGen model, the correlations are linear functions of system power capacity and energy capacity. 


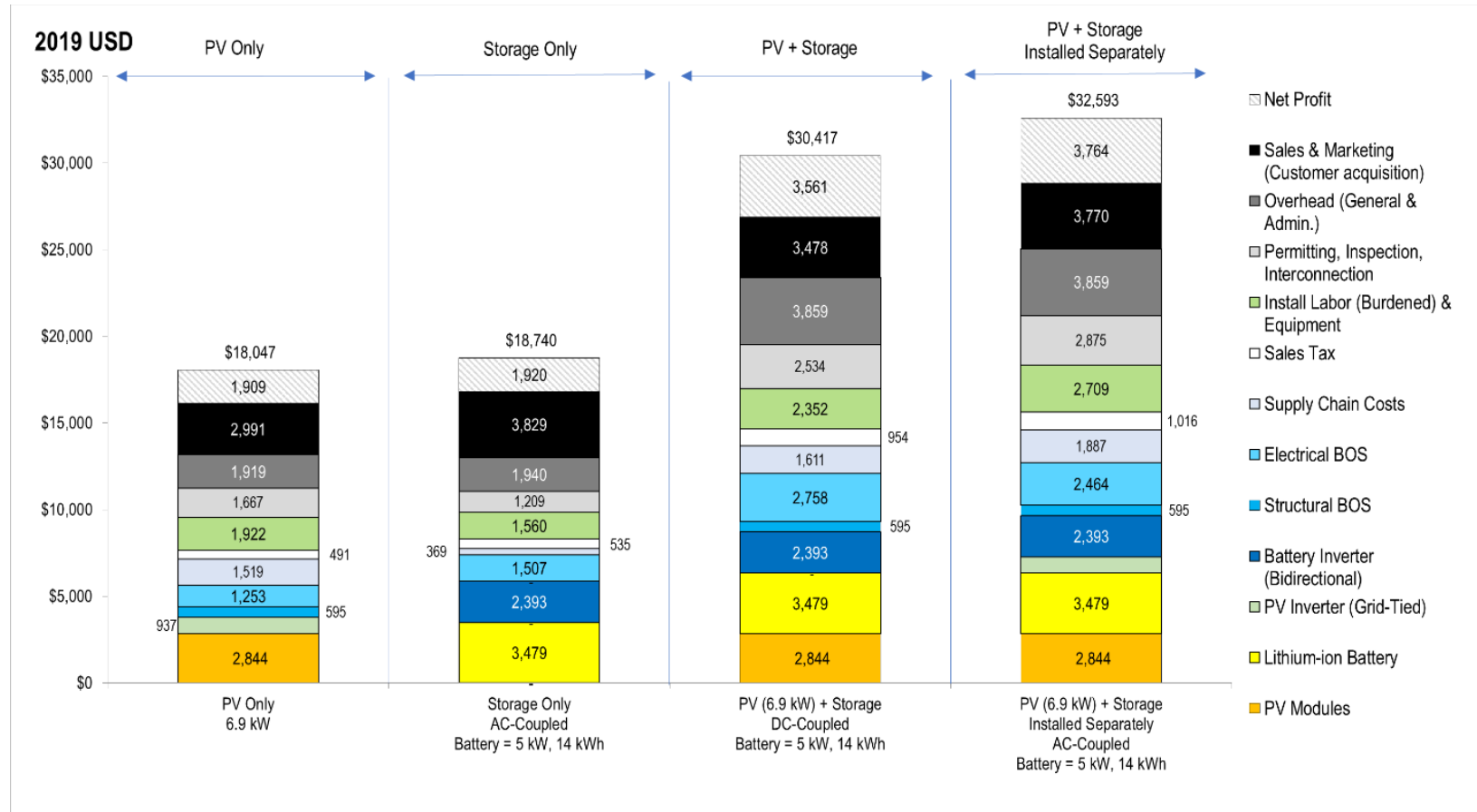

Figure ES-4. Cost of residential PV-stand-alone, BESS-stand-alone, and PV+BESS systems estimated using NREL bottom-up models

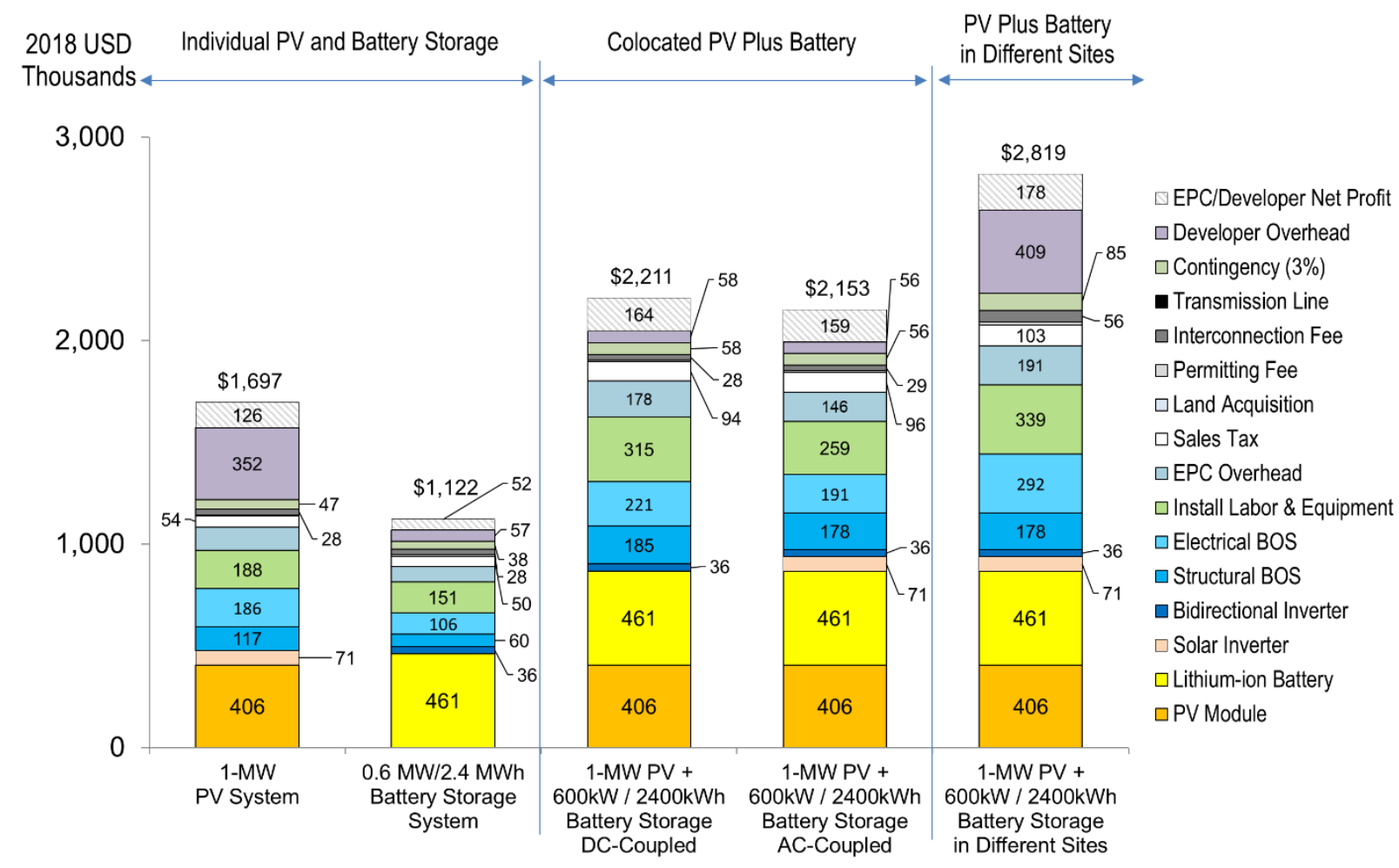

Figure ES-5. Estimated costs of commercial and industrial stand-alone PV, stand-alone BESS, and PV+BESS using NREL bottom-up model 
Projected Residential and Commercial/Industrial BESS Costs: For both residential and commercial/industrial BESS, future BESS cost projections are based on relative component level cost reductions sourced from BNEF (Figure ES-6), which uses learning rates and future capacity projections specific to residential BESS systems (BNEF 2019b). Projected costs for representative residential BESS, shown in Figure ES-6 and ES-7, are calculated by applying the BNEF cost reduction projections to the current costs described above. The resulting Advanced, Moderate, and Conservative Scenario cost projections for representative residential and commercial/industrial BESS are shown in Figure ES-7.

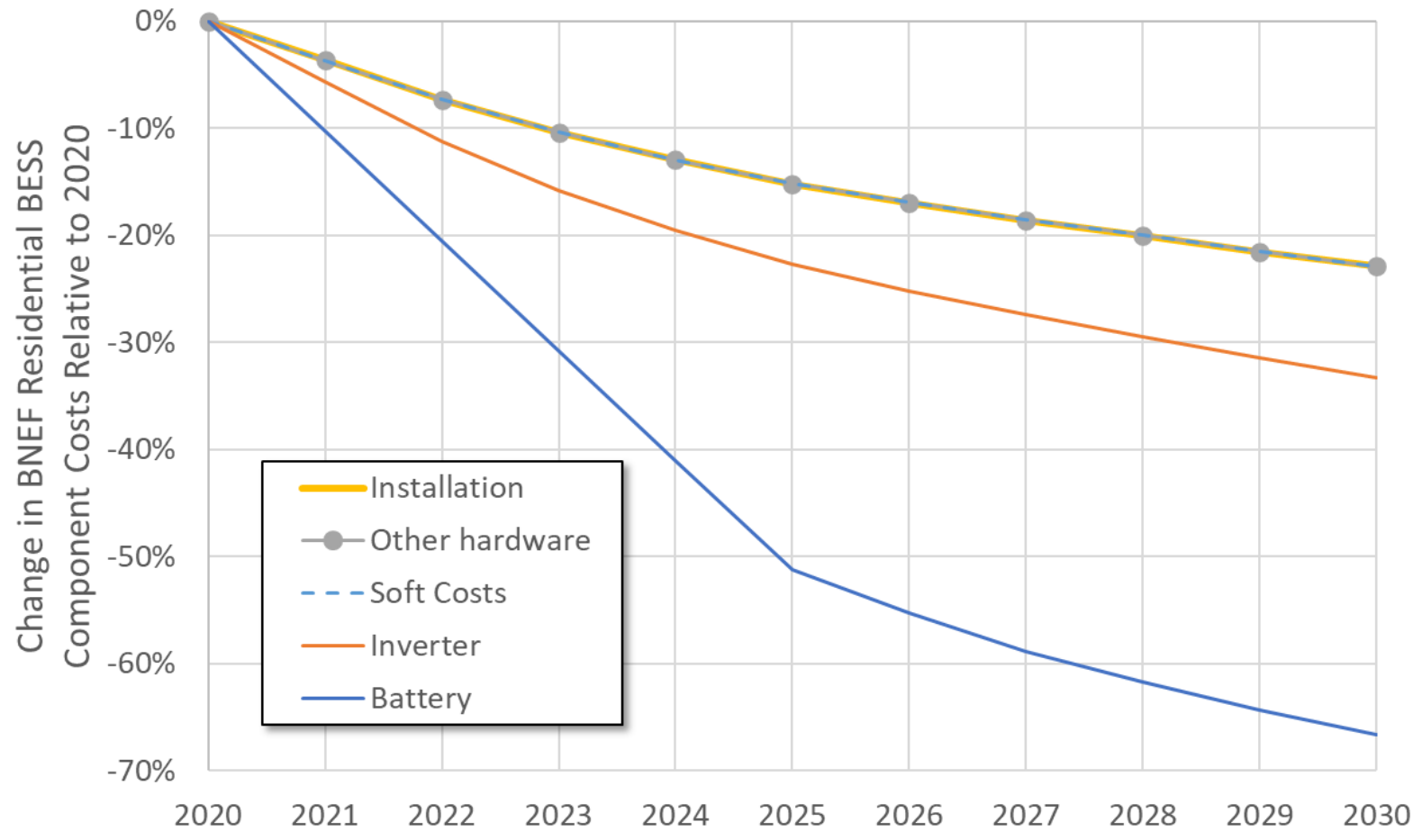

Figure ES-6. Relative changes in projected component costs for residential BESS

Data Source: (BNEF 2019b) 


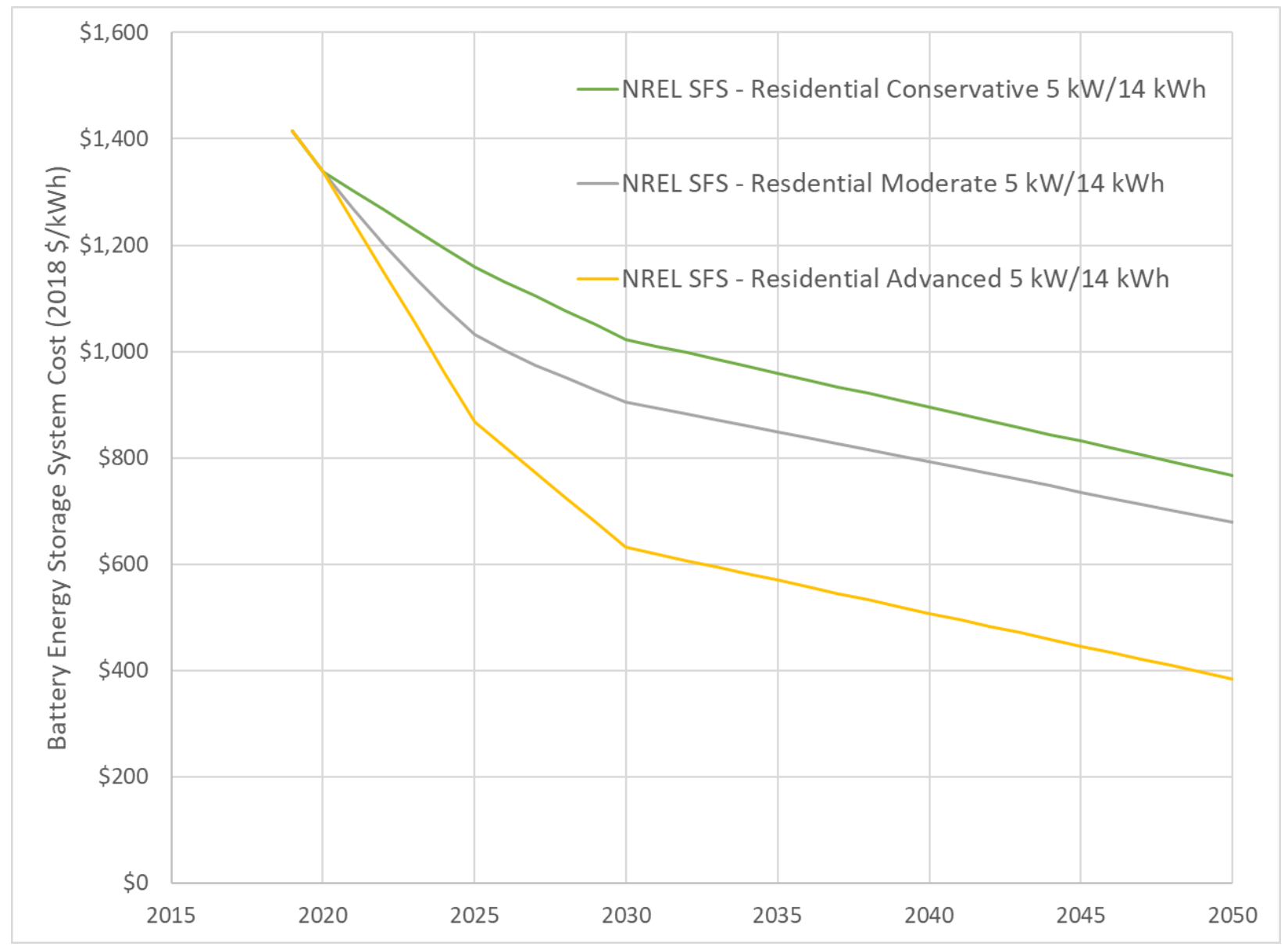

Figure ES-7. Moderate, Advanced, and Conservative Scenario cost projections for representative residential BESS

\section{Summary of Storage Technologies and Metrics Comparison}

To be consistent and clear in our analysis of energy storage technologies, Section 2 defines and summarizes the key metrics related to energy storage. The metrics needed to quantify electricity storage costs differ from those for electricity generation. Electricity generation equipment is sized based on only its power capacity, or the amount of power $(\mathrm{kW})$ it can provide to the grid, and the equipment is typically costed in capacity terms $(\$ / \mathrm{kW})$. In contrast, energy storage systems are sized based on two factors: their power capacity and their energy capacity, or how much energy $(\mathrm{kWh})$ they can store. Energy capacity relative to power capacity $(\mathrm{E} / \mathrm{P})$ determines a system's storage duration, or how long it can provide power at its rated power capacity. To assess energy storage system costs, one must know both the energy capacity and power capacity (or storage duration).

The data sources for the current technology costs and other parameters used in the comparison in Figure ES-8 are based on a variety of sources with ranges of uncertainty, especially in emerging technologies (Table ES-1). 
Table ES- 1. Data Sources for Energy Storage Technologies

\begin{tabular}{|c|c|c|}
\hline Storage Type/Technology & $\begin{array}{l}\text { Reference Year for } \\
\text { Current (2019) Costs }\end{array}$ & Primary Data Source \\
\hline \multicolumn{3}{|l|}{ Thermal Storage } \\
\hline Pumped thermal energy storage (PTES) & 2020 & McTigue et al. In Press \\
\hline \multicolumn{3}{|l|}{ Electrochemical Storage } \\
\hline Lithium-ion battery (weighted value) (LIB) & 2020 & $\begin{array}{l}\text { Multiple sources; } \\
\text { see References (p. 59) }\end{array}$ \\
\hline Lead-acid battery & 2020 & Mongird et al. 2020 \\
\hline Redox flow battery (flow batteries) & 2020 & Mongird et al. 2020 \\
\hline Sodium sulfur battery & 2018 & Mongird et al. 2019 \\
\hline Sodium metal halide battery & 2018 & Mongird et al. 2019 \\
\hline Zinc-hybrid cathode battery & 2018 & Mongird et al. 2019 \\
\hline Ultracapacitors & 2018 & Mongird et al. 2019 \\
\hline $\begin{array}{l}\text { Hydrogen storage (using electrolyzers, } \\
\text { salt caverns, and combustion turbines) }\end{array}$ & 2020 & Hunter et al. 2021 \\
\hline $\begin{array}{l}\text { Hydrogen storage (using electrolyzers, } \\
\text { salt caverns, and stationary fuel cells)c }\end{array}$ & $2020^{a}$ & Hunter et al. 2021 \\
\hline \multicolumn{3}{|l|}{ Electromechanical Storage } \\
\hline Compressed air energy storage (CAES) & 2020 & Mongird et al. 2020 \\
\hline Liquid air energy storage (LAES) & 2020 & Olympios et al. 2021 \\
\hline Pumped-storage hydropower (PSH) & 2020 & Mongird et al. 2020 \\
\hline Flywheel & 2018 & Mongird et al. 2019 \\
\hline Gravity & 2018 & Schmidt 2018 \\
\hline
\end{tabular}

\footnotetext{
a And [the/a] future year as defined in Hunter et al. 2021

b Shown in figures in this report as $\mathrm{H} 2$ Elec-salt cavern- CT

c Shown in figures in this report as $\mathrm{H} 2$ Elec-salt cavern- FC
}

We compare current costs for energy storage by separating the total capital costs for energy storage into two components - a power capacity term $(\$ / \mathrm{kW})$ and an energy component $(\$ / \mathrm{kWh})$ - and then plotting them on the same graph (Figure ES-8). Technology total capital cost $(\$ / \mathrm{kW})$ for a given duration is calculated by multiplying storage duration by the energy capital cost component value $(\$ / \mathrm{kWh})$ and adding the power capital cost component $(\$ / \mathrm{kW})$. The results demonstrate that technologies with high power component costs and low energy component costs are generally more economic for long-duration storage applications. Technologies with low power component costs and high energy component costs are more appropriate for short-duration storage.

Technologies with both low power and low energy component costs will be the lowest cost overall. LIB, being closest to the origin of the graph, have the lowest power and energy component costs of the technologies presented. Being on either side of the dashed line indicates a tendency toward power or energy but lower absolute costs could still make one technology a project choice. Meanwhile, technologies like hydrogen storage, compressed air energy storage (CAES) and (PSH) are close to the $y$-axis indicating that buying the power "capacity" (MW) is the more expensive portion of the project than storing and handling either the water or compressed air, making these technologies more suitable for deploying with much longer durations. 


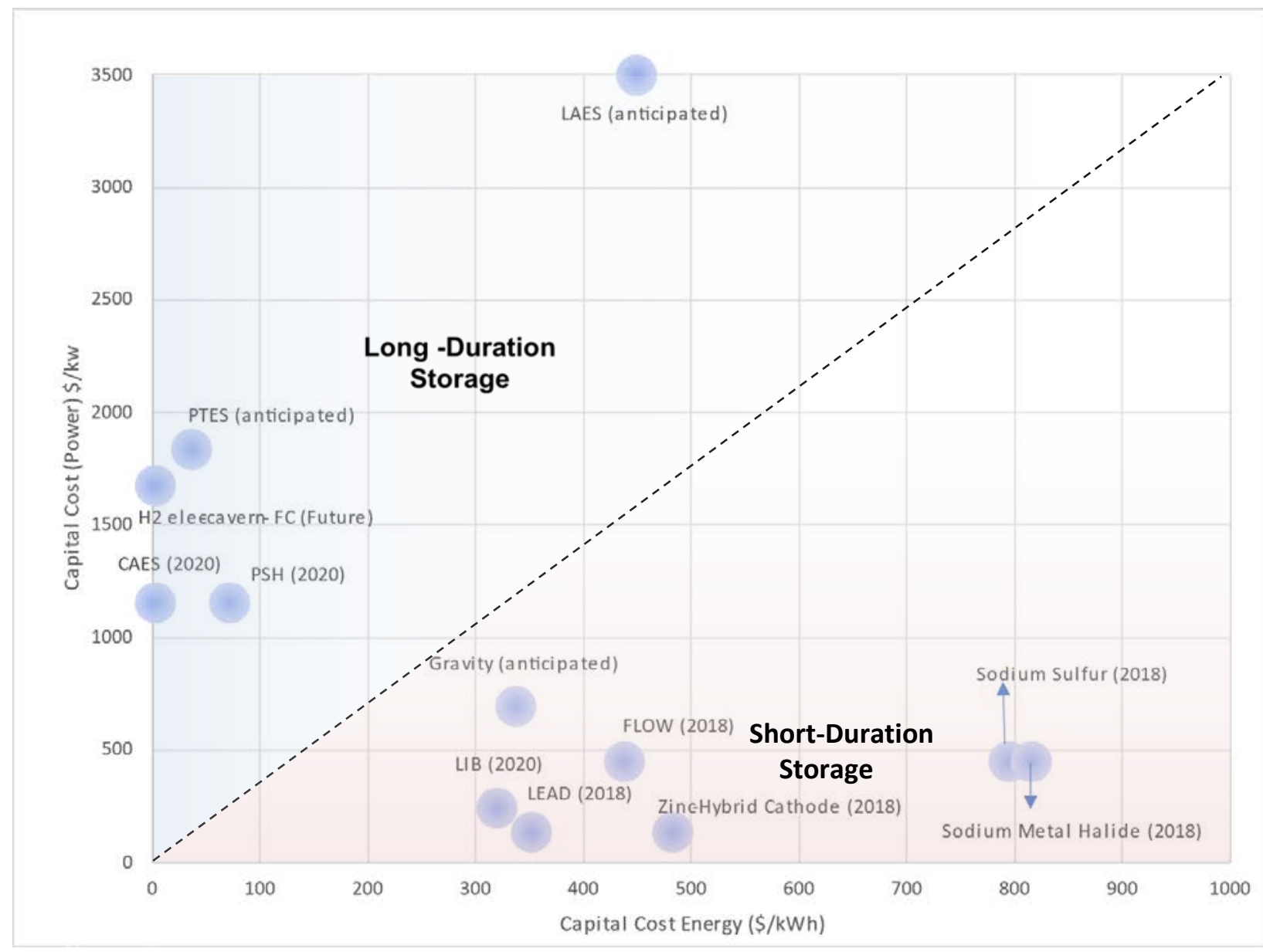

Figure ES-8. Capital cost for energy (\$/kWh) versus capital cost for capacity $(\$ / \mathrm{kW})$ for various technologies

Energy storage technologies can also be compared across their total capital costs and storage durations, as shown in Figure ES-9. In addition to showing the current costs of several technologies, the chart demonstrates the changing landscape over 5 years as LIB costs continue to decrease. As shown in the chart, LIB is currently the cheapest option at 4 hours of duration and are anticipated to continue near-term price reductions. At 4 hours of duration, the non-LIB battery types as well as gravity, pumped thermal, and LAES are all significantly more expensive than LIBs. Cost reductions for any of these technologies could also occur as the energy storage market grows, especially those technologies that are emerging now.

At over 8 hours of duration, the ratio of energy to duration costs changes such that several technologies are at total capital costs comparable to or lower than LIBs. Pumped thermal energy storage (PTES) is anticipated to be cheaper that LIB in most cases, and hydrogen storage costs become more competitive - especially if future cost improvements are realized as described by Hunter et al. (2020). This flip with longer durations indicates several technologies might be competitive with LIBs at longer duration. PSH and CAES also enter the picture at longer durations on the graph, at costs where it might be expected that they would be deployed more. However, as we look to the future and an anticipated decrease in LIB capital costs of an additional $50 \%$ from current by 2030, the capital cost advantage of most non-LIB technologies decreases resulting in LIB capital costs potentially being below the other technologies even at these longer durations. 
Capital costs alone do not determine energy storage costs. Operational costs, efficiencies and lifetimes must also be considered to determine lifetime project costs. Doing so is complicated by the fact that these values all depend on how the storage is used in the system (e.g., frequently for backup, capacity, and energy time-shifting). We use the levelized cost of storage (LCOS) to allow for comparison of technologies that are providing the capabilities discussed in Section 2, including four hour, 8-12 hour and long-duration technologies. However, the shortcomings of attempting to use a single LCOS to capture the diverse use cases for storage are also highlighted in that discussion. These shortcomings make it difficult to compare storage costs in a simplified way. This limitation also underscores the need for system wide assessments using capacity expansion and production cost models.

In summary, in this report, we review a variety of energy storage technologies with storage durations ranging from minutes to months. We quantified the current costs of those technologies, recognizing that energy storage technologies must be described in terms of both their power $(\mathrm{kW})$ capacity and energy $(\mathrm{kWh})$ capacity to assess their costs and potential use cases (Section 2.3). And we examine LIB and PSH costs support the broader modeling activities.

More information and related data and information associated with this report are available at https://www.nrel.gov/analysis/storage-futures.html. 


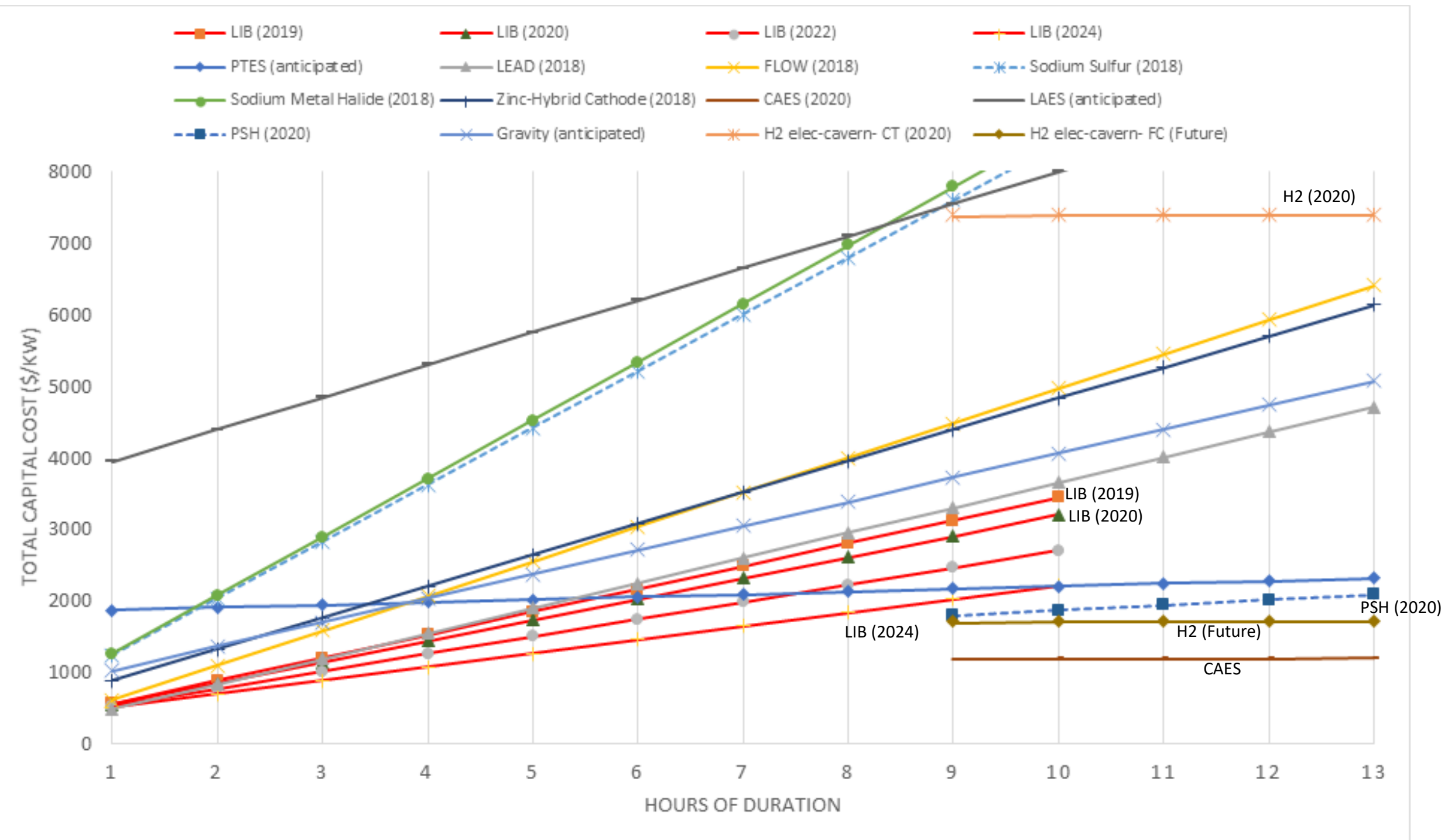

Figure ES-9. Total investment cost $(\$ / \mathrm{kW})$ for a system with $100 \mathrm{MW}$ of storage with varying durations

Flywheels and ultracapacitors are not included in the figure, as they are deemed to be unsuited for these durations. 


\section{Table of Contents}

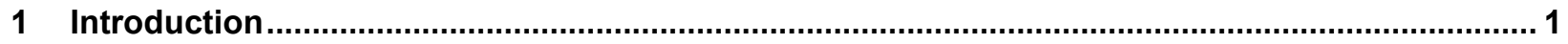

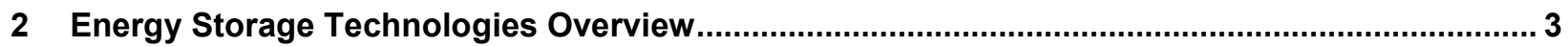

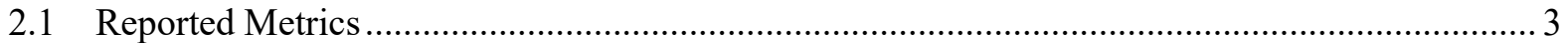

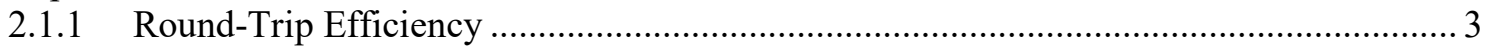

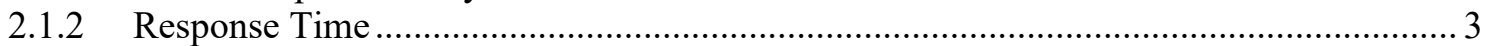

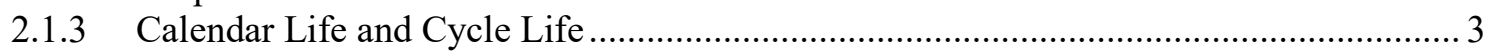

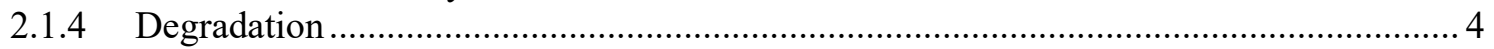

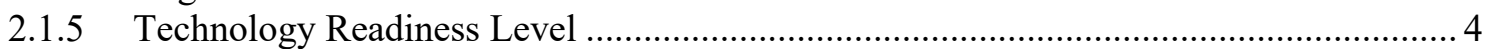

2.1.6 Total Capital Cost (total \$ OR \$/kW OR \$/kWh) …................................................... 4

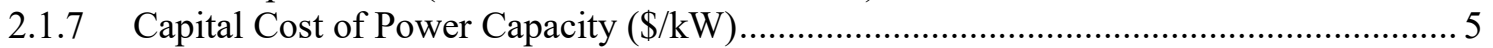

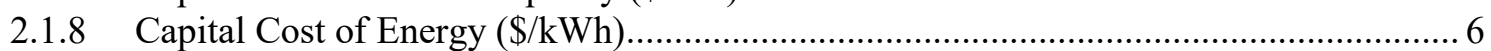

2.1.9 Operation and Maintenance: Fixed $(\$ / \mathrm{kW}$-year) and Variable $(\$ / \mathrm{kWh}-\mathrm{year})$................. 6

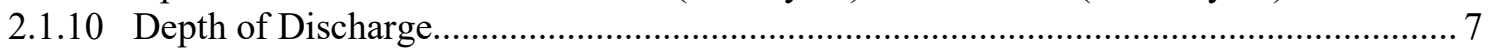

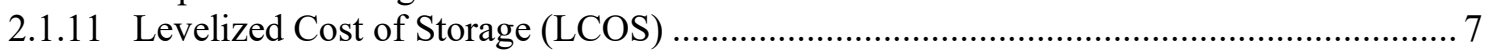

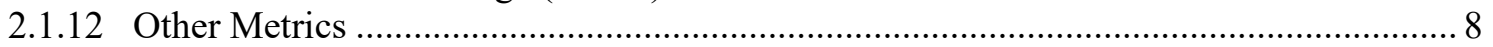

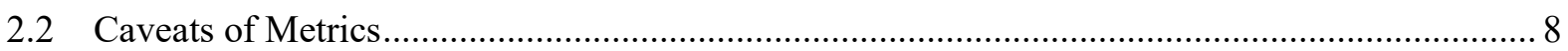

2.3 Impacts of Anticipated Services Provided by Storage Technologies on Technology Selection... 9

2.4 Cost and Performance Characteristics of Technologies Considered......................................... 11

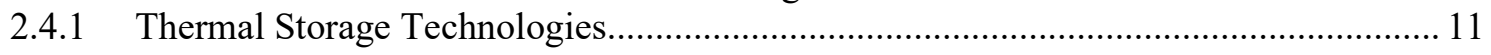

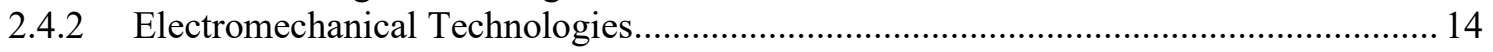

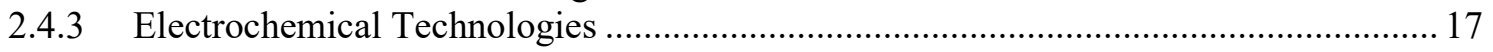

2.5 Comparison of Current Costs of Technologies …................................................................. 24

3 Battery Energy Storage System (BESS) Cost Assumptions and Projections for Scenario

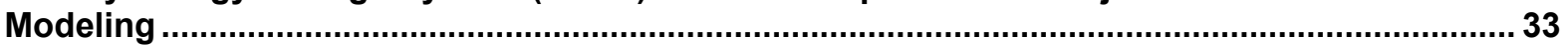

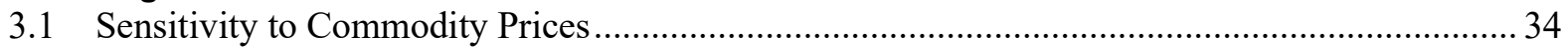

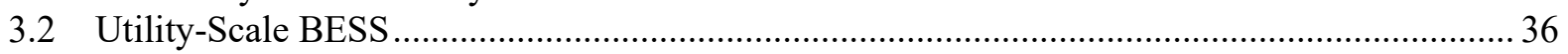

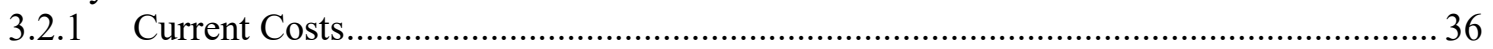

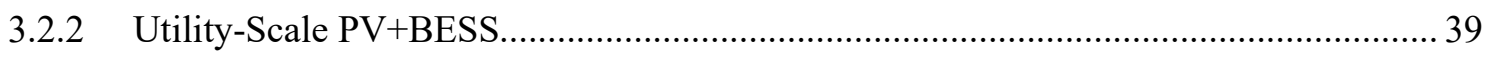

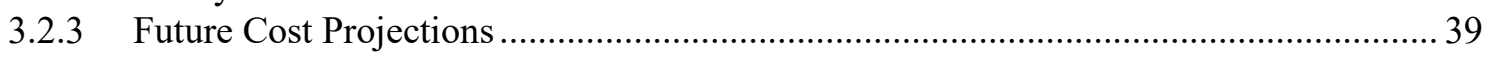

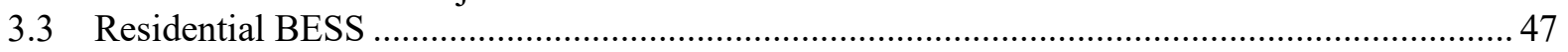

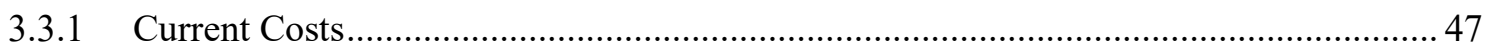

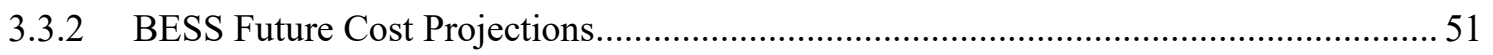

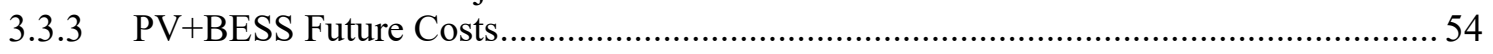

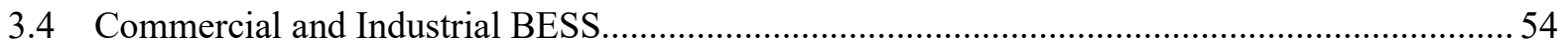

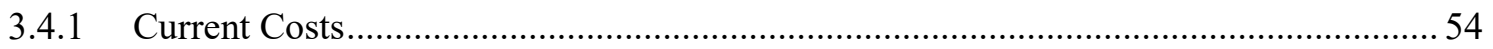

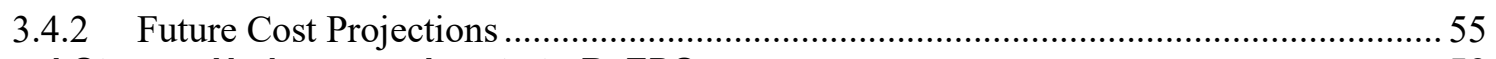

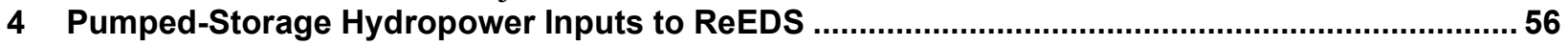

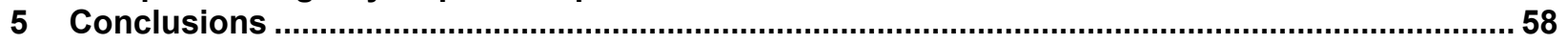

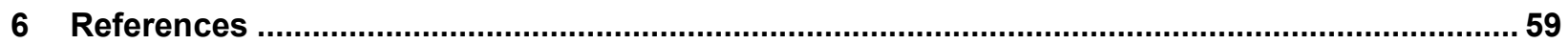




\section{List of Figures}

Figure ES-1. 2019 U.S. utility-scale LIB storage costs for durations of 2-10 hours (60 MW Figure ES-2. 2019 U.S. utility-scale LIB storage costs for durations of $2-10$ hours $\left(60 \mathrm{MW}_{\mathrm{DC}}\right)$ in $\$ / \mathrm{kW}$.. $\mathrm{x}$ Figure ES-3. Utility-scale BESS Moderate Scenario cost projections, on a $\$ / \mathrm{kWh}$ basis (left) and a $\$ / \mathrm{kW}$ basis (right) ..............................................................................................

Figure ES-4. Cost of residential PV-stand-alone, BESS-stand-alone, and PV+BESS systems estimated using NREL bottom-up models ....................................................................................

Figure ES-5. Estimated costs of commercial and industrial stand-alone PV, stand-alone BESS, and PV+BESS using NREL bottom-up model .......................................................................

Figure ES-6. Relative changes in projected component costs for residential BESS................................ xiii

Figure ES-7. Moderate, Advanced, and Conservative Scenario cost projections for representative

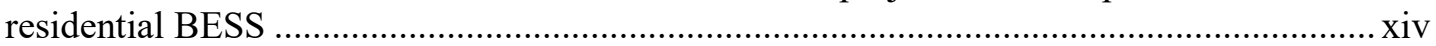

Figure ES-8. Capital cost for energy $(\$ / \mathrm{kWh})$ versus capital cost for capacity $(\$ / \mathrm{kW})$ for various technologies. xvi

Figure ES-9. Total investment cost $(\$ / \mathrm{kWh})$ for a system with $100 \mathrm{MW}$ of storage with varying durations

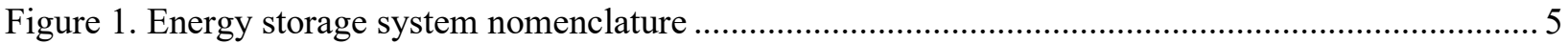

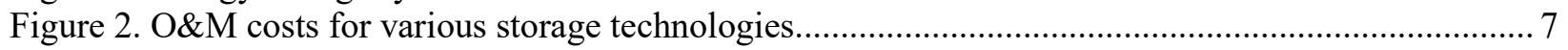

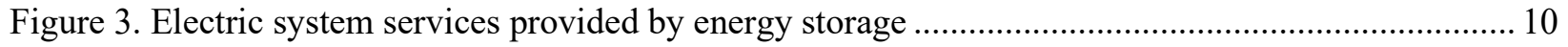

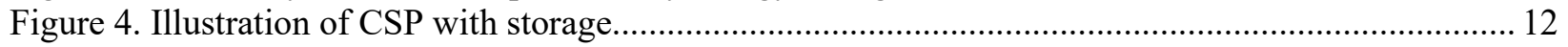

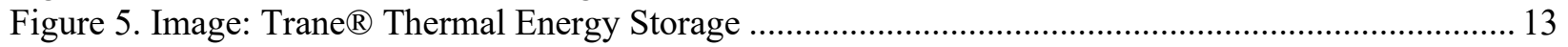

Figure 6. Schematic of PTES system or Carnot battery using liquid storage ......................................... 14

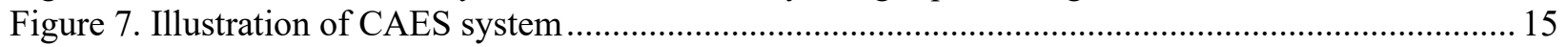

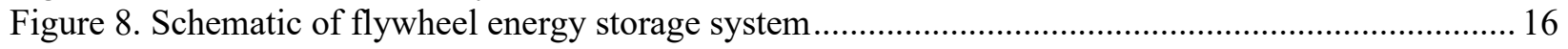

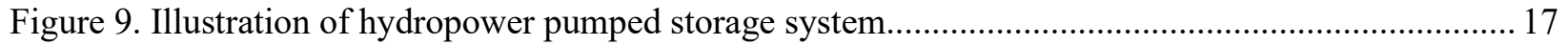

Figure 10. 2019 BNEF battery price survey results (with cell and pack split) ....................................... 18

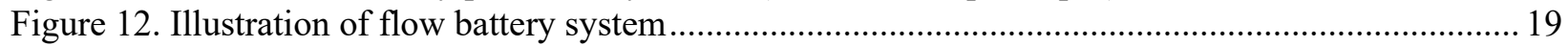

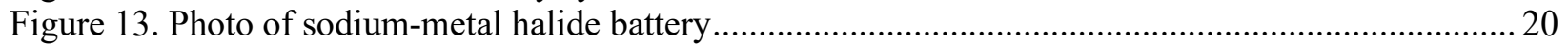

Figure 14. Illustration of grid-scale lithium-ion battery system ....................................................... 21

Figure 15. Past and projected market share of different LIB chemistries through 2030 .......................22

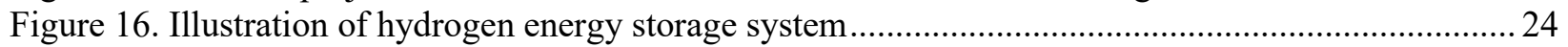

Figure 17 . Power capacity cost component $(\$ / \mathrm{kW})$ versus energy capacity cost component $(\$ / \mathrm{kwh}) \ldots \ldots .27$

Figure 18. Total investment cost $(\$ / \mathrm{kW})$ for a system with $100 \mathrm{MW}$ of storage with varying durations...28

Figure 19. Projected newly installed capacity of PSH for scenarios used in HydroVision study............... 30

Figure 20. Round-trip efficiency of energy storage technologies........................................................ 31

Figure 21. Levelized cost of storage $(\$ / \mathrm{kWh})$ of energy storage technologies included in this study........ 32

Figure 22. Battery pack prices (real 2019 \$/kWh) for different end-use applications ............................... 33

Figure 23. Expected battery demand by sector and LIB price projections ............................................ 34

Figure 24. Raw material costs for different LIB chemistries by year ................................................... 35

Figure 25. Sensitivity of nickel-manganese-cobalt (811) LIB pack (percentage change) to metal

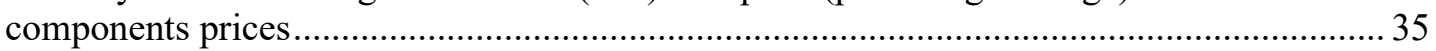

Figure 26. 2019 U.S. utility-scale LIB stand-alone storage costs for durations of 2-10 hours (60 MW $\mathrm{MC}_{\text {) }}$

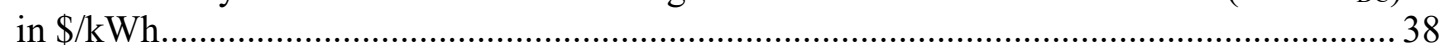

Figure 27. 2019 U.S. utility-scale LIB stand-alone storage costs for durations of 2-10 hours (60 MW $\mathrm{MC}_{\text {) }}$

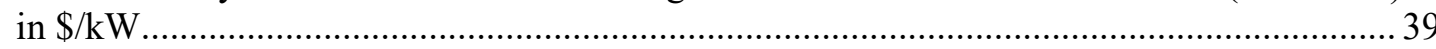

Figure 28. Normalized battery cost projections for 4-hour LIBs, with values relative to 2019 from Cole

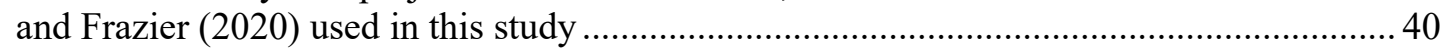

Figure 29. Methodology for projecting utility-scale BESS costs ..................................................... 41

Figure 30. Utility-scale BESS Moderate Scenario cost projections, on a $\$ / \mathrm{kWh}$ basis (left) and

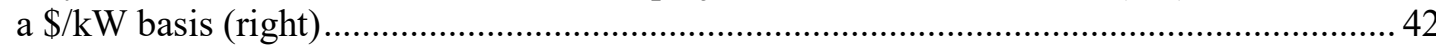


Figure 31. Utility-scale BESS Advanced Scenario cost projections, on a $\$ / \mathrm{kW}$ basis and $\$ / \mathrm{kWh}$ basis ... 43 Figure 32. Utility-scale BESS Conservative Scenario cost projections, on a $\$ / \mathrm{kW}$ basis and $\$ / \mathrm{kWh}$ basis

Figure 33. Comparison of current and future utility-scale BESS cost estimates from different sources.... 45

Figure 34. Comparison of utility-scale BESS future cost projections .................................................. 46

Figure 35. Cost of residential PV-stand-alone, BESS-stand-alone, and PV+BESS systems estimated using

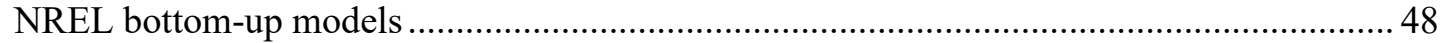

Figure 36. Comparison of current residential BESS total and component costs from NREL and BNEF .. 49

Figure 38. Relative changes in projected component costs for residential BESS................................. 52

Figure 39. Comparison of BNEF and Schmidt et al. (2018) residential BESS installed costs Storage Futures Study scenarios with time on a $\$ / \mathrm{kWh}$ basis......................................................... 53

Figure 40. Estimated costs of commercial and industrial stand-alone PV, stand-alone BESS, and

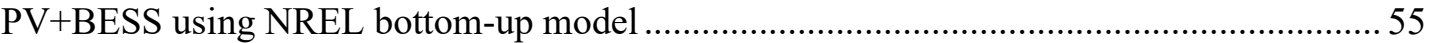

Figure 41. Modeled new PSH resource potential.................................................................................5 57

Figure 42. National PSH supply curve of capital cost versus cumulative capacity potential ....................57

\section{List of Tables}

Table ES- 1. Data Sources for Energy Storage Technologies .................................................................

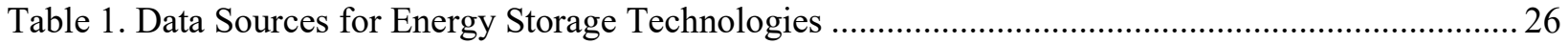

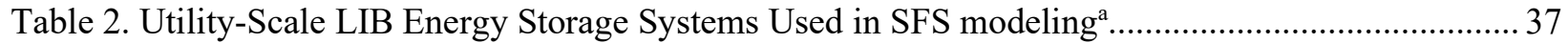

Table 3. Residential Storage-Only Modeling Inputs and Assumptions ${ }^{\mathrm{a}}$................................................ 47

Table 4. Assignment of Component Cost Categories from NREL Model to BNEF Component Cost Categories, and Learning Rates Assumed for the Moderate Scenario ................................... 51

Table 5. Commercial and Industrial LIB Energy Storage Systems: 2019 Model Inputs and Assumptions

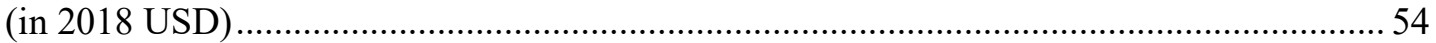

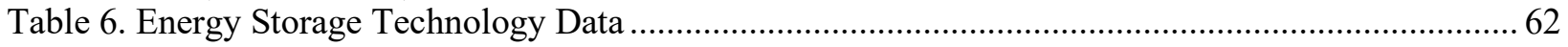




\section{Introduction}

Energy storage has been used for hundreds of years to shift thermal energy from day to night and from season to season. Originally, this was in the form of thermal energy as large buildings were designed with thick walls to mitigate temperature fluctuations to reduce the need for fires. For centuries, ice was transported great distances or stored underground from the prior winter to preserve food in the summer. More recently, the first pumped hydropower electrical storage plant was deployed in 1907 with the first use in the United States by Connecticut Electric and Power Company in $1930 .{ }^{2}$ Since then, pumped-storage hydropower (PSH) has been the dominant form of electricity storage in the United States and globally. However, because of recent rapid decreases in grid-scale battery storage costs combined with recent dramatic price drops and increased deployment trends for solar photovoltaic (PV) and land-based wind, we anticipate an increase in energy storage demand and are already seeing this in the market. Both solar PV and land-based wind technologies are variable in their output so the energy they generate and supply to the grid will not always match the current demand for energy. As they make up a larger portion of total energy generation capacity, this creates potential for significant storage being optimally mixed in as these technologies grow in the marketplace.

The goal of this report is twofold, which is reflected in two parts of the report. The first half of the report (Section 2) takes a broad look across a variety of mature and emerging electricity storage technologies. The goal of this section is to provide a current understanding of the relative capabilities of these technologies, gather information about the system cost and performance, and provide background information on storage technologies that will be helpful to stakeholders seeking to understand this sector. To do this, we introduce and describe a variety of relevant metrics that can be used to compare and contrast energy storage technologies. The second half of the report (Sections 3-4) deals with the detailed current and future costs of energy storage technologies provided to the models performing future scenarios for the larger Storage Futures Study (SFS), of which this report is a part. That section is limited to distributed and grid-scale BESS and grid-scale PSH, as these are (1) commercial technologies that already have been deployed in the United States and have sufficient available data to inform forward projections and (2) the energy storage technologies used in the detailed modeling done in the broader SFS. However, because the energy models consider only a few parameters such as cost, storage duration, and capacity factor, BESS and PSH function as a proxy for any of the emerging technologies that eventually reach comparable cost and performance levels.

The SFS uses the Regional Energy Deployment System (ReEDS) model and the Distributed Generation Market Demand (dGen) model to project grid-scale and distributed capacity deployments, respectively. These models and the scenarios used in the SFS guide the boundaries of this report. Because they can neither model nor anticipate multiday energy storage needs, storage durations for BESS are limited to 10 hours, and PSH plants are assumed to have sufficient storage to operate as needed within the diurnal variations represented in the model (i.e., 12-hour duration). At this time, energy storage technologies in dGen consist of only

\footnotetext{
2 “A Ten-Mile Storage Battery." Popular Science, July 1930, p. 60. https://books.google.com/books?id=sigDAAAAMBAJ\&pg=PA60\&dq=1930+plane+\%22Popular\&hl=en\&ei=zxiV TtztJ-

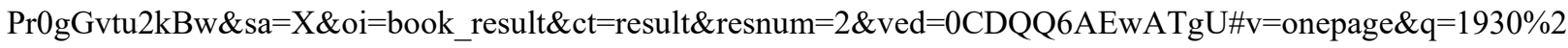
Oplane $\% 20 \% 22$ Popular\&f $=$ true
} 
distributed BESS technologies, which limits the distributed energy storage technologies we explore in this report. ReEDS currently cannot model generation and energy storage hybrid systems, so we neither explore or nor include the costs of utility-scale PV+BESS in this report. Cost estimates for these systems, which are provided by Feldman et al. (2021) and included here, show that the difference between stand-alone and colocated PV and BESS is small and should not significantly impact results. Finally, some of the technologies discussed here (LIB in particular) have costs and performance that are rapidly changing, so this report may not reflect current values. The reader is encouraged to check for updated information before using the values and conclusions in this report. 


\section{Energy Storage Technologies Overview}

This section portrays various energy storage technologies across a variety of metrics. The characteristics of each technology are discussed, as is the potential for disruption in the storage technology space.

\subsection{Reported Metrics}

Appropriate metrics can be difficult to define for energy storage technologies because of the many use cases, values, and configurations of energy storage technologies. Given the range in technology scales from massive PSH systems utilizing huge reservoirs that last for decades to small grid-enabling technologies that discharge in sub-second increments, comparing these technologies and the growing role that they all are pursuing is daunting. Here we have gathered a variety of metrics with which we seek to compare technologies. This set of metrics will not determine the full value of the storage technologies within the grid or behind the meter; other parts of the SFS will perform those functions. Here we do hope to supply metrics and present information that helps set the energy storage landscape for the reader.

\subsubsection{Round-Trip Efficiency}

The round-trip efficiency (RTE) is equal to the energy supplied by the storage device during the discharge phase divided by the energy provided to the device during the charging phase. This metric is dramatically different across technologies we consider in this report, as it ranges from $27 \%$ for hydrogen systems including combustion turbines (page 17) to $92 \%$ for ultracapacitors. Additionally, CAES adds natural gas to the compressed air prior to the combustion turbine to increase power output and so RTEs for CAES are sometimes reported to be greater than one. While RTE is just one component of the overall cost equation, a low RTE for a technology requires that all the other cost components (e.g., capital cost, O\&M, project development, and construction time) be lower for the technology to be competitive. Raising the RTEs of technologies - but especially those with significant losses - through R\&D can provide significant benefits in cost-effectiveness.

\subsubsection{Response Time}

Response time is defined as the time that it takes a storage system to go from rest to rated output. Response times for battery systems are typically around 1 second (with the battery system design allowing that to be slightly shorter or longer). PSH and CAES and other mechanical systems have longer response times (Mongird et al. 2019), which may or may not matter depending on the grid services being provided by the resource.

\subsubsection{Calendar Life and Cycle Life}

Calendar life is defined as the lifetime of the system absent degradation that is due to cycling. Cycle life is defined as the number of charge-discharge cycles a system can go through in its useful lifetime. When a system is being cycled, the lesser of the calendar life or the cycle life determines the actual lifetime of the system. Significant cycling will lead to an actual lifetime that is much shorter than the calendar life of the storage device. Note that full or partial replacement of battery cells or packs can extend both calendar and cycle life. 


\subsubsection{Degradation}

Degradation is the decrease in technology performance with time and/or the number of charge/discharge cycles. Degradation is a critical metric, as some technologies degrade strongly with use, including LIB. Other technologies indicate that with appropriate O\&M, their degradation is negligible. Degradation can be a strong function of how the storage technology is used and cycled, thus making it nonlinear with both time and usage. The levelized cost of storage (LCOS) equation described in Section 2.1.11 (page 7) incorporates the impact of these degradation rates over the lifetime of a system. The LCOS equation includes several degradation rates, including the calendar degradation and cycling degradation. Degradation is most impactful for batteries and chemical systems. Mechanical, thermal systems, and electromechanical systems broadly have minimal degradation each year. This has been shown over many decades with PSH specifically in that its lifetime is assumed to be 40 years or more in ReEDS. Finally, not including the degradation of a storage system (or conversely not accounting for upgrades during the lifetime to augment the storage system) can lead to incorrect dispatch (i.e., dispatching to capture arbitrage values insufficient to compensate for accelerated aging of the system).

\subsubsection{Technology Readiness Level}

A technology readiness level (TRL) is a common metric for assessment of R\&D needs and technology potential that categorizes the extent to which a technology has been developed. DOE (2011) defines nine technology readiness levels:

- TRL 1: Basic principles observed and reported

- TRL 2: Technology concept and/or application formulated

- TRL 3: Analytical and experimental critical function and/or characteristic proof of concept

- TRL 4: Component and/or system validation in laboratory environment

- TRL 5: Laboratory-scale, similar system validation in relevant environment

- TRL 6: Engineering/pilot-scale, similar (prototypical) system validation in relevant environment

- TRL 7: Full-scale, similar (prototypical) system demonstrated in relevant environment

- TRL 8: Actual system completed and qualified through test and demonstration

- TRL 9: Actual system operated over the full range of expected mission conditions

The TRL level of technologies can be very important for these analyses and for assessing the cost uncertainty as many of the technologies being discussed here have not been piloted yet, let alone developed either individually in a large commercial facility or as part of a supply chain.

\subsubsection{Total Capital Cost (total $\$$ or $\$ / k W$ or $\$ / k W h$ )}

As discussed above, storage technologies have both a power component cost and an energy/duration component cost. The total capital cost includes the cost of all of the initial investment to build the system. This includes not only the equipment but also installation; project development; engineering, procurement, and construction (EPC); customer acquisition; and other costs. The total capital cost can be described in terms of total cost $(\$)$, power capacity $(\$ / \mathrm{kW})$ or energy capacity $(\$ / \mathrm{kWh})$. The storage duration (in hours) can be used to convert between total capacity cost on a power or energy basis. For this reason, comparisons of total capital costs for technologies must consider storage duration. Note that in this analysis, we use the nameplate 
capacity for costing and not the "usable"3 capacity. We should also note that we use the nameplate capacity of storage systems when we determine capital costs.

A common nomenclature for what is included in the total capital cost is important. Different cost values reported in literature describe various portions of the overall cost. Below in Figure 1, we provide a diagram that structures some of the nomenclature for energy storage systems. In the diagram, from Mongird et al. (2020), key acronyms include ESS (energy storage system), ESB (energy storage block), and ESBOS (energy storage balance of system). This nomenclature is important throughout this report, as other publications refer only to the capital cost of the core storage component and do not include the other costs needed to use an energy storage system.

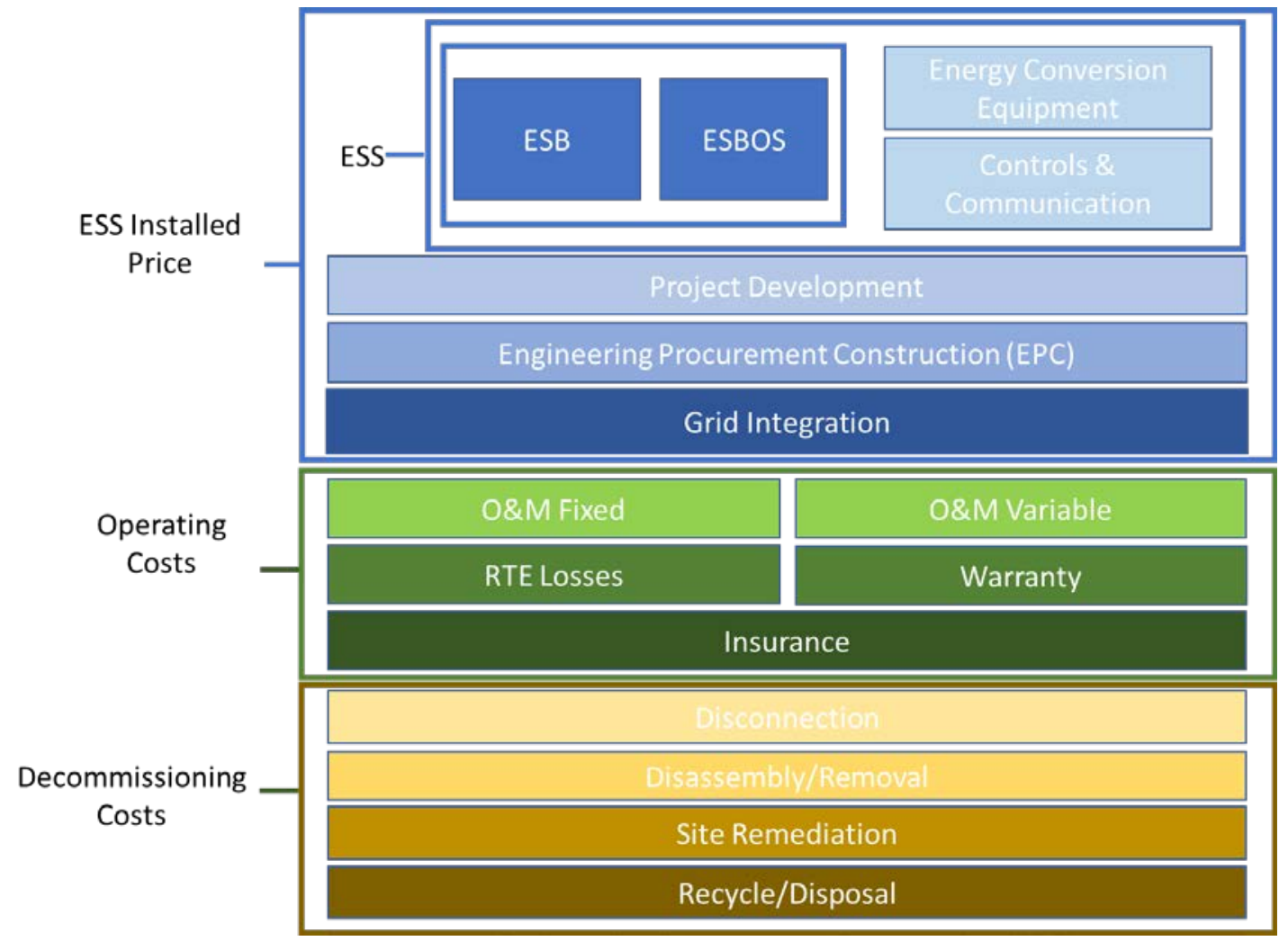

Figure 1. Energy storage system nomenclature

\subsubsection{Capital Cost of Power Capacity $(\$ / k W)$}

As discussed above, storage technologies have both a power component cost and an energy/duration component cost. When used as a specific cost component, this metric - the capital cost of power capacity — speaks to the relative cost of building out the capacity independent of the duration of the storage system. This is the portion of the installed cost of a technology that can be attributed to equipment that converts energy to electricity and delivers it to the grid. This cost component will need to be combined with the capital cost of energy capacity ( $\$ / \mathrm{kwh} ; 2.1 .8)$ to calculate the total capital cost (Section 2.1.6, page 4). In some systems, such as PSH, the power capacity capital cost is the majority of the overall cost with the

\footnotetext{
${ }^{3}$ Usable capacity refers to the capacity of energy storage when practical constraints are considered. For example, a $10-\mathrm{kWh}$ battery that operates assuming a 90\% depth of discharge has a usable storage capacity of $9 \mathrm{kWh}$.
} 
cost for additional duration being low. Note that for this analysis we use the nameplate capacity rather than the usable capacity.

\subsubsection{Capital Cost of Energy (\$/kWh)}

As discussed above, storage technologies have both a power component cost and an energy/ duration component cost. When used as a specific cost component, this metric - the capital cost of energy - speaks to the cost of building out the duration or energy capacity independent of the power of the storage system. This is the portion of the installed cost of a technology that can be attributed to equipment that stores the energy. This cost component will need to be combined with the capital cost of power capacity $(\$ / \mathrm{kW}$; Section 2.1 .7$)$ to calculate the total capital cost (Section 2.1.6, page 4). Battery systems in particular are currently dominated by this cost instead of the capacity cost component. Additionally, it should be noted that this metric might vary significantly with increasing duration such as for CAES, hydrogen, PSH, and LAES.

\subsubsection{Operation and Maintenance: Fixed (\$/kW-year) and Variable (\$/kWh-year)}

Operation and maintenance (O\&M) costs include all costs needed to keep storage equipment operating as specified by the manufacturer and by the design and use case of the system throughout the economic lifetime of the plant. Fixed O\&M costs include all necessary costs that are not based on usage (i.e., costs that need to be paid no matter what the use case is). ${ }^{4}$ Variable O\&M costs are for the necessary activities that are a function of the amount of usage of the storage system. The O\&M costs for most storage systems are lower than for generation systems - particularly fossil fuel plants. However, our definition of O\&M excludes the cost of energy for charging the system and the cost of augmenting the energy storage system that is due to degradation or for any assumed replacements. Other resources might include those costs in the O\&M or related reserve accounts.

As an example of O\&M costs, Figure 2 represents the reported O\&M costs for the storage technologies described and compared in Section 2.4. As is evident in the figure, several technologies have more significant anticipated O\&M costs, and several-typically those with no moving mechanical parts - have significant less O\&M costs.

\footnotetext{
${ }^{4}$ For a discussion of use cases, see Section 2.3
} 


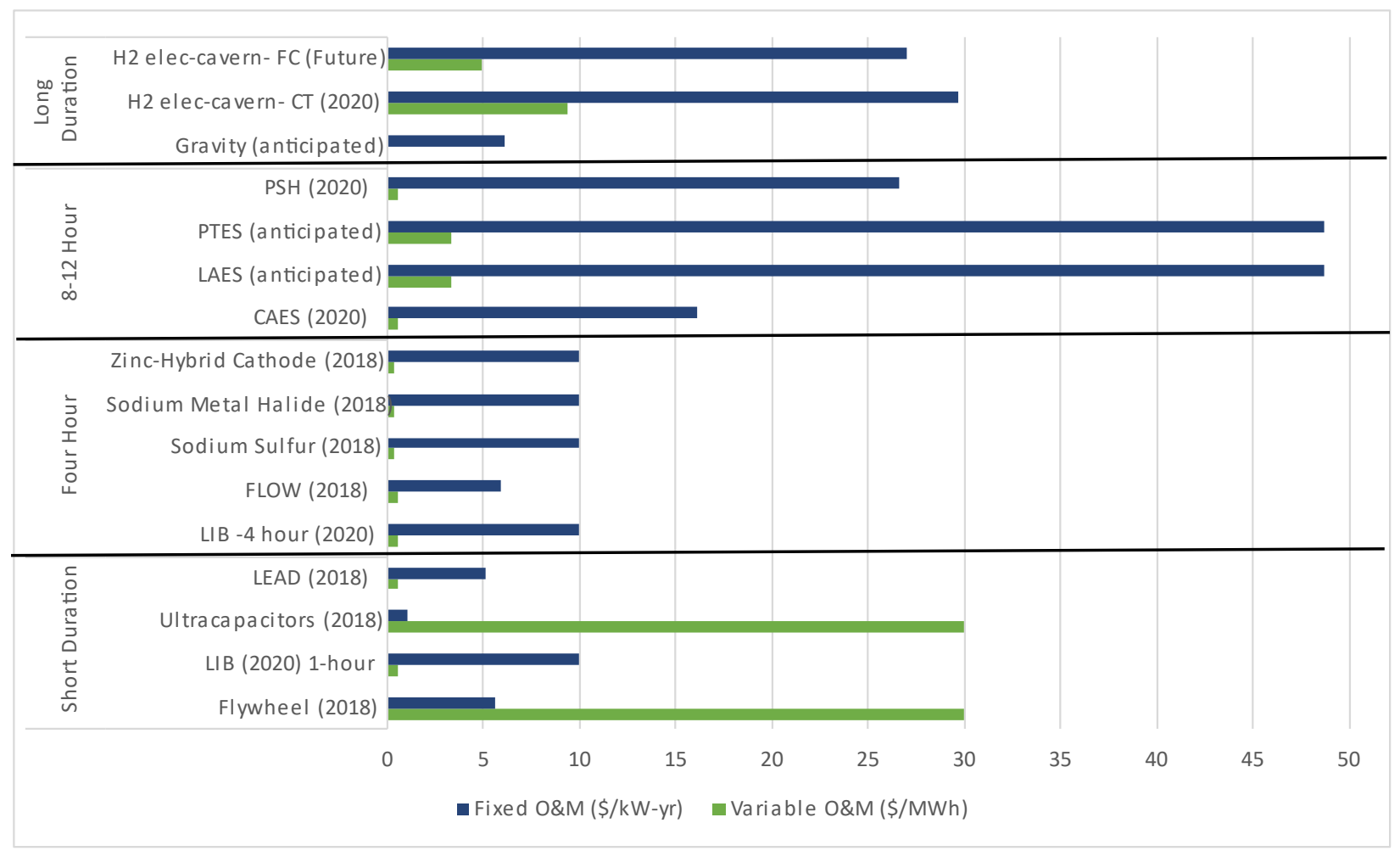

Figure 2. O\&M costs for various storage technologies

\subsubsection{Depth of Discharge}

This metric — depth of discharge - is used primarily for battery technologies. It indicates the fraction or percentage of the reduction in charge from a fully charged battery system and is the opposite of the state of charge. In at least some battery technologies, there is a direct relation between the depth of discharge and the cycle life as indicated in the LCOS equation.

\subsubsection{Levelized Cost of Storage (LCOS)}

For stand-alone storage systems, the levelized cost of storage is a useful metric for comparison across storage technologies because it can combine the capital cost, charging cost and the round trip efficiency of the storage product as well as degradation over time into a single metric. It is defined as the present value of all costs for the system divided by the present value of all energy output from the system. Among the costs for the system, LCOS is the cost of purchasing electricity for the system throughout its lifetime. Of course, many system characteristics of both grid and behind-the-meter storage impact the value of a storage system (and particularly the next marginal storage system); however, for comparing between technologies within the same use case (Section 2.3), LCOS can be helpful.

For this analysis, we use the LCOS metric equation defined by Schmidt et al. (2019) and described here. Several different implementations of this metric are described in the literature with varying levels of complexity. For this report, we approached this more simply from an illustrative approach. And it should be noted that the version we use here does not include either tax implications or incentives. Note that the cost of the electricity or energy to charge the storage system has a significant impact on the overall LCOS. This is important because as the price of 
renewables and natural gas is anticipated to fall or stay low over the next several decades, the LCOS for any new storage deployment (independent of technology) will fall as well. The basic equation is:

$$
\begin{aligned}
& \operatorname{LCOS}\left[\frac{\$}{M W h}\right] \\
& =\frac{\text { Investment cost }+\sum_{n}^{N} \frac{\text { O\&M Cost }}{(1+r)^{n}}+\sum_{n}^{N} \frac{\text { Charging cost }}{(1+r)^{n}}+\frac{\text { End }- \text { of }- \text { life cost }}{(1+r)^{N+1}}}{\sum_{n}^{N} \frac{E l e C_{\text {Discharged }}}{(1+r)^{n}}}
\end{aligned}
$$

where:

- Investment Cost $=$ total capital cost (Section 2.1.6) of the entire system including BOS and other indirect costs but excluding financing costs

- $\quad$ O\&M Cost = the annual sum of both the variable and fixed operating costs

- End-of-Life Cost = either the decommissioning cost or, as a negative cost, the value of the installation at the end of the life of the system (salvage value); following the convention set by Schmidt (2019), we assume no end-of-life cost, but in some situations, this cost could be significant if remediation or recycling of the system is required. As shown in Figure 1, there are several entries under remediation costs which are not included with this assumption.

- $\quad$ Charging Cost $=$ the cost of the electricity (or energy more broadly) needed to be purchased as input to the system; for this, we assumed a constant $2.5 \mathrm{cents} / \mathrm{kWh}$ in all cases throughout the year based on typical wholesale prices.

- $\quad$ Elec $_{\text {Discharged }}=$ the annual sum of electricity discharged through the system; a function of the number of cycles each year as well as the RTE of the system

- $r=$ the discount rate typically or, in this case, the weighted adjusted cost of capital (values used are in Appendix 1)

- $\mathrm{n}=$ the number of years during which the system operates; we assume varying lifetimes that are appropriate for each technology (assumptions in Appendix 1)

\subsubsection{Other Metrics}

Other, related metrics include the levelized cost of solar and storage, and the levelized cost of generation and storage. These metrics assume a direct tie between the generation capacity (solar or other) and the storage system such that the storage system is only or predominantly charged by the generating station. In fact, these hybrid systems are often treated as a black box generation system that, while it is higher in cost, produces output profiles that are more valuable to the grid. We do not consider such hybrid storage technologies at grid scale in this report, but we describe PV+battery hybrids for distributed or behind-the-meter systems in Section 3.

\subsection{Caveats of Metrics}

Here we list some caveats for the metrics and the technologies we consider:

- Though we work toward having a broad range of technologies and minimal, distinct sources to reduce variance across cost methodologies, that is not completely possible. 
Many of our technology costs are from the efforts at Pacific Northwest National Laboratory (Mongird et al. 2019; 2020). However, cost and performance data for gravity, LAES, hydrogen, and PTES are all from separate sources.

- LIB storage system costs are calculated using a bottom-up model developed by the National Renewable Energy Laboratory (NREL) (Feldman et al. forthcoming). We used the NREL model in place of similar data in Mongird et al. (2020) for two reasons. First, it allowed us to use the most up-to-date information possible for this key energy storage technology. Second, it allowed us to estimate the costs of a wide range of LIB BESS configurations for use in our capacity expansion models rather than being confined to interpolating between a few data points.

- Though a large market has been built up around LIB, many of the other storage technologies we consider here are in development and piloting stages and have not deployed multiple systems. Therefore, many of these technology costs are highly uncertain. Even for existing technologies, modifications and new configurations add to the uncertainty.

- Though we would like to represent all cost data fort the same point in time (as of the release), Mongird et al. (2019) provided either 2018 or 2025 data. For these technologies, we used the 2018 data. Additionally, for the emerging technologies, their first deployments are several years away, which results in variance from reported costs and supplies as well.

- Several technologies have costs that can vary significantly by location. Specifically, CAES, PSH, and hydrogen storage in caverns (other hydrogen storage options are not location-specific) all can have significantly different costs depending on location. The ReEDS model includes regionally specific PSH supply curves for the United States, which is discussed in Section 5. Relatedly, the availability of appropriate locations for PSH, CAES or hydrogen cavern storage not only varies the cost but can prohibit these technologies in regions completely. One alternative to the use of geologic storage for hydrogen is to use underground pipes for hydrogen storage (Hunter et al. 2020). If this option is chosen, then initial costs and LCOS will be higher, but would not vary geographically as widely. Geographically agnostic storage technologies can increase cost but make them feasible in a wider range of regions.

- Our LCOS equation considerer neither tax implications nor incentives and degradation data were difficult to determine for several technologies from the literature and so was removed. We assume tax implications will impact grid technologies equally across the grid technologies, and our intent is to show the LCOS without incentives to focus solely on the aspects of the technologies. ${ }^{5}$

\subsection{Impacts of Anticipated Services Provided by Storage Technologies on Technology Selection}

Energy storage can be valuable in a variety of services or use cases, but especially a series of ancillary or grid services, capacity value, and energy shifting. For distributed behind-the-meter storage, backup power and general bill savings are additional key values to system owners. As shown in Figure 3, these grid services are distributed across a range of timescales at which these

\footnotetext{
${ }^{5}$ Note that existing state policy and incentives are indeed driving recent energy storage deployment, especially in the northeastern United States.
} 
services are needed. Additionally, the figure indicates that although some of these capabilities can be compensated in markets, others cannot currently receive payments and still others might be valued in only certain U.S. electric-sector markets.

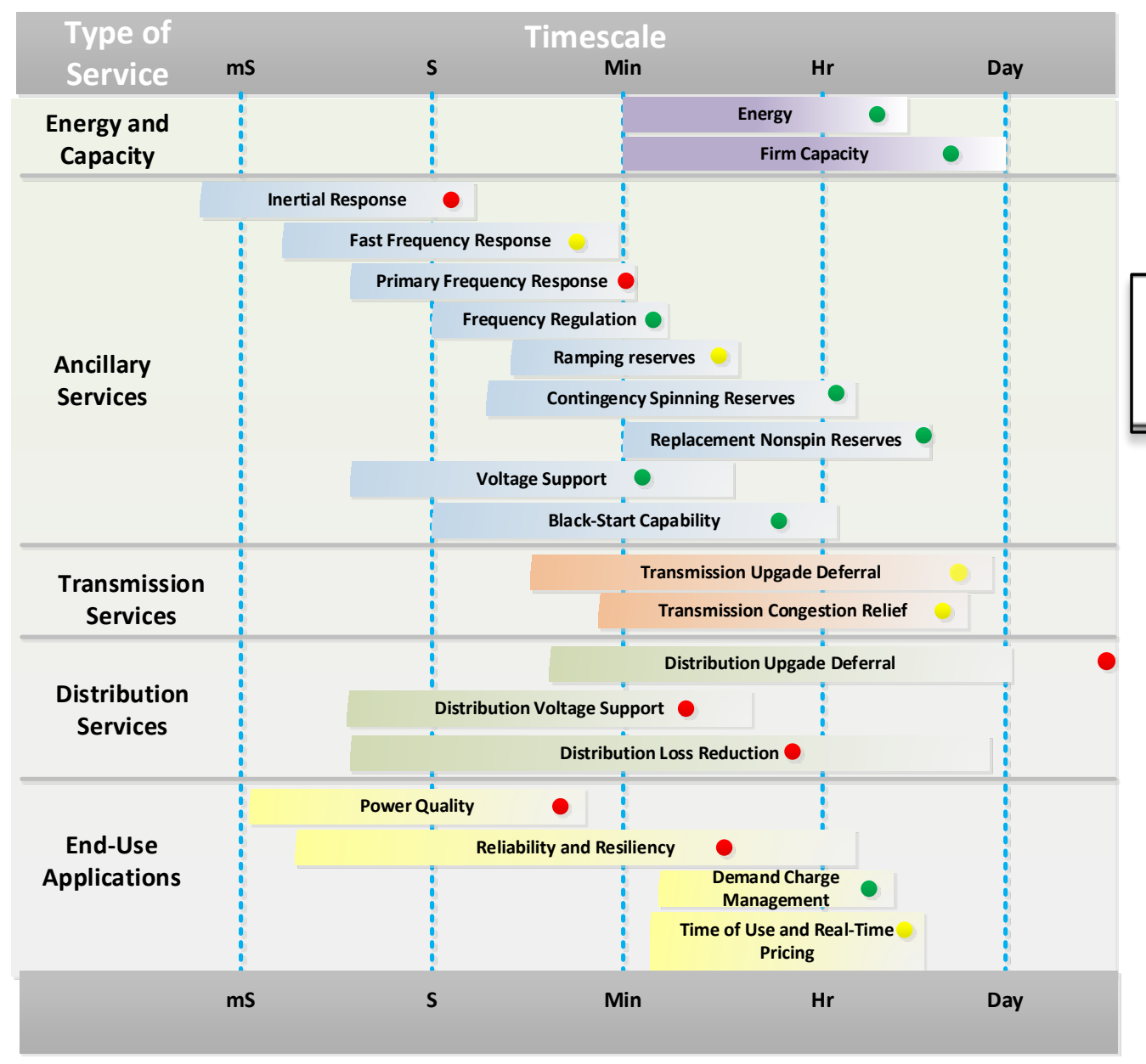

Services currently compensated in some markets

Proposed or early adoption services Currently not compensated services

Figure 3. Electric system services provided by energy storage

\section{Source: Vahan Gevorgian, NREL $\mathrm{mS}=$ millisecond, $\mathrm{S}=$ second}

Several of the technologies we consider here can contribute to all these use cases, but several technologies are applicable to just a subset of these needs. In the current first phase of energy storage deployment (as discussed in Denholm et al. (2021)), most systems are being deployed to meet ancillary services needs and anticipate being compensated for this market. Because of the timescales for these services and the size of this market (i.e., smaller than the energy and capacity services markets), batteries located in strategic positions around the grid with shorter durations are adequate. Additionally, flywheel systems are also critical in these markets as well and the bulk of flywheel storage has a duration of typically 15 minutes. Finally, ultracapacitors can provide short-duration (15 minute) high-power energy to assist with short-term grid fluctuations. More slowly responding technologies, such as PSH, are not applicable for many of these services. 
To the issue of transmission upgrade deferral and distribution grid upgrade deferral, these services could be met by various technologies. On the distribution side, because of the anticipated smaller system size and location either close to distribution transformers or behind the meter at the building level, these needs are anticipated to be met by batteries. However, large-scale transmission avoidance could be met by much larger scale technologies, including $\mathrm{PSH}, \mathrm{CAES}$, and other technologies.

Energy and capacity are anticipated to be the largest future markets for energy storage (much larger than the grid services market) (Denholm et al. 2021), and they can last from timescales of minutes to over 12 hours. Some of the emerging storage technologies can be more cost-effective at these longer duration levels. These would include technologies for which the cost of capacity is much higher than the cost of additional duration of storage (as demonstrated in Figure 17, page 27). These technologies would include PSH (and the emerging technology closed-loop PSH, which has fewer geographic and environmental constraints), thermal storage technologies (including LAES and PTES), hydrogen, and gravity. The future value to the grid for these longduration technologies are uncertain because few data are available on when and at what size storage durations higher than 8-10 hours would be beneficial to the system and with what other changes to the system (e.g., high natural gas prices, high levels of variable renewable energy, or increasing load growth). Behind the meter, another common service that often makes a battery system (or PV and battery) cost-effective is demand charge reduction. Behind-the-meter storage applications contribute to effectively providing the capacity needed by the system by reducing the net load peaks.

In the next section (Section 2.4), a 4-hour duration storage is presented to examine providing peaking capacity and eight hours to provide energy shifting or longer/flatter peak matching. As this shows, some technologies are more cost-competitive at the 4-hour level (or below) and several technologies are more cost-competitive at longer durations.

\subsection{Cost and Performance Characteristics of Technologies Considered}

In this section, we seek to provide a high-level overview of a broad range of existing and emerging energy storage technologies. Additional technologies have been discussed, but for those listed here, we have some level of techno-economic data. We represent three groupings of storage technologies - thermal, electromechanical, and electrochemical - each of which has its own typical characteristics; although within each general grouping, different technology providers can have significant variations.

\subsubsection{Thermal Storage Technologies}

The first grouping of technologies are thermal storage technologies. For this study, this category includes concentrating solar power with thermal storage, building thermal storage, and pumped thermal energy storage.

\section{Concentrating Solar Power with Thermal Storage}

Concentrating solar power (CSP) concentrates energy from the sun using mirrors to focus the sun's rays to a small area. The two main types of commercial CSP concentrators are parabolic troughs and heliostats. Parabolic troughs consist of a long U-shaped mirror that concentrate the 
sun to a glass receiver tubing centered in the trough created by the mirror. Heliostats are flat mirror panels that concentrate the sun to a receiver usually at the top of a tall tower. With both types, the concentrated solar energy heats a fluid in the receiver. This heat energy can be used immediately through a conventional Rankine-cycle steam turbine to generate electricity or more relevant for this discussion, stored in a thermal storage system.

Today's thermal storage employ high-temperature molten salts in a 2-tank (hot and cold) configuration. Storage durations for CSP systems vary, but they often are in excess of 4 hours and have been able to provide continuous power output throughout the night. CSP with thermal storage is represented within the scenarios to be run in SFS modeling efforts using ReEDS and presented in other reports. However, as CSP with thermal storage is not traditionally a stand-alone electricity storage technology that can take electricity off the grid like the other technologies discussed here, we do not include it in the various technology comparisons in Section 2.4 (page 27). CSP with thermal storage does not show significant deployment in the scenarios with higher levels of storage, but additional effort and global deployment could work to lower the overall cost of a $\mathrm{CSP}+$ thermal storage system. Additionally, examples in North Africa and elsewhere indicate the emergence of hybrid plants including CSP, thermal storage, LIB, and PV with the option to convert electricity into thermal heat as one of the charging options. ${ }^{6}$

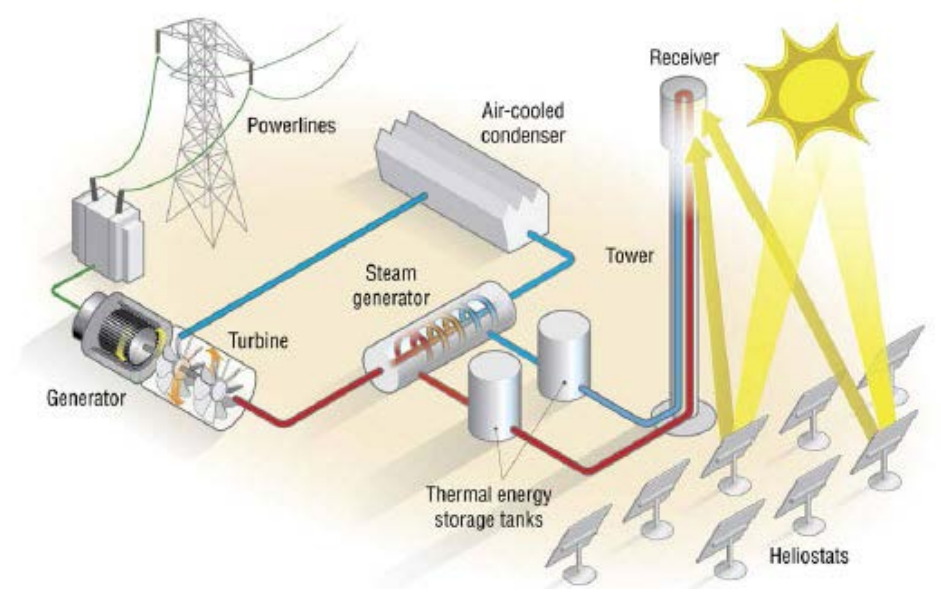

Figure 4. Illustration of CSP with storage

Source: Illustration by AI Hicks, NREL Utility-Scale Power Tower Solar Systems: Performance Acceptance Test Guidelineshttps://www.nrel.gov/docs/fy13osti/57272.pdf

\section{Building Thermal Storage}

The oldest of energy storage technologies, thermal storage integrated into buildings — of all sizes - has historically moderated temperature swings within the buildings via thermal mass. In modern times, thermal storage in buildings has been used to avoid utility-rate variations, including primarily time-of-use charges and demand charges for cooling. Peak shaving is typically done by creating ice at night and then using that ice to cool circulated air or water for cooling the next day. These systems can be quite large and are not typical in residential homes.

\footnotetext{
${ }^{6}$ See, for example, "Morocco Pioneers PV with Thermal Storage at 800 MW Midelt CSP Project," Susan Kraemer, SolarPACES, posted April 25, 2020, https://www.solarpaces.org/morocco-pioneers-pv-to-thermal-storage-at-800mw-midelt-csp-project/.
} 


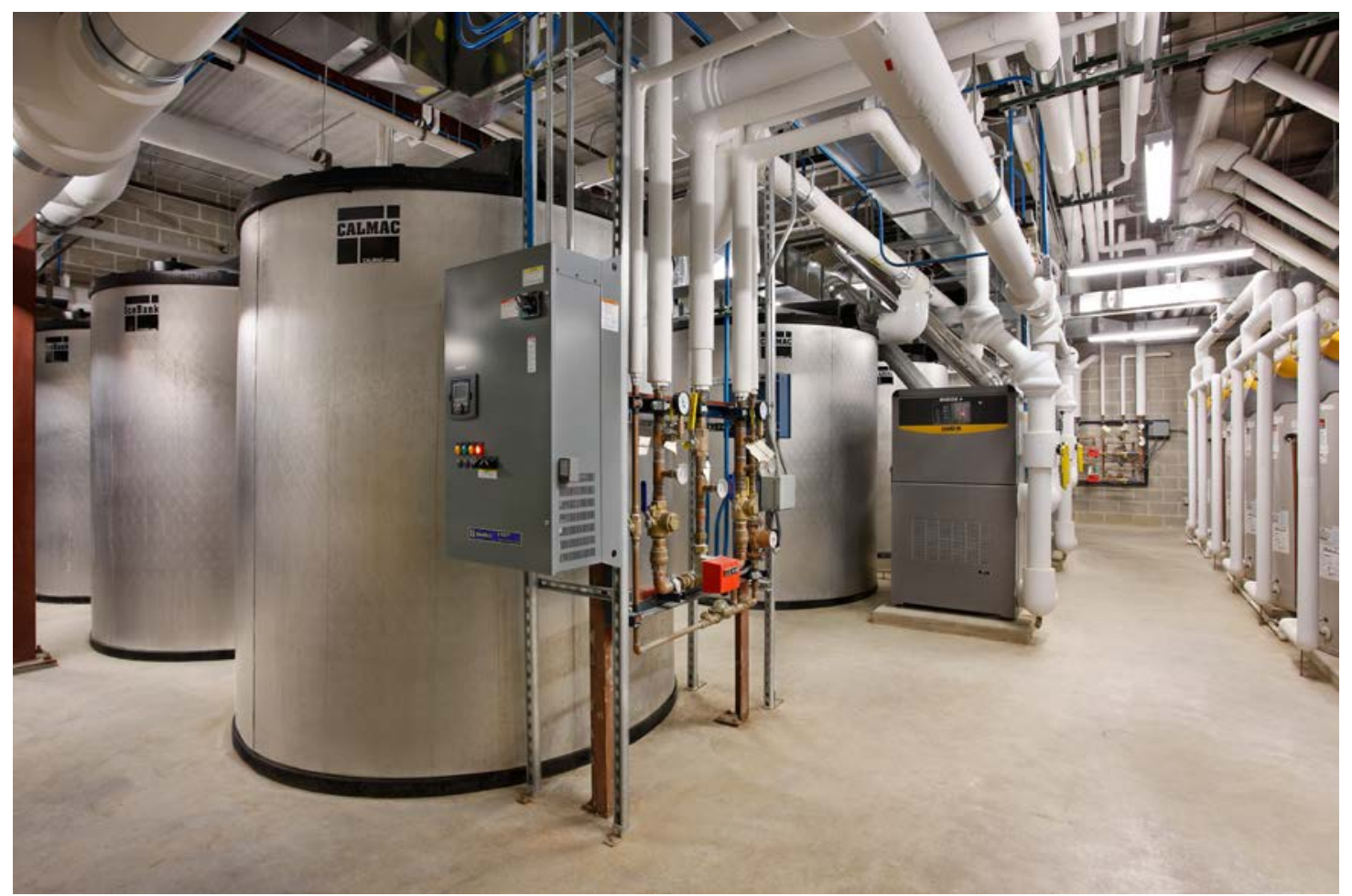

Figure 5. Image: Trane® Thermal Energy Storage

Source: Trane Corporation

\section{Pumped Thermal Energy Storage (or Carnot Batteries)}

An emerging family of energy storage systems are known as pumped thermal energy storage (PTES) or Carnot batteries. ${ }^{7}$ These devices convert electricity into heat, which is stored as thermal energy and then later converted back into electricity by means of reversible thermodynamic cycles. At the most basic level, each system has a hot and cold store with an electrically driven heat pump to transfer heat to the hot store and then uses the hot store later to drive a turbine. Various cycles and thermal storage systems have been investigated, including:

- Joule-Brayton cycles with sensible energy storage, such as pebble beds (McTigue, White, and Markides 2015), concrete storage (Desrues et al. 2010), or molten salts (Laughlin 2017); rock and concrete systems can operate over a wider range of temperatures, whereas molten salt systems benefit from developments by the CSP industry.

- Trans-critical carbon dioxide cycles with hot water and ice storage (Morandin et al. 2013).

- Steam Rankine cycles with latent heat storage (Steinmann 2014); an electrical heater can be used in place of the heat pump to reduces cost and avoid the need for a cold storage (e.g., one technology heats a volcanic rock packed bed and discharges the heat through a conventional steam turbine).

\footnotetext{
${ }^{7}$ For more information about Carnot batteries, see "IEA Energy Storage Task 36: Carnot Batteries," https://www.eces-a36.org/.
} 


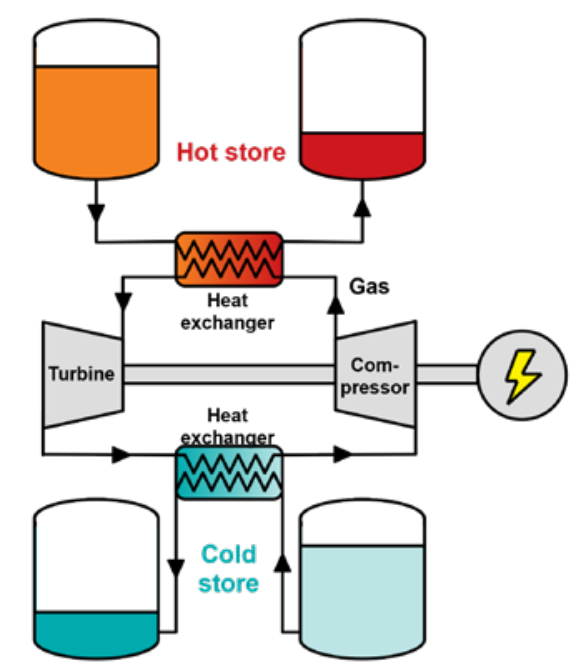

Figure 6. Schematic of PTES system or Carnot battery using liquid storage

The heat pump is shown during charge.

Source: "Pumped Thermal Electricity Storage: Grid-Scale, Cheap Materials, Known Tech, Compact, Install Anywhere," Antoine Koen and Pau-Farres Antunez, Energy Post, March 5, 2020, https://energypost.eu/pumpedthermal-electricity-storage-grid-scale-cheap-materials-known-tech-compact-install-anywhere/.

Various other distributed and grid-scale designs and concepts are being pursued. Several of them, such as ice storage for commercial buildings have already been commercialized. The technologies above are highlighted here because the companies and technologies have either reached or are approaching commercial viability and have garnered interest from the electric sector broadly.

\subsubsection{Electromechanical Technologies}

Electromechanical technologies comprise our second grouping of technologies, which includes very mature technologies such as PSH as well as emerging technologies like gravity storage. The electromechanical technologies that we chose to examine include compressed air energy storage, liquid air energy storage, pumped-storage hydropower, flywheels, gravity, and hydrogen storage.

\section{Compressed Air Energy Storage (CAES)}

Compressed air energy storage (CAES) has historically focused on compressing air into a large underground cavern and then, when needed, decompressing the air, and combining it with natural gas to significantly increase the efficiency of the natural gas combustion turbine. This technology has been analyzed for many years and is represented in the ReEDS model. In the United States, one commercial-scale CAES plant is in operation: the 110-MW plant Macintosh, Alabama, has operated for 27 years. Without more plants and experience, the uncertainty around costs is higher with CAES technology. Also, CAES plants have longer development timelines than above-ground storage technologies (Mongird et al. 2019). Most importantly, the traditional CAES implementation is geographically constrained, as it must be located near an appropriate underground cavern. Finally, several CAES developments have been announced in the United States, including developments by Burbank Power (for a site in Utah) and by PG\&E. 


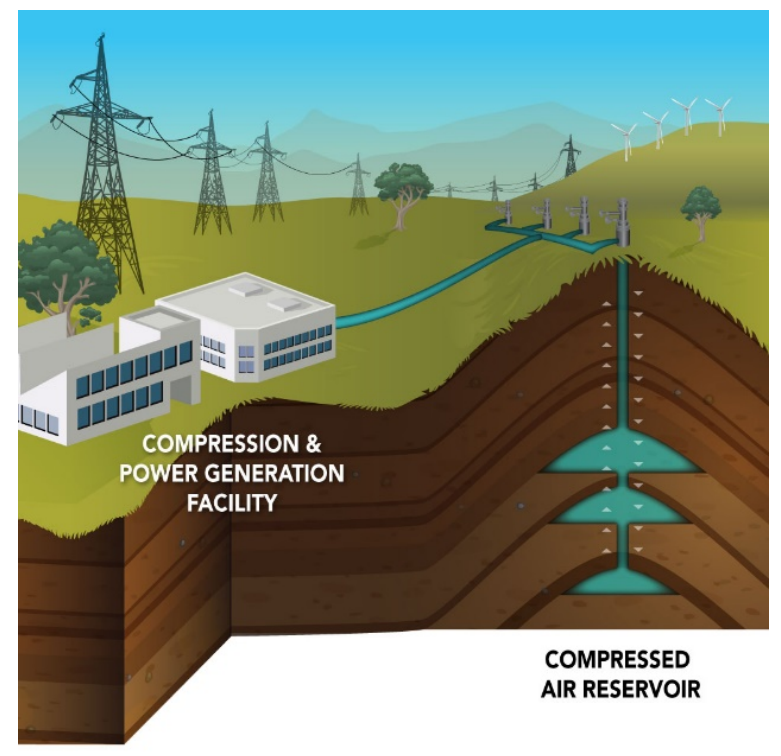

Figure 7. Illustration of CAES system

Source: "Compressed Air Energy Storage," PNNL, http://caes.pnnl.gov

\section{Liquid Air Energy Storage (LAES)}

Liquid air energy storage (LAES) seeks to harness some of the same fundamental physics of CAES but without the need for geological formations. In this technology, electricity is used to compress air until it becomes a liquid, and the released thermal energy is saved in a high-grade thermal store. LAES systems can use waste heat from nearby industrial processes to raise the RTE. Recent attention has been raised by a high-profile set of test plants and planned commercial-size plants. ${ }^{8}$ Current costs are uncertain but ongoing improvements and prime siting (i.e., close to thermal supply and demand) could make this option more viable.

\section{Flywheels}

Flywheels are another technology that has been developed and deployed, particularly in the storage use case of providing grid services. Over $931 \mathrm{MW}$ of flywheels are deployed globally. A flywheel relies on the kinetic energy of a rotating weighted shaft in a nearly frictionless environment to provide power via inertia when needed. They are typically used only for shortterm power, and vendors typically provide storage durations of only 0.25 hour, with power sizes up to $20 \mathrm{MW}$ (Mongird et al. 2019).

\footnotetext{
${ }^{8}$ See, for example, "Highview Power Bringing 50-MW Cryogenic Storage Plant to UK," Power Engineering, October, 21, 2019, https://www.power-eng.com/2019/10/21/highview-power-bringing-50-mw-cryogenic-storageplant-to-uk/.
} 


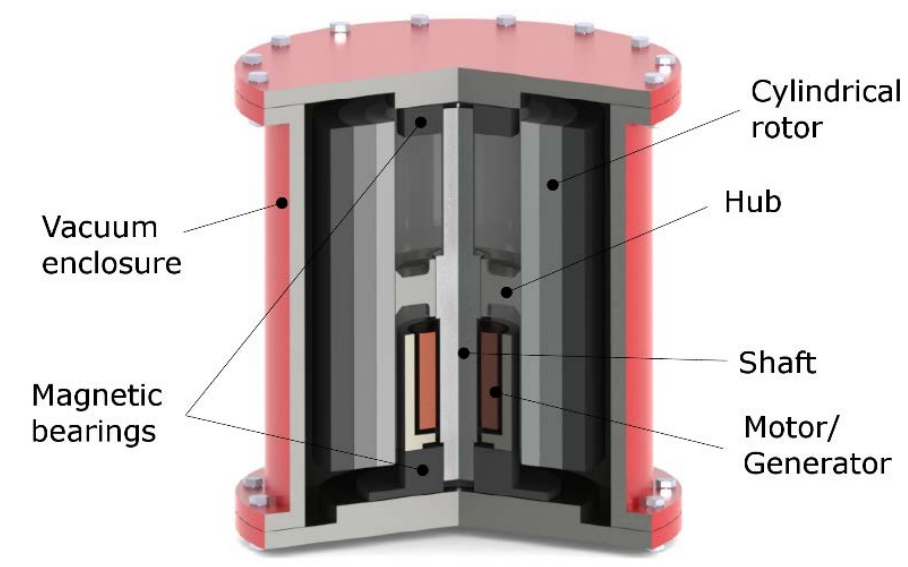

Figure 8. Schematic of flywheel energy storage system

Source: By Pjrensburg - a rendering from a solid-works model, edited to include labels, in png format Previously published: 2012-04-29, CC BY-SA 3.0, https://commons. wikimedia.org/w/index.php?curid=19258681

\section{Gravity Energy Storage}

The physics concept behind gravity energy storage can be as simple as using electricity to raise a large mass and then creating electricity when that potential energy is released. The practice of gravity energy storage has taken many forms over the years and, with the recent increase in interest in energy storage, new variations of the technology and companies are entering this space regularly. From recent ideas such as pushing a train filled with rocks up a hill and letting it roll down while running generators to dropping a heavy weight down a shaft, raising a heavy weight by pumping water underneath it, or stacking and unstacking hundreds of large concrete blocks, all these technologies focus on increasing and releasing potential energy. Due to the scale, these technologies are likely most competitive at large scale and long-duration. Of course, once built, many could also provide shorter duration capabilities as well. suited for large-scale and longer-duration use cases. Most of these vendors for these technologies have either not yet reached or are just now reaching commercial deployment; so, the costs reported are still preliminary and we rely here on a single source by Schmidt (2018) for cost and performance estimates. An additional selling point in terms of bankability is that most of the components are from other industries and thus mature.

\section{Pumped-Storage Hydropower (PSH)}

In the United States and globally, pumped-storage hydropower (PSH) is by far the largest source of electricity storage currently on electric systems. There are $23 \mathrm{GW}$ installed in the United States, ${ }^{9}$ with installations dating to 1960, when expectations of nuclear and fossil baseload power drove the system assumptions. PSH, which has an RTE of $80 \%$, is capable of load shifting (arbitrage), providing planning and operating reserve, and reducing curtailment of variable renewable energy. It is sometimes colocated with existing hydropower facilities. Though growth of PSH has slowed

\footnotetext{
${ }^{9}$ DOE OE Global Energy Storage Database, https://www.sandia.gov/ess-ssl/global-energy-storage-database/.
} 
in recent decades as tracked by the EIA (2019), recent interest has grown and several closed-loop ${ }^{10}$ PSH systems have entered the planning stages, including Goldendale (1,200 MW in Washington state), Gordon Butte (400 MW in Montana), and Banner Mountain (400 MW in Wyoming). And DOEs HydroVision report (DOE 2016) presents various scenarios for the growth of PSH; scenarios from that report are summarized in Section 3 (page 33).

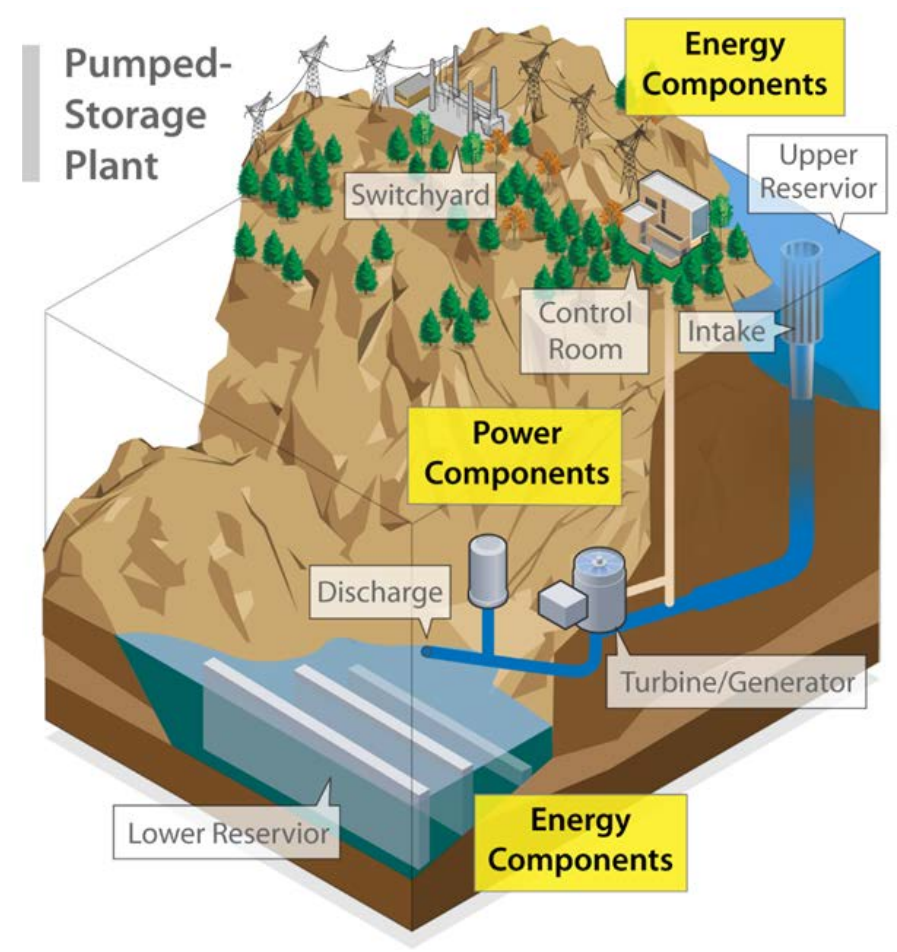

Figure 9. Illustration of hydropower pumped storage system

Source: (Denholm et al. 2021)

\subsubsection{Electrochemical Technologies}

Finally, the third grouping of energy storage technologies are electrochemical technologies. There is dramatic and growing interest in batteries from both distributed and grid-scale project developers amid recent dramatic price drops in LIB chemistries (see Figure 10, page 18). Lower battery storage costs combined with significant decreases in solar PV and wind costs have led many experts to postulate that the combination of technologies will be market leaders going forward; that hypothesis is something the SFS will explore.

For this portion of the SFS, we collect battery costs for a variety of technologies. LIBs are the current market growth leader in energy storage deployments, with over $99 \%$ market share by capacity deployment in the United States in 2019 (Wood Mackenzie P\&R/ESA 2020), but many of the other battery technologies have their own advantages and market niches.

\footnotetext{
${ }^{10}$ Closed-loop PSH is not part of a river system.
} 


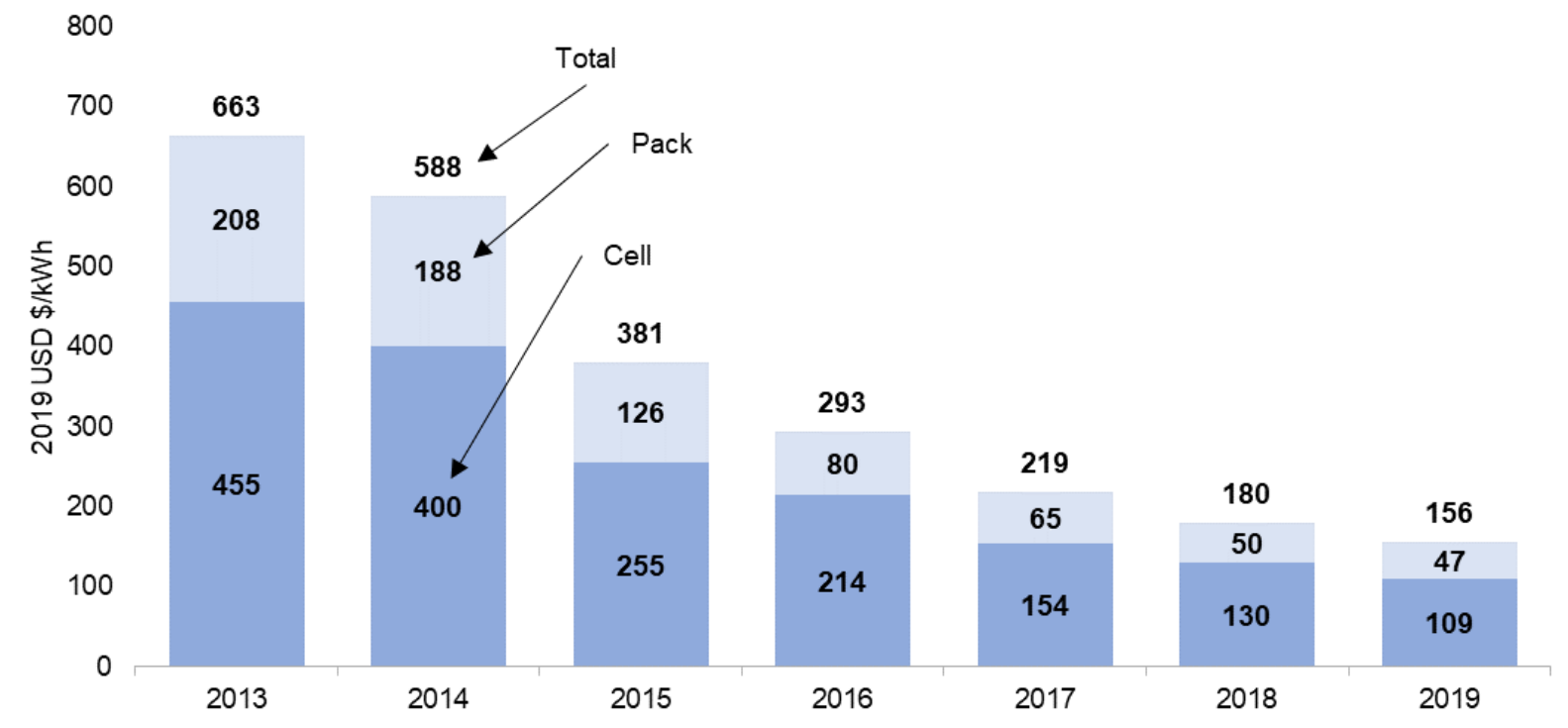

Figure 10. 2019 BNEF battery price survey results (with cell and pack split)

Data Source: (Frith and Goldie-Scot 2019)

Throughout this report, the battery cell, battery module and battery pack are referenced. These are stages of assembly of the overall battery system. The battery cell is the smallest unit of the battery system. The battery cells are wired together into a battery module of various cells to achieve a desired voltage level. These modules are then combined into a battery pack which contains sensors and controls to monitor the battery and provide safety controls.

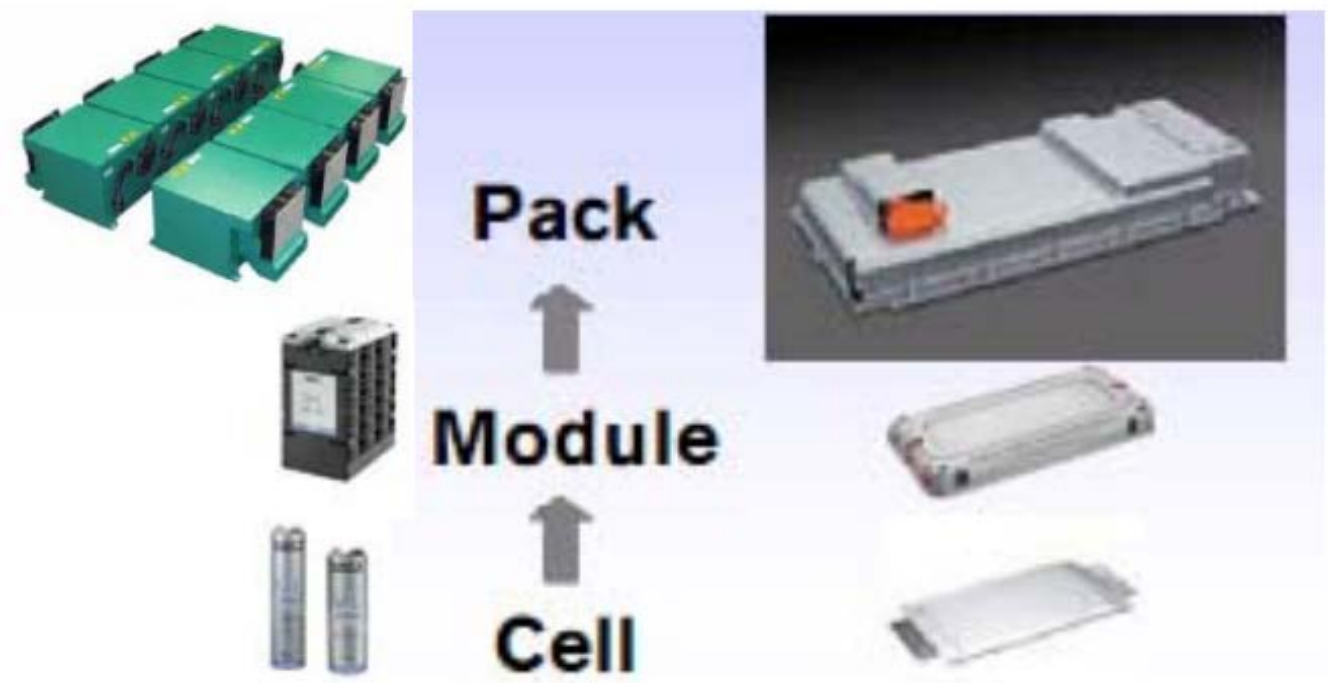

Figure 11 Battery cell, module, and pack diagram (Pesaran, Kim, and Keyser 2009)

\section{Lead-Acid Batteries}

Of the battery technologies studied here, lead-acid batteries have a large overall market (as a result of their use in vehicle ignition batteries) and have been used extensively for off-grid applications. They continue to be used extensively with mini-grids in developing countries, 
although some of that market is shifting to LIBs (ESMAP 2019). Lead-acid batteries are a mature technology with existing pathways for recycling and reuse. Unfortunately, they are limited by the cycle life as a function of depth of discharge. There are applications such as capacity for resource adequacy, but a typical daily cycling would limit the lifetime to 3 years or less (Mongird et al. 2019). Several groups ${ }^{11}$ are looking at advanced lead batteries (i.e., lead carbon batteries) and are seeking ways to increase the cycle life and improve other characteristics of batteries under the Advanced Lead-acid Battery Consortium. ${ }^{12}$

\section{Flow Batteries}

According to the DOE Global Energy Storage Database, ${ }^{13}$ there are $300 \mathrm{MW}$ of operating, under construction or contracted capacity of flow batteries as of July 2020; this capacity makes this family of battery types one of the more common grid-scale energy storage technologies. A flow battery is typically composed of two tanks of fluid material, and both are pumped across opposite sides of ion-selective membrane. Ion exchange (and therefore current) occurs through the membrane. A few advances are being explored as well including hybrid systems, membrane-less systems, and several chemistry variations (Mongird 2019).

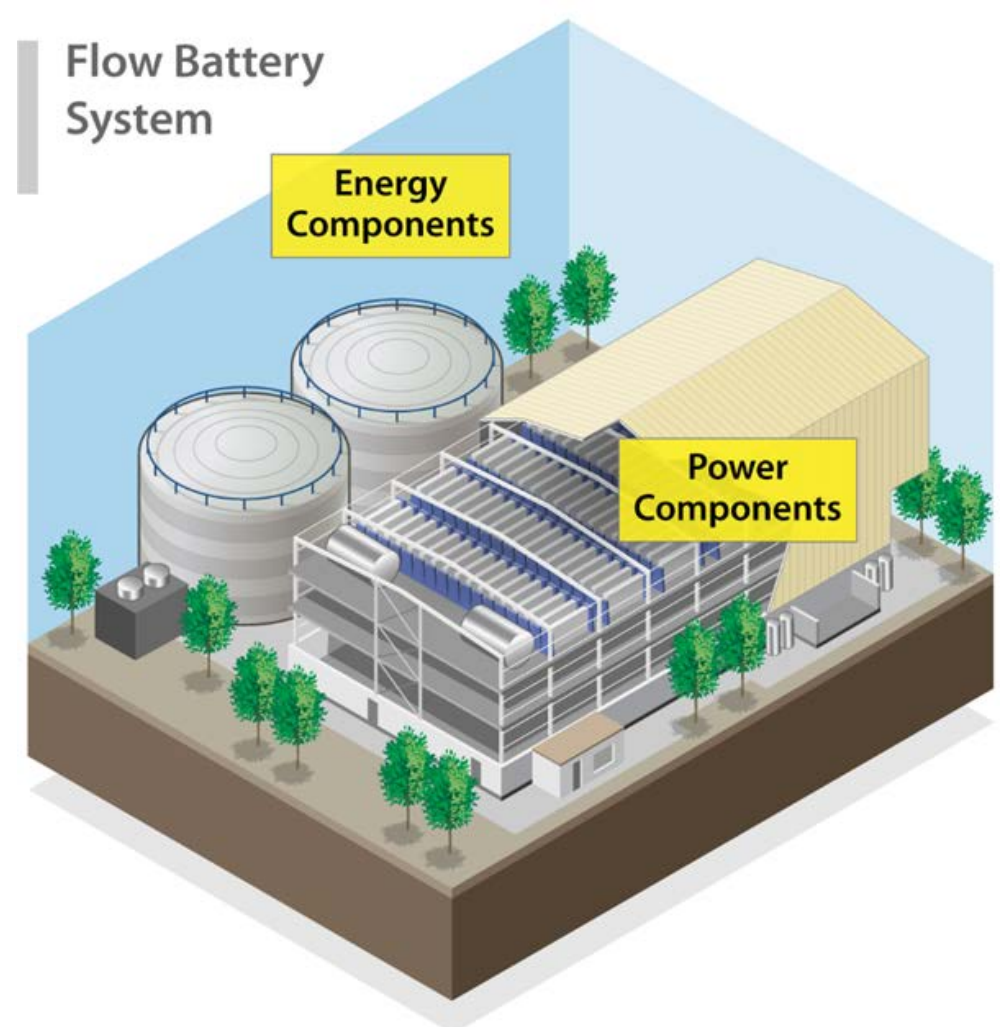

Figure 12. Illustration of flow battery system

Source: (Denholm et al. 2021)

\footnotetext{
${ }^{11}$ See 'Advanced Lead Acid Battery Consortium," 2017, https://www.sciencedirect.com/topics/engineering/advanced-lead-acid-battery-consortium

${ }^{12} \mathrm{https} / / /$ batteryinnovation.org/

${ }^{13}$ DOE OE Global Energy Storage Database, https://www.sandia.gov/ess-ssl/global-energy-storage-database/.
} 


\section{Sodium Sulfur Batteries}

Of the batteries we describe here, sodium sulfur batteries are unique in that they are hightemperature batteries that operate at $300^{\circ} \mathrm{C}$. As of 2018 , over $189 \mathrm{MW}$ of this technology are installed around the world (Mongird et al. 2019), which implies greater maturity than other emerging high-temperature liquid metal batteries. One electrode is molten sodium, and the other is molten sulfur. The downside to this type of battery is that the battery temperature needs to be maintained even when the battery is not in use and a freezing of the active material could result in a decreased lifetime. This disadvantage makes them unlikely to be deployed except in large central systems.

\section{Sodium Metal Halide Batteries}

Like sodium sulfur batteries, sodium-metal halide batteries ${ }^{14}$ are also molten batteries that are composed of sodium and sodium-chloride operating between $270^{\circ} \mathrm{C}$ and $350^{\circ} \mathrm{C}$. The key difference in composition is that nickel has been substituted for sulfur in sodium metal halide batteries. About $19 \mathrm{MW}$ of sodium-metal halide are deployed in the United States (Mongird et al. 2019). The technology is currently used mostly in bus fleets, but it still requires independent heaters to maintain the molten state needed for operation. Research is ongoing to make them cheaper and reduce their operating temperature. Given the brief history of these batteries, which date to 1999 , there are no dominant players at this time and there are possibilities to reduce the costs of the technology in the near term with additional research.

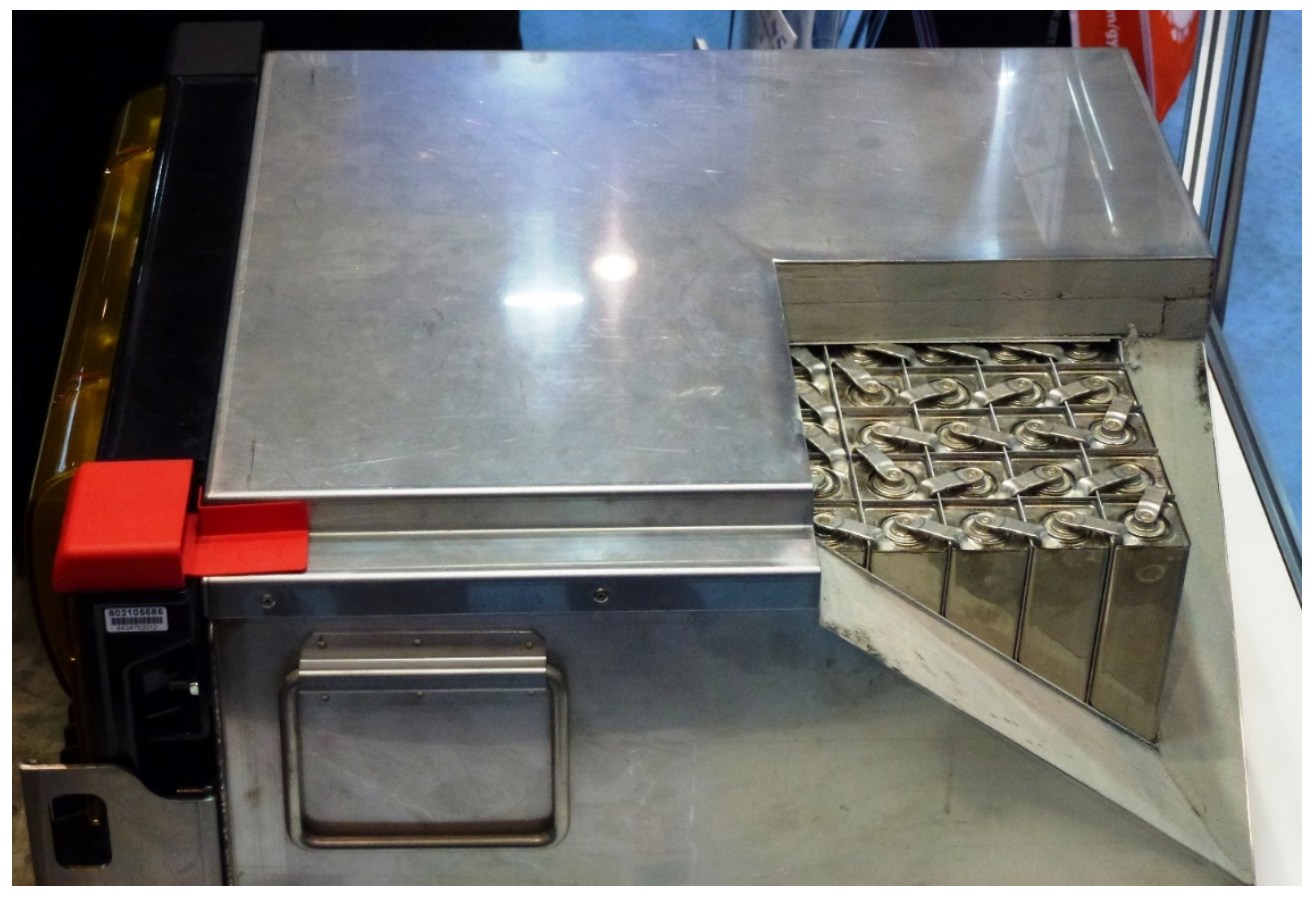

Figure 13. Photo of sodium-metal halide battery

Source: Rudolf Simon - Own work, CC BY-SA 3.0, https://commons. wikimedia.org/w/index.php?curid=18740786

\footnotetext{
${ }^{14}$ Sodium-metal halide batteries are commonly known as zebra batteries.
} 


\section{Zinc-Hybrid Cathode Batteries}

Zinc-hybrid cathode battery technology has several features that make it attractive, including high energy density, inexpensive and widely available materials, and a nondendritic electrolyte. Variations include $\mathrm{Zn}-\mathrm{MnO} 2, \mathrm{Zn}-\mathrm{Ni}$, and Zinc-Air. And several firms are actively researching and considering deploying this emerging technology.

\section{Lithium-Ion Batteries}

As with the other batteries we consider here, a lithium-ion battery (LIB) is a rechargeable battery with lithium ions moving through an electrolyte from the negative electrode (usually graphite or composite) to the positive electrode (a lithium compound that drives most of the characteristic differences between the different chemistries described). LIB technology was first researched in the 1970's and has been used broadly in consumer electronics starting in the 1990's. LIB deployments are now growing in the burgeoning electric vehicle (EV) market and also being deployed into the electric grid for energy storage as either as stand-alone systems or hybridized with solar PV, wind, or other generation technologies.

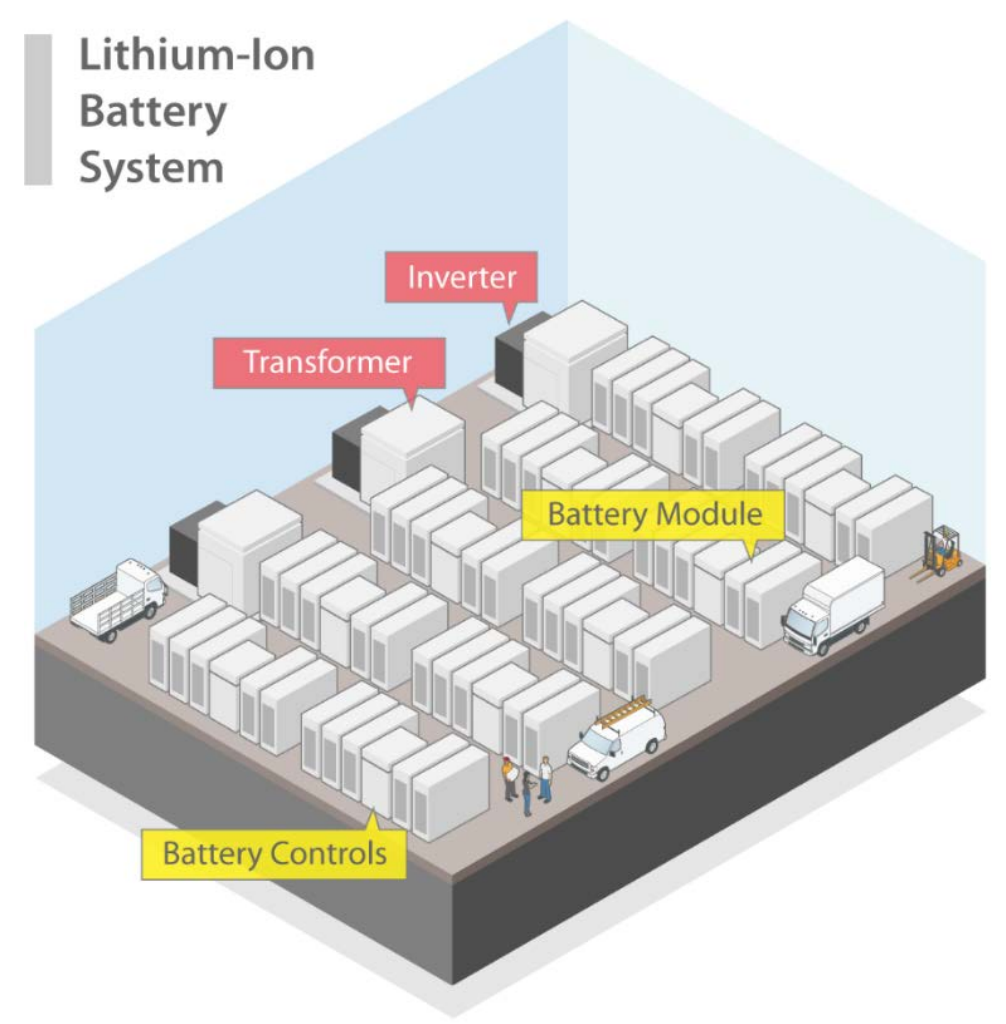

Figure 14. Illustration of grid-scale lithium-ion battery system

Source: (Denholm et al. 2021)

Interconnection queues around the United States ${ }^{15}$ indicate significant additional LIB systems could be seriously proposed over the next few years. Many chemical configurations of the anode, cathode, and electrolyte have been deployed and are under development. Key cathode

\footnotetext{
${ }^{15}$ Generation, Storage, and Hybrid Capacity in Interconnection Queues (Lawrence Berkeley National Lab) https://emp.lbl.gov/generation-storage-and-hybrid-capacity
} 
compounds include NMC (nickel-manganese-cobalt), LFP (lithium, iron, phosphate) and NCA (nickel, cobalt, aluminum). BNEF and others postulate that the dramatic ramp-up in the EV market (and building on the consumer electronics market) will continue to lower the cost of several chemistries of LIBs broadly (see Figure 25, page 35). Currently, NMC is the most commonly used cathode chemistry, but a new Wood-McKinsey forecast ${ }^{16}$ indicates LFP will grow to dominate the grid-storage market over the next few decades (Figure 15).

Several factors influence the choice of cathodes, anodes, and electrolytes, and significant research has been conducted globally on all these components. DOE is working to reduce the use of critical materials in lithium ion batteries by moving to chemistries with lower cobalt content and to diversify global supply chains to mitigate supply risk ${ }^{17}$. The anticipated rapid growth of the EV market will both drive down cost (with spillover into the stationary storage market) but will also put pressure on the supply chain, leading to diversification of supply. For example, LFP components have a broader global ability to increase supply chain than NMC, which has fewer locations for its growth (Igogo et al. 2019).

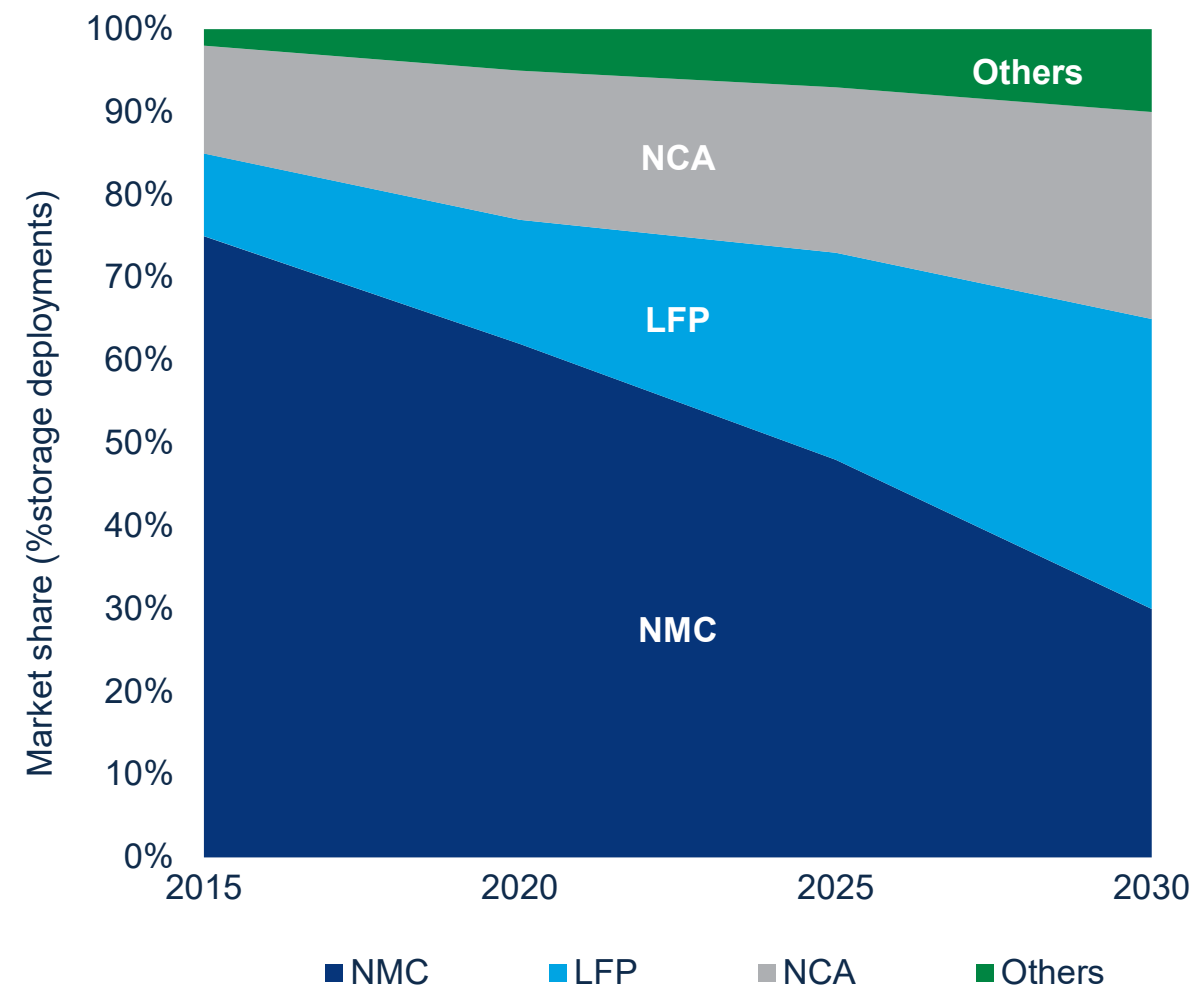

Figure 15. Past and projected market share of different LIB chemistries through 2030

Source: Wood Mackenzie Energy Storage Service

\footnotetext{
16 "LFP to Overtake NMC as Dominant Stationary Storage Chemistry by 2030 ," Wood Mackenzie, August 17, 2020, https://www.woodmac.com/press-releases/lfp-to-overtake-nmc-as-dominant-stationary-storage-chemistry-by$\underline{2030 /}$

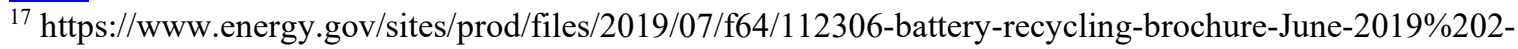
web150.pdf
} 
Recent cost reductions of LIBs, which have been driven by growth in both the EV market and the grid market, have been both significant and surprising, with cost decreases of over $80 \%$ being reported from 2010 to 2019 (Frith and Goldie-Scot 2019). A literature search of future projections of cost by Cole and Frazier (2020) anticipates additional significant cost reductions in the future scenarios as well (see Section 3).

\section{Ultracapacitors}

Historically, capacitors are used extensively in components of the electric grid to provide very short-term emergency power so that the grid can be shut down smoothly in the event of an outage. Ultracapacitors are a form of capacitor that typically stores up to 100x the energy per volume of electrolytic capacitors, and they can charge and discharge much faster than batteries with extremely high cycle life. Ultracapacitors are much more expensive than any batteries, and they are typically only built with low energy/power (E/P) capacity ratios (typically 0.25 hours) (Mongird et al. 2019). Ultracapacitors can be paired with other battery technologies (lacking quick response) due to their quick response but short-duration. A variety of companies manufacture ultracapacitors (or supercapacitors) for grid, transport, and other applications.

\section{Hydrogen Storage}

Various existing and potential methods can be used, in this case, to create hydrogen from electricity, store this hydrogen, and then then convert it back into electricity for the grid. NREL has contributed to a recent paper on hydrogen energy storage (Hunter et al. 2020) as one of several long-duration storage options, and we gather data primarily from this source for this report. Hunter et al. (2020) present several options for storing the hydrogen (e.g., in salt caverns and pipes) and several methods for converting hydrogen to electricity, including via a combined cycle turbine, a stationary fuel cell, or a fuel cell designed for heavy-duty vehicle applications. Stationary fuel cells are designed to be more durable and to operate continuously for years, leading to higher capital costs than heavy-duty vehicle fuel cells, which are designed more for intermittent operation than in grid storage systems. For this report, the current costs were represented by an electrolyzer to cavern storage to a combustion turbine to convert the hydrogen back to electricity. For the future state of hydrogen, the stationary fuel cell and salt cavern configuration is chosen (again with electrolyzers albeit cheaper than current electrolyzers). Hydrogen can store energy over extended periods of time. Additionally, there are a variety of high value uses for hydrogen within the industrial and transportation sectors that could develop alongside a market for hydrogen energy storage. The development of these markets in parallel could reduce costs by enabling economies of scale and enabling capital-intensive equipment (such as electrolyzers) to be monetized by multiple sectors (costs reported in Section 2.5). Hydrogen can also be used to produce synthetic fuels, which can then be used for power generation. Such concepts are in early stages of development and were therefore outside the scope of the current study.

As shown in Figure 16, there are two pathways shown for using the compressed hydrogen stored underground. One pathway is via a fuel cell. The other pathway is perhaps of equal interest for current deployments using hydrogen via a combustion turbine. At an overnight capital cost of \$1296 (2018 USD) for a hydrogen combined-cycle turbine versus a cost of a stationary PEM Fuel cell of $\$ 1320$ (2018 USD), the overall total cost (including electrolysis and compression) makes the turbine pathway slightly cheaper. The "future" H2 pathway we display in section 2.5 
incorporates an anticipated significant cost reduction in the stationary fuel cell pathway to $\$ 425$. The key takeaway is that there are several pathways to utilize hydrogen as a short-term or longterm electricity storage medium with a variety of external market factors and the possibility of significant future cost reductions.

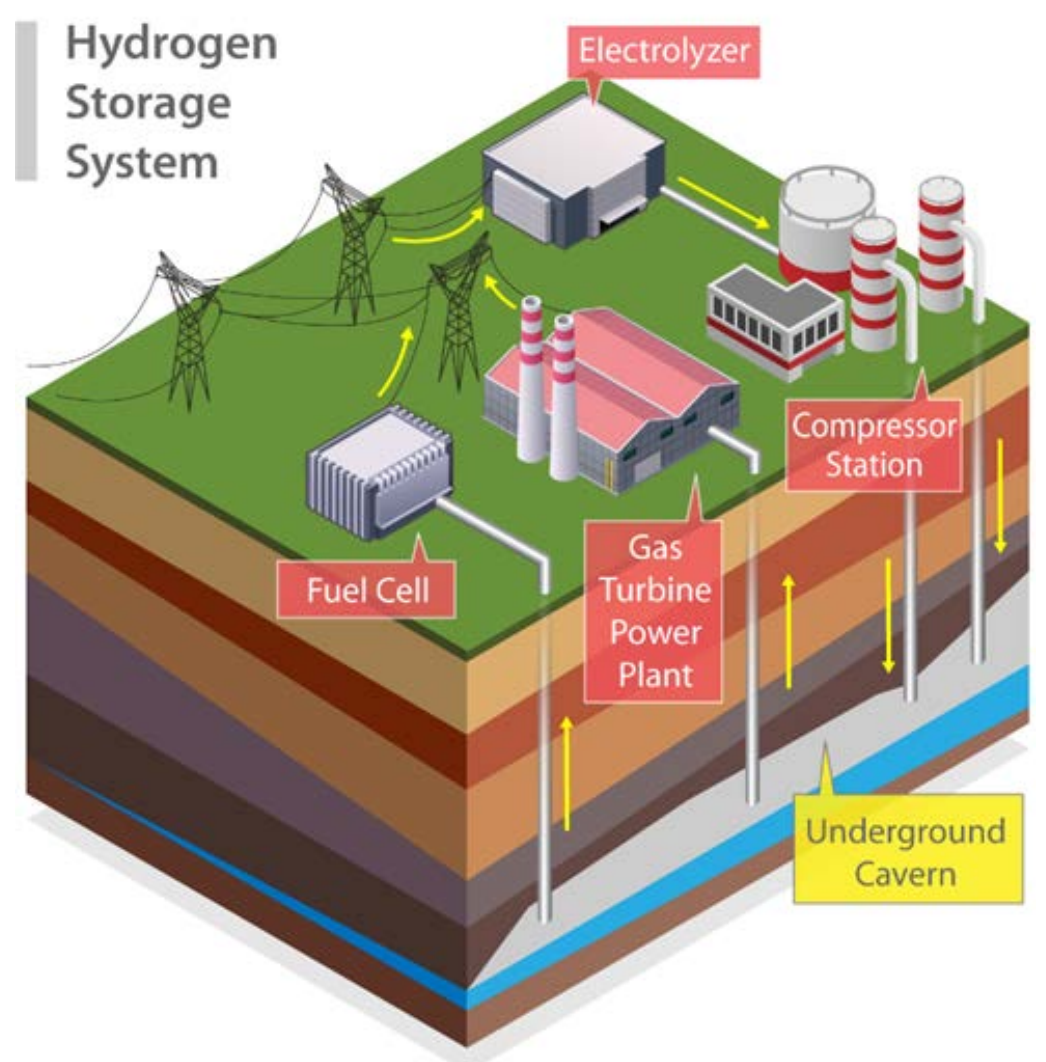

Figure 16. Illustration of hydrogen energy storage system

Source: (Denholm et al. 2021)

\subsection{Comparison of Current Costs of Technologies}

In this section, we compare the cost and performance of energy storage technologies. It is difficult to meaningfully compare a broad range of storage technologies that apply to different use cases and across different sectors from distributed residential to grid-scale storage. Therefore, we attempt to compare the technologies appropriately in the context of this study. As we primarily model PV and distributed batteries for the distributed sector in this analysis, most of our comparisons are across grid-scale technologies and we seek to explore how the technology characteristics might impact the grid-scale market penetrations of different technologies. As stated above, comparisons are also difficult because storage technology costs are a function of both capacity and duration (as well as efficiency and other metrics).

As stated above, one of the difficulties of assessing the economics of storage technologies is that the linkage with the services they will provide impacts the price they receive for their services. This is, of course, different from typical generators as they simply produce electric power. Storage systems' cost, performance, and value all change as systems are sized for the need and 
throughout their lifetime as they might shift from providing grid services to eventually assisting with peaking power. Therefore, the presentation of storage data must include both power and duration components. Figure 17 (page 27) plots the relative costs for the storage technologies we consider by their power capacity and energy capacity cost components. To be clear, this is not the total capital cost represented in two different ways but rather the portion of the capital cost associated with the power of the system and the capital cost associated with the energy or duration of the system. The total capital cost would be the sum of the capital cost power and the duration multiplied by the capital cost energy. Note that some outliers (flywheels and ultracapacitors) are not shown.

The data sources for each of these technologies is recent, but no sole source contained data on all technologies. The electrochemical technologies (except for LIBs, which are updated within this study) are from energy storage cost reports by Mongird et al. $(2019 ; 2020)$, data for PTES are from other work at NREL (McTigue et al. In Press), hydrogen data are from NREL longduration storage work (Hunter et al. 2020), and gravity storage data are from analysis by Schmidt (2018).

The data sources for technology costs and other parameters used in this comparison are from a variety of sources, which we sought to compare as equitably as possible while accepting ranges of uncertainty especially in emerging technologies.

The ideal energy storage technology is in the lower left corner of Figure 17 (page 27), where low costs for both power and duration appear. Storage technologies that are best for grid services would be cheaper for power and more expensive for duration. Conversely, long-duration storage (e.g., over 10 hours) could be more expensive for power but the cheapest option for duration. The figure shows several battery technologies all similarly aligned at $450 \$ / \mathrm{kW}$, but LIB (using a weighted average cost across all chemistries) is closer to the cheapest point because of its low dollars per kilowatt-hour cost. Note that CAES and PSH are located close to $0 \$ / \mathrm{kWh}$ and have their capital costs captured mostly on the dollars per kilowatt scale. Note that several technologies have cost values outside the range of the graphic including ultracapacitors, flywheels and H2-elec-cavern-CT. Specific values are in Appendix A. 
Table 1. Data Sources for Energy Storage Technologies

\begin{tabular}{|c|c|c|}
\hline Storage Type/Technology & $\begin{array}{l}\text { Reference Year for } \\
\text { Current (2019) Costs }\end{array}$ & Primary Data Source \\
\hline \multicolumn{3}{|l|}{ Thermal Storage } \\
\hline Pumped thermal energy storage (PTES) & 2020 & McTigue et al. In Press \\
\hline \multicolumn{3}{|l|}{ Electrochemical Storage } \\
\hline Lithium-ion battery (weighted value) (LIB) & 2020 & $\begin{array}{l}\text { Multiple sources; } \\
\text { see References (p. 59) }\end{array}$ \\
\hline Lead-acid battery & 2020 & Mongird et al. 2020 \\
\hline Redox flow battery (flow batteries) & 2020 & Mongird et al. 2020 \\
\hline Sodium sulfur battery & 2018 & Mongird et al. 2019 \\
\hline Sodium metal halide battery & 2018 & Mongird et al. 2019 \\
\hline Zinc-hybrid cathode battery & 2018 & Mongird et al. 2019 \\
\hline Ultracapacitors & 2018 & Mongird et al. 2019 \\
\hline $\begin{array}{l}\text { Hydrogen storage (using electrolyzers, } \\
\text { salt caverns, and combustion turbines) }\end{array}$ & 2020 & Hunter et al. 2021 \\
\hline $\begin{array}{l}\text { Hydrogen storage (using electrolyzers, } \\
\text { salt caverns, and stationary fuel cells) }\end{array}$ & $2020^{a}$ & Hunter et al. 2021 \\
\hline \multicolumn{3}{|l|}{ Electromechanical Storage } \\
\hline Compressed air energy storage (CAES) & 2020 & Mongird et al. 2020 \\
\hline Liquid air energy storage (LAES) & 2020 & Olympios et al. 2021 \\
\hline Pumped-storage hydropower (PSH) & 2020 & Mongird et al. 2020 \\
\hline Flywheel & 2018 & Mongird et al. 2019 \\
\hline Gravity & 2018 & Schmidt 2018 \\
\hline
\end{tabular}




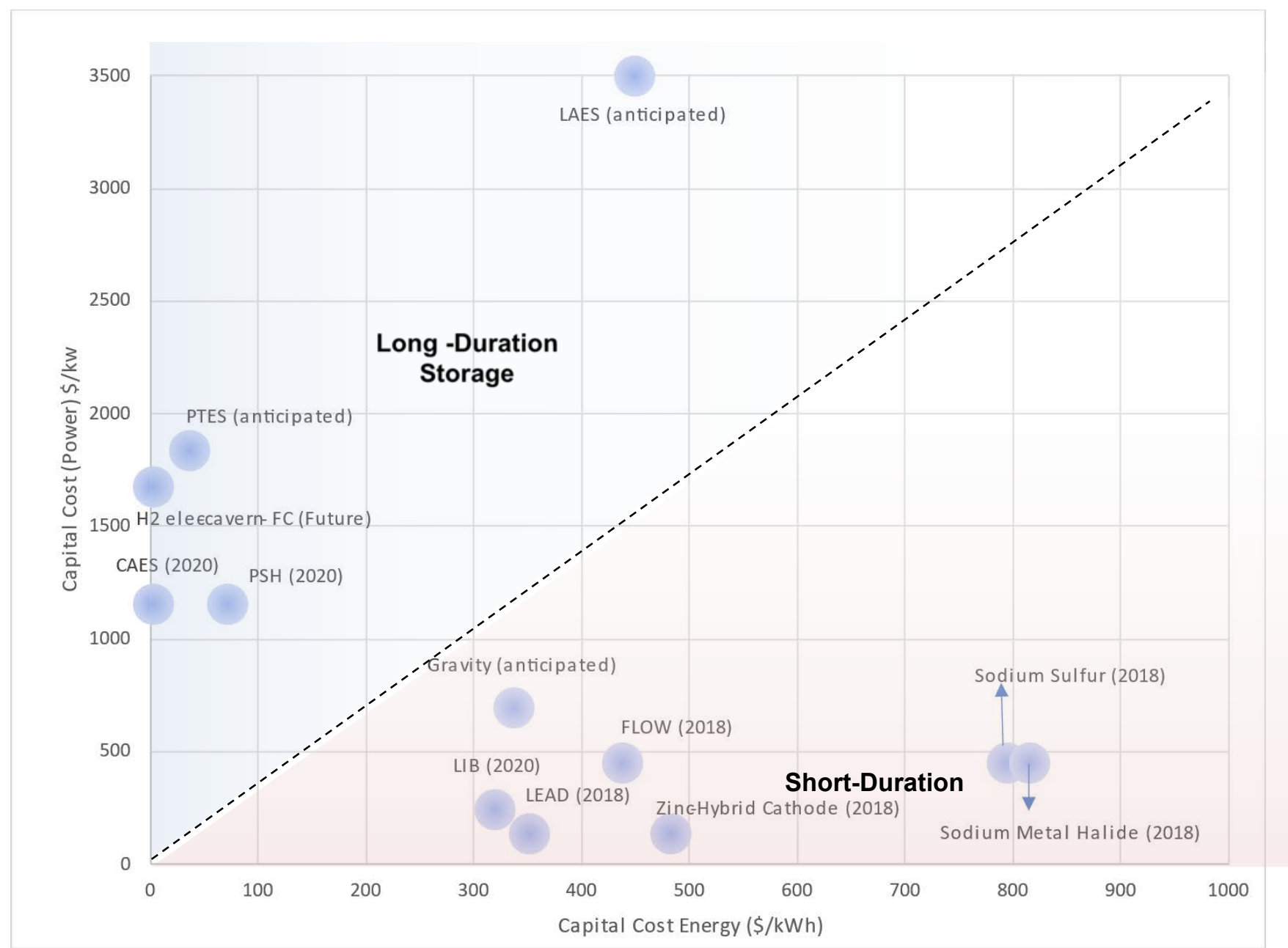

Figure 17 . Power capacity cost component $(\$ / k W)$ versus energy capacity cost component (\$/kwh)

The figure demonstrates the technologies for which cost does not vary significantly with additional duration.

Figure 18 shows the total investment cost in $\$ / \mathrm{kWh}$ for various technologies, assuming a 100MW storage system with varying levels of storage. These ranges of sizes are selected because of the current and near-term (next 10 years) focus on 4 hours of battery storage capacity as the typical size, for our interest in longer-duration storage, and to illustrate how total system costs change with storage duration among technologies. We select $100 \mathrm{MW}$ as a significant size of storage for the grid currently. Eventually, much larger storage systems might be composed of 100 -MW or larger modules, but that is not currently typical. Note that this graph has four lines for LIB showing the progression of costs from 2019 to 2024 and thereby current and anticipated cost reductions. 


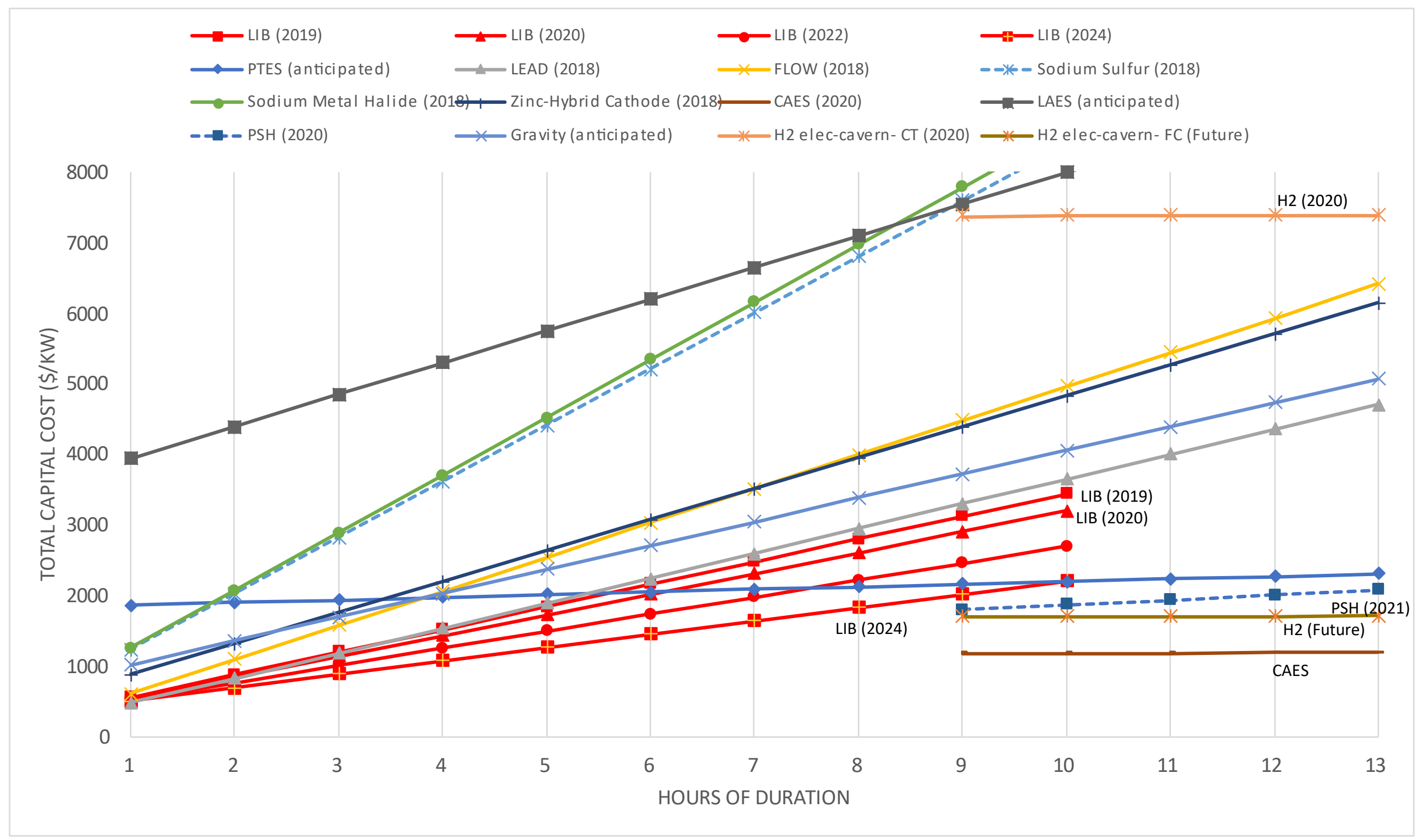

Figure 18. Total investment cost $(\$ / k W)$ for a system with $100 \mathrm{MW}$ of storage with varying durations

Flywheels and ultracapacitors are not included in the figure, as they are deemed to be inappropriate for these durations. 
At the 4-hour duration mark in Figure 18, LIB (current through 2024) is the cheapest choice ${ }^{18}$ by capital cost for energy storage with the anticipated costs for PTES, gravity energy storage, flow batteries, and zinc-hybrid cathodes virtually tied as the next cheapest technologies. At the highcost end of the spectrum are flywheels and ultracapacitors, which have been left off the graph as they are not cost competitive beyond very short durations $(\sim 0.25$ hours $)$.

At more than 8 hours of duration, the ratio of energy to duration costs changes such that several technologies are at capital costs comparable to or lower than LIBs. Pumped thermal energy storage (PTES) is anticipated to be cheaper that LIB in most cases, and hydrogen storage costs are competitive if future cost improvements are realized as described by Hunter et al. (2020). This flip with longer durations indicates several technologies might be competitive with LIBs at longer duration. PSH and CAES also enter the picture at longer durations on the graph, at costs where it might be expected that they would be deployed more. However, as we look to the future and an anticipated decrease in LIB capital costs of an additional 50\% from current by 2030, the capital cost advantage of non-LIB technologies decreases resulting in potentially LIB capital costs being below the other technologies even at these longer durations.

Several of the factors impacting PSH deployment were discussed within the DOE Hydropower Vision Study (DOE 2016). As that study showed (Figure 19, page 30), in the base case, minimal new PSH was built in the United States. However, with technology improvements, low-cost financing, and improved environmental considerations, PSH could add $35 \mathrm{GW}$ of additional long-duration capacity by 2050 in one of the core scenarios. Since the Hydropower Vision report was published, investor interest has also grown in closed-loop PSH systems, which have now entered the planning stage at several locations. As discussed in Section 2.4 .2 (page 14), despite its apparent low cost, CAES is geographically constrained. The lack of any new, large installations in decades makes uncertainty high about CAES future deployment and is further proof that factors beyond cost are preventing more deployments.

Finally, the other technologies that are explored are more expensive than PSH, CAES and LIBs. However, it is important to remember that several of these other technologies (gravity, LAES, flow batteries, several battery chemistries) are at early stages of commercialization. Therefore, they could have more dramatic price decreases as the number of systems grows and capital costs decrease. The developers of these technologies anticipate being cost-competitive when they achieve their deployment goals.

\footnotetext{
${ }^{18}$ Lead-acid batteries have costs comparable to current LIB costs, but they are not included here because of a low cycle lifetime that continues to limit the market in comparison to other battery technologies.
} 


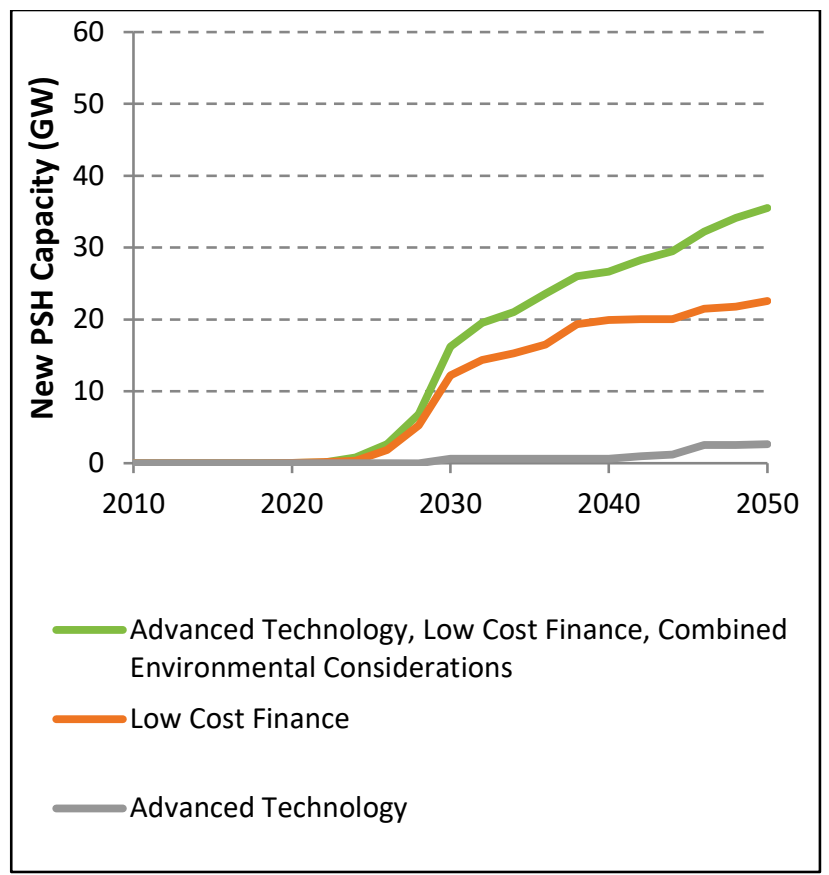

Figure 19. Projected newly installed capacity of PSH for scenarios used in HydroVision study

Source: (DOE 2016)

Several manufacturers are considering these long durations for their technologies. However, as we look to the future and an anticipated decrease in LIB capital costs of an additional $50 \%$ by 2030 (described in Section 3), the capital cost advantage even at longer durations decreases significantly, potentially with LIB capital costs below those of other technologies.

Another key metric to discuss is that of the RTE. Figure 20 shows the RTE of all the technologies we considered. The RTE value is critical and important but also usually limited by the physics of a given technology and engineering a way to a higher RTE value is difficult. Some efficiencies could be gained in thermal systems by improving thermodynamics and materials. In batteries, significant research is seeking new combinations of materials and also manufacturing improvements to improve the RTE and thereby reduce the heat generated and degradation. However, it is not anticipated that RTE will increase significantly for these existing technologies over the next decade. 


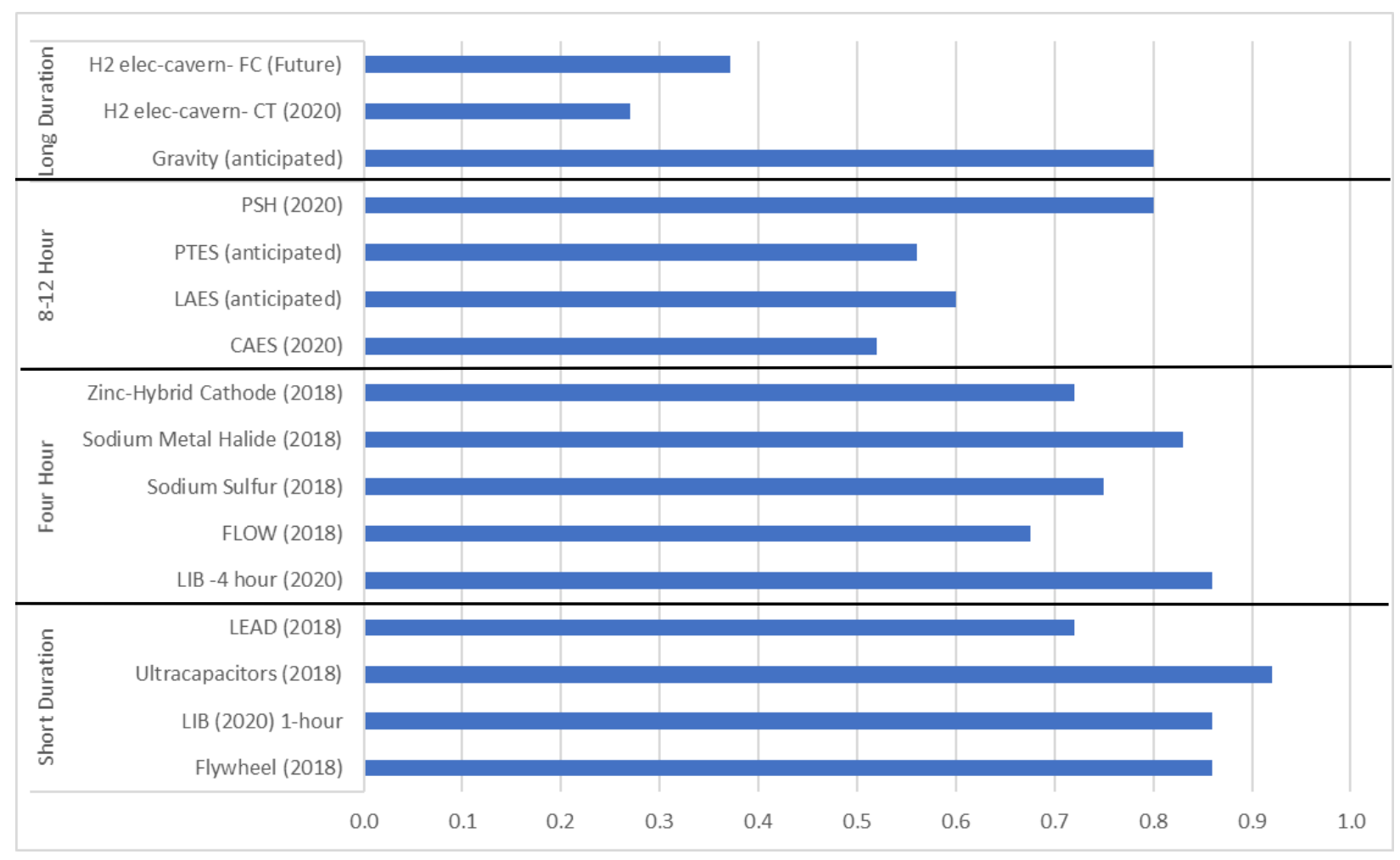

Figure 20. Round-trip efficiency of energy storage technologies

It is important to understand that LIBs and, in fact, most battery chemistries in Figure 20 have an RTE close to or above $80 \%$. LIBs are $86 \%$ RTE, and RTE trends downward - to near 70\% - for zinc-hybrid, sodium-sulfur, and lead acid battery technologies. Two thermal technologies (CAES and PTES) have RTEs of 50\%-60\%. Finally, the hydrogen RTE (electrolyzers, compression, storage, and fuel cell or combustion turbine) of $27 \%$ (with combustion turbine) and $37 \%$ (fuel cells) are lower than the others.

Again, the RTE by itself does not indicate that a technology may or may not be cost-effective. However, a low RTE (especially combined with more expensive charging electricity) means other technologies can have a higher capital cost and still end up with a similar levelized cost of storage value over time.

Building on the impacts of RTE on overall cost, Figure 21 shows the LCOS for several of these technologies within a certain use case or duration. As described above, the LCOS is a metric that seeks to combine the capital cost, O\&M costs, salvage costs, charging costs, and storage system throughput, notably by including the RTE and the depth of discharge to calculate the amount of energy discharged during operation. This metric does not speak to the value of the array of services that the storage device can provide. Also, the metric should not be used to compare storage technologies to generation technologies. As with capital cost, the LCOS will change with the duration of the storage system such that durations 1 hour and 10 hours will have different LCOS values. With these caveats, the authors consider this metric to be important in part because of the wide variation in both capital cost and RTE across all these technologies. The values used to calculate the LCOS for each technology vary by technology, but we hold the charging price constant (at the US wholesale price of 2.5 cents $/ \mathrm{kwh}$ ) and the WACC for all at 
$6.5 \%$, DOD and RTE are taken from the data sources for each technology and the number of cycles per year are 660 for short duration, 330 for four and 8-12 hour while the value is 52 for long-duration technologies (which is approximately a $10 \%$ capacity factor for long-duration). Again, these values are all assumed to be for large grid-scale batteries with noted levels of duration but could vary significantly when deployed into different grids with unique needs. Note that we do not include short-duration technologies (including flywheels and ultracapacitors) because their dispatch is vastly different from these technologies.

The LCOS results broadly indicate similar trends to what we saw with the total capital investment for the system. For 4-hour duration use cases (such as much of the time-shifting and peak capacity provision that is driving the market today), we see that the LIB LCOS is the lowest of the technologies at this duration. We anticipate that gap to widen as LIB costs continue to fall relative to other technologies. Within the 8-hour to 12-hour duration, PTES and CAES have lower LCOS than LAES. Of course, these costs are uncertain, as PTES and LAES are still under active development and have not been deployed widely. Finally, under long duration, we see that the potential cost reductions for this hydrogen storage pathway (described in Hunter (2020) could significantly reduce the LCOS which is an example of the possible changes in relative attractiveness in emerging technologies.
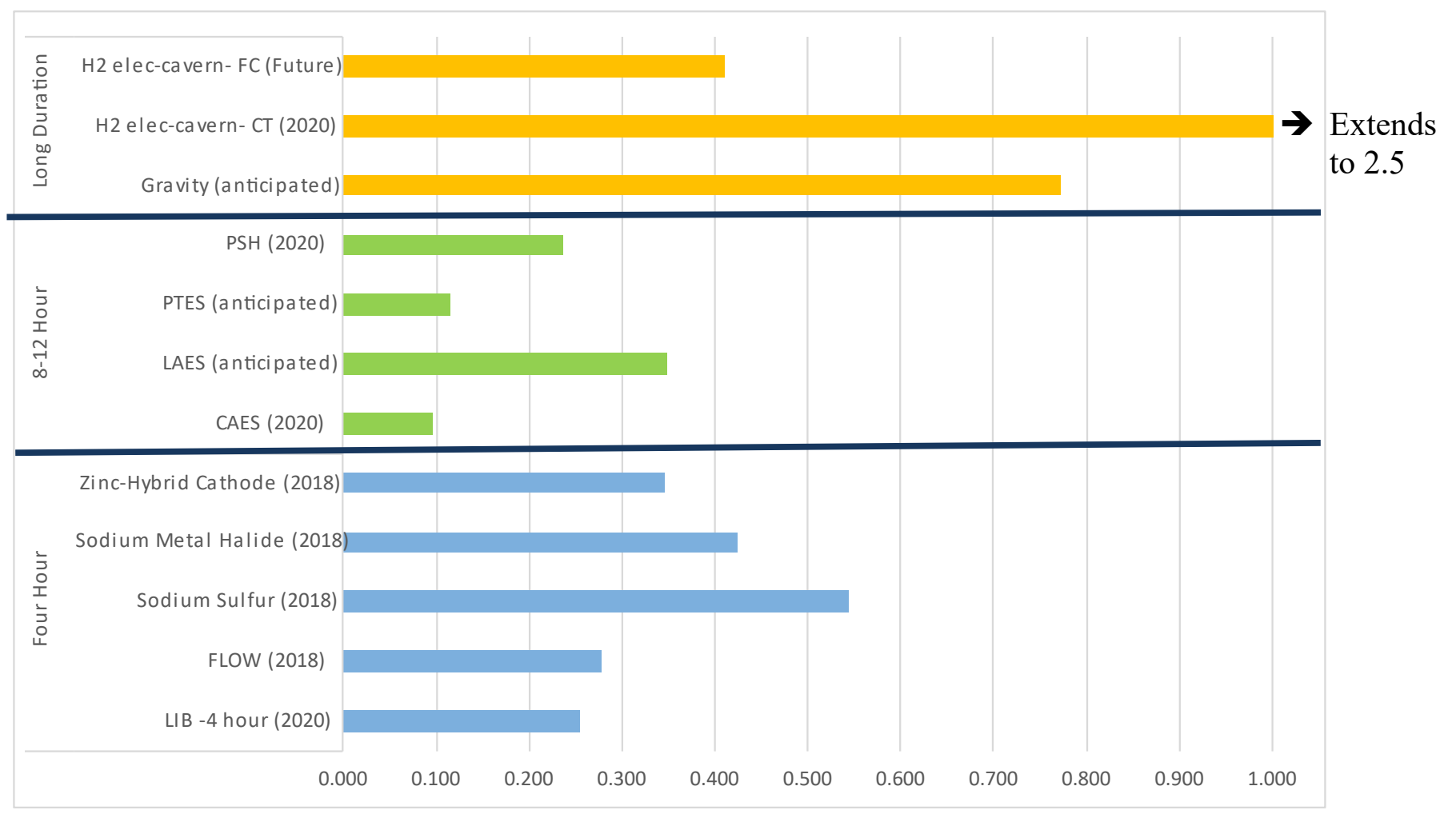

Figure 21. Levelized cost of storage $(\$ / \mathrm{kWh})$ of energy storage technologies included in this study

Technologies are differentiated by duration (4-hour, 10-hour, and 16-hour). 


\section{Battery Energy Storage System (BESS) Cost Assumptions and Projections for Scenario Modeling}

In this section, we estimate the current and projected cost for utility-scale, commercial/industrial, and residential battery energy storage systems (BESS) for use in concurrent SFS modeling analyses. The projections are made by estimating the current costs of BESS for each market segment and applying a cost projection curve for future costs. For all BESS, we assume LIB technology is used, although we do not specify the type of battery chemistry (e.g., NMC or LFP), and we note that these serve as a proxy - in other words, that any battery chemistry (including non-LIB technology) that can meet these same cost and performance characteristics can be equally competitive in the market.

The price of LIB packs depends on the chemistry used and its intended end use. Most BESS projects use either lithium-ion nickel-manganese-cobalt (NMC) batteries, which are sourced mainly from South Korea, or lithium-iron-phosphate (LFP) batteries, which are sourced mainly from China (BNEF 2019b). Figure 22 illustrates how battery pack costs vary with end use. The differences in prices are due to differences in the cell and pack design, and to battery performance requirements (e.g., end uses such as hybrid EVs that require faster charging rates) (Frith and Goldie-Scot 2019). To account for these differences, BNEF uses a volume-weighted average for tracking LIB prices. BNEF, in their 2019 LIB price survey, pegged the volumeweighted average price for a LIB pack at 2019 USD \$156/kWh (Frith and Goldie-Scot 2019).

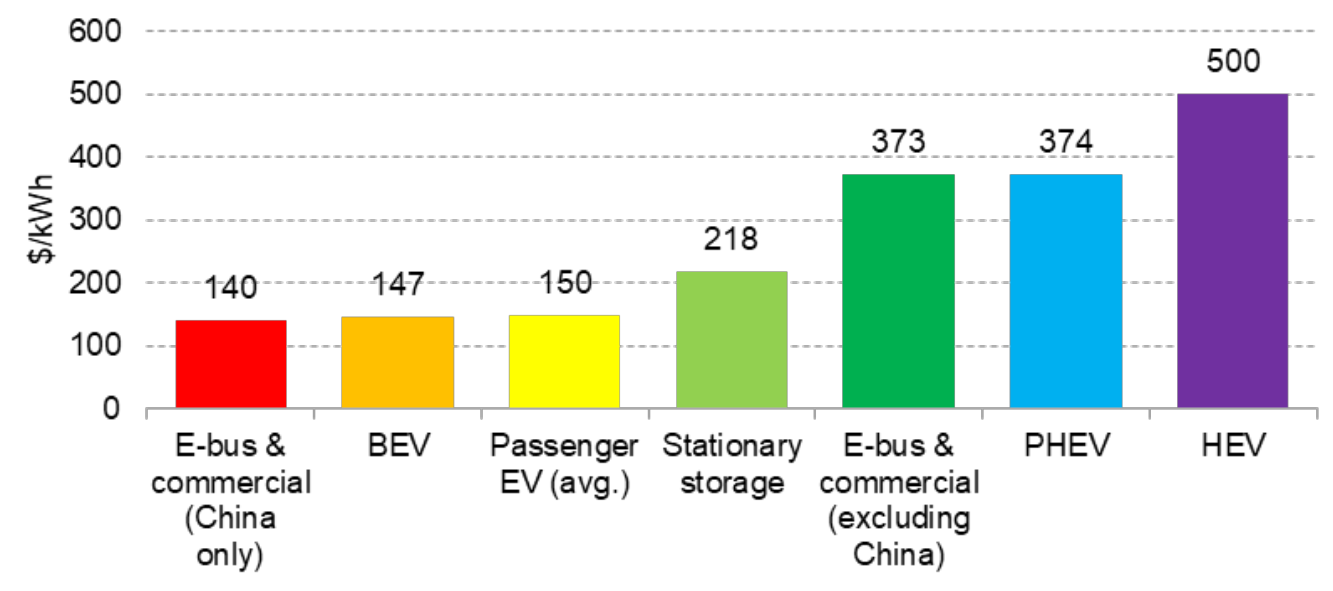

Figure 22. Battery pack prices (real $2019 \$ / \mathrm{kWh}$ ) for different end-use applications

Data Source: (Frith and Goldie-Scot 2019)

LIB demand is projected, both in the SFS and elsewhere, to increase rapidly as battery pack prices continue to decrease, and EVs are expected to dominate the LIB market in the future, according to BNEF (see Figure 23). BNEF (2019) assumes an 18\% learning rate for LIB pack prices, meaning the price of LIB packs decreases by $18 \%$ for every doubling in cumulative manufactured storage capacity. Because the underlying technologies and manufacturing processes are similar, we assume the growth of the EV LIB pack market will also significantly impact prices in the stationary energy storage market. For pricing battery packs (not the entire 
system) for BESS, we adopt the methodology described in Energy Storage System Costs Survey 2019 (BNEF 2019b). That methodology uses the BNEF 2019 Lithium-Ion Battery Price Survey (Frith and Goldie-Scot 2019) average volume-weighted battery pack price projections as the basis of the LIB pack prices but adds a premium to account for lower volumes in the stationary storage LIB market compared to the EV LIB market. The projections presented in the Energy Storage System Costs Survey 2019 start at current LIB prices for stationary storage and assume they converge with the volume-weighted battery pack price projections in 2019 Lithium-Ion Battery Price Survey by 2025, but at a premium. For utility-scale projects, the premium results in the battery pack price in 2025 and beyond being $10 \%$ above the volume-weighted average battery pack price, and for residential-scale projects the price is assumed to be $20 \%$ above the volume-weighted battery pack price average (BNEF 2019b).

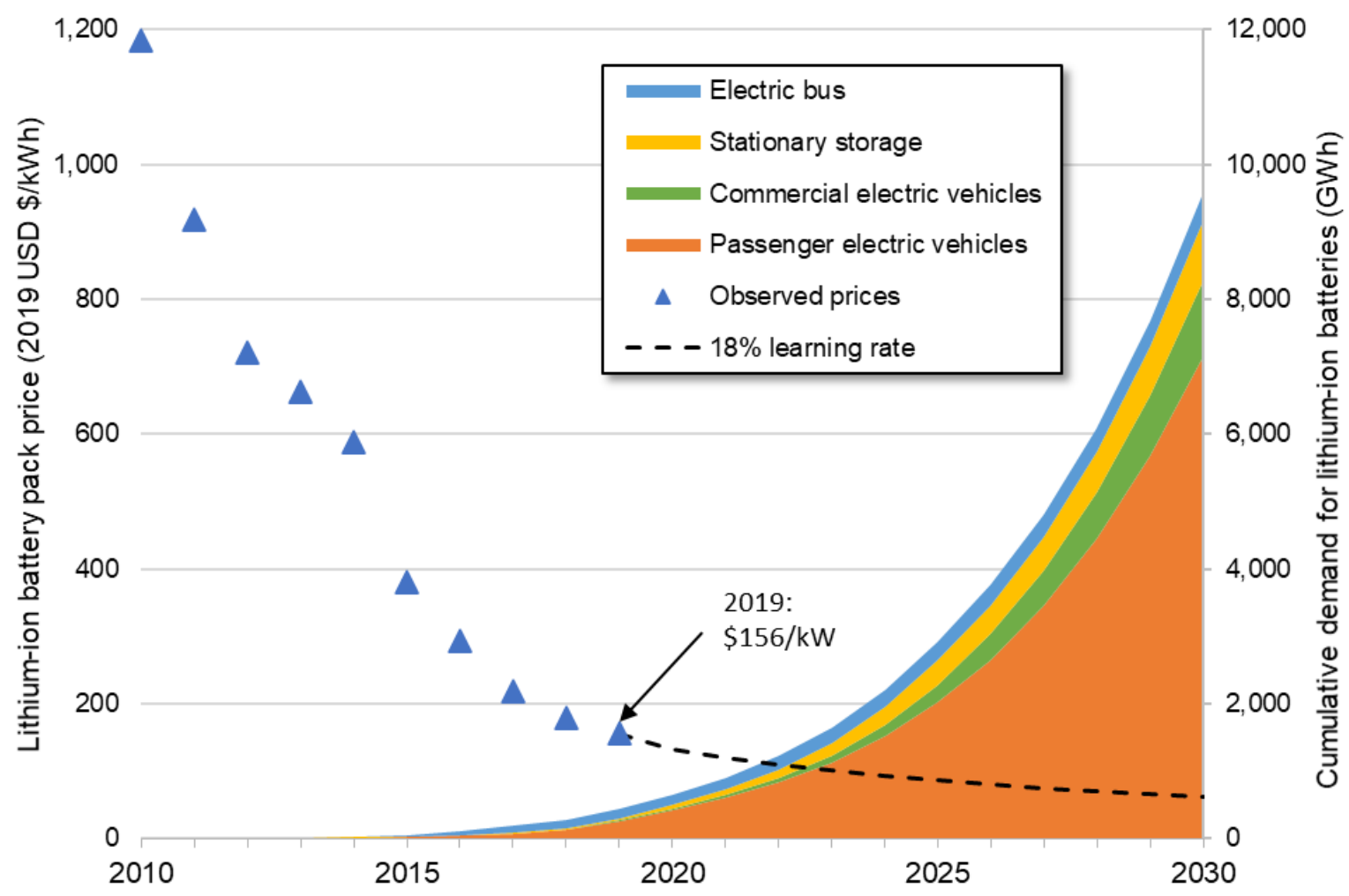

Figure 23. Expected battery demand by sector and LIB price projections

Data Source: (Frith and Goldie-Scot 2019)

\subsection{Sensitivity to Commodity Prices}

The commodity prices of the metals used in LIBs vary with supply and demand. With LIB deployment projections so high, there is concern that metal commodity prices could increase as demand for batteries increases. The impact on battery prices depends on the battery chemistry that is used and how much metal is required. Figure 24 shows raw material costs for a range of LIB chemistries in recent years. The figure shows that regardless of chemistry, raw material costs are decreasing year over year. This trend suggests that newer battery designs are less sensitive to fluctuations in commodity metal prices because the modern designs require less metal for a given storage capacity. It also shows the actual chemistry has a significant impact 
on raw material costs, with LFP battery chemistry having significantly lower raw material costs. BNEF further showed that battery pack prices are fairly insensitive to large swings in metal commodity prices (see Figure 25) (Frith and Goldie-Scot 2019). For an NMC 811 battery, doubling the commodity price of lithium would only increase battery pack costs by $5 \%$ and doubling nickel costs would increase battery pack costs by $8.3 \%$. Given that raw material costs are only a fraction of the battery pack cost, and the battery pack costs are only a fraction of the BESS cost, it appears that metal commodity prices would have to increase several times to significantly affect BESS prices.

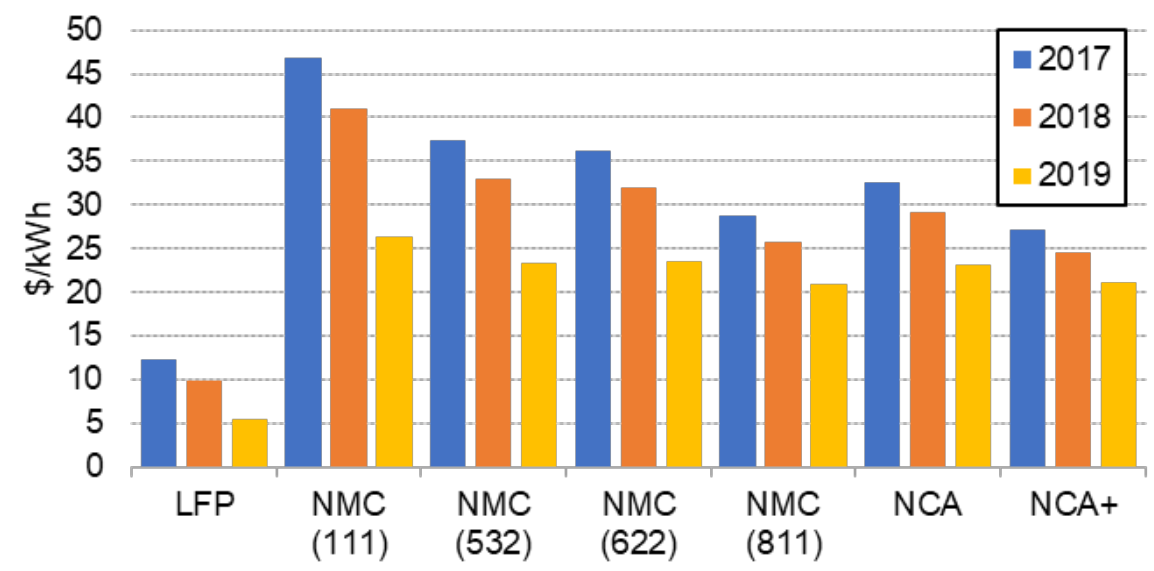

Figure 24. Raw material costs for different LIB chemistries by year

Data Source: (Frith and Goldie-Scot 2019)

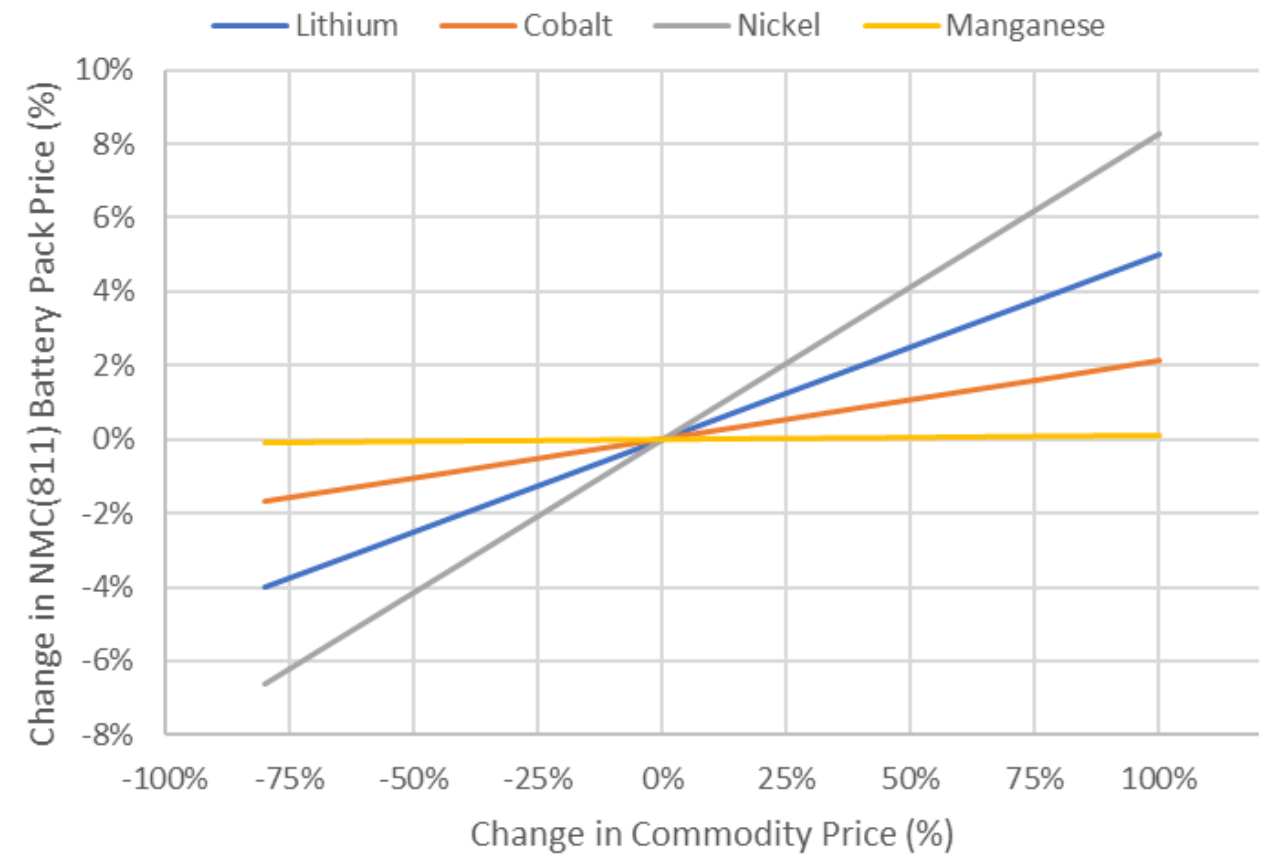

Figure 25. Sensitivity of nickel-manganese-cobalt (811) LIB pack (percentage change) to metal components prices

Data Source: (Frith and Goldie-Scot 2019) 


\subsection{Utility-Scale BESS}

Utility-scale BESS are multimegawatt projects connected directly to the grid that provide electric system services such as ancillary services, energy shifting, and firm capacity (see Section 2.3 and Figure 3, page 10). At the end of 2019, 1,208 MW of front-of-the-meter utility-scale BESS were installed in the United States, and another 80,230-MW of front-of-the-meter BESS were under development or contract (Wood Mackenzie Power \& Renewables/ESA U.S. Energy Storage Monitor 2020). The dramatic growth that this pipeline implies reinforces the industry perception that LIB costs are currently at a cost-effective level and are perceived to be continuing to decline. For this study, we assume a stand-alone $60-\mathrm{MW}_{\text {DC }}$ LIB storage system with storage durations of 2-10 hours.

\subsubsection{Current Costs}

Current (2019) costs for utility-scale BESS used in SFS are based on a bottom-up cost model using the data and methodology in Feldman et al. (2021). The bottom-up BESS model accounts for:

- Major components such as the LIB pack and inverter

- The balance of system (BOS) needed for the installation, such as battery containers, electrical wiring, electronic controls, safety systems

- The installation labor and equipment

- Soft costs such as sales tax, overhead, and profit.

Feldman et al. (2021) generated costs for systems with storage durations of 0.5-4.0 hours. For this study, we use the same model and data to develop costs for BESS with storage durations of $2,4,6,8$, and 10 hours (Table 2). Storage durations of 1 hour or less typically serve the smaller ancillary services market, which is not a priority in capacity expansion models like ReEDS and are not included. We include storage durations up to 10 hours to study the role of longer-duration storage on the grid under different scenarios. 
Table 2. Utility-Scale LIB Energy Storage Systems Used in SFS modelinga

\begin{tabular}{|c|c|c|c|}
\hline $\begin{array}{l}\text { Model } \\
\text { Component }\end{array}$ & Modeled Value & Description & Sources \\
\hline Battery total size & $60 \mathrm{MW}_{\mathrm{DC}}$ & $\begin{array}{l}\text { A baseline case to match a } 100-\mathrm{MW} \\
\text { PV system }\end{array}$ & $\begin{array}{l}\text { Feldman et al. } \\
2021\end{array}$ \\
\hline $\begin{array}{l}\text { Battery size per } \\
\text { container }\end{array}$ & $\begin{array}{l}\text { 2.5-MWh (megawatt-hour) } \\
\text { per } 40 \text {-ft container }\end{array}$ & $\begin{array}{l}\text { Assumption to compute the number of } \\
\text { containers }\end{array}$ & $\begin{array}{l}\text { Feldman et al. } \\
2021\end{array}$ \\
\hline LIB pack price & $\$ 188 / \mathrm{kWh}$ & Ex-factory gate (first buyer) prices & BNEF 2019a \\
\hline Storage duration & $2-10$ hours & Duration determines energy (MWh). & This study \\
\hline $\begin{array}{l}\text { Battery central } \\
\text { inverter price }\end{array}$ & $\$ 0.06 / \mathrm{W}$ & Ex-factory gate (first buyer) prices & $\begin{array}{l}\text { Wood- } \\
\text { Mackenzie, } \\
\text { Gupta } 2019\end{array}$ \\
\hline Inverter size & $2.5 \mathrm{MW}$ per inverter & $\begin{array}{l}\text { Used to determine the number of battery } \\
\text { inverters }\end{array}$ & $\begin{array}{l}\text { Feldman et al. } \\
2021\end{array}$ \\
\hline Electrical BOS & $\$ 0.07-\$ 0.14 / \mathrm{W}$ & $\begin{array}{l}\text { Includes conduit, wiring, DC cable, energy } \\
\text { management system, switchgear, } \\
\text { transformer, and monitor and controls for } \\
\text { each container. Determined by the number } \\
\text { of containers, transformers, and row } \\
\text { spacing. }\end{array}$ & $\begin{array}{l}\text { Feldman et al. } \\
2021\end{array}$ \\
\hline Structural BOS & $\$ 0.01-\$ 0.05 / \mathrm{W}$ & $\begin{array}{l}\text { Includes foundation, battery containers, } \\
\text { and inverter house. Determined by the } \\
\text { number of containers, inverters, } \\
\text { transformers, and the spacing between } \\
\text { containers. }\end{array}$ & $\begin{array}{l}\text { Feldman et al. } \\
2021\end{array}$ \\
\hline Installation labor & $\begin{array}{l}\text { Electrician: } \$ 27.47 / \text { hour } \\
\text { Laborer: } \$ 18.17 / \text { hour }\end{array}$ & $\begin{array}{l}\text { National average modeled labor rate } \\
\text { assumes nonunionized labor }\end{array}$ & BLS 2019 \\
\hline Sales tax & $5 \%$ & U.S. average & $\begin{array}{l}\text { RS Means } \\
2017\end{array}$ \\
\hline $\begin{array}{l}\text { EPC overhead } \\
\text { and profit }\end{array}$ & $\begin{array}{l}8.67 \% \text { for equipment and } \\
\text { material; } 23 \%-69 \% \text { for labor } \\
\text { costs; varies by system size, } \\
\text { labor activity, and location }\end{array}$ & $\begin{array}{l}\text { Costs associated with EPC selling, general } \\
\text { and administrative expense; warehousing; } \\
\text { shipping; logistics }\end{array}$ & $\begin{array}{l}\text { Feldman et al. } \\
2021\end{array}$ \\
\hline $\begin{array}{l}\text { Developer cost: } \\
\text { developer } \\
\text { overhead }\end{array}$ & $3 \%$ of total installation cost & $\begin{array}{l}\text { Includes overhead expenses such as } \\
\text { payroll, facilities, travel, legal fees, } \\
\text { administrative, business development, } \\
\text { finance, and other corporate functions }\end{array}$ & $\begin{array}{l}\text { Feldman et al. } \\
2021\end{array}$ \\
\hline $\begin{array}{l}\text { Developer cost: } \\
\text { contingency }\end{array}$ & $3 \%$ & Estimated as markup on the total EPC cost & $\begin{array}{l}\text { Feldman et al. } \\
2021\end{array}$ \\
\hline $\begin{array}{l}\text { Developer cost: } \\
\text { EPC/developer net } \\
\text { profit }\end{array}$ & $5 \%$ & $\begin{array}{l}\text { Applies a percentage margin to all costs } \\
\text { including hardware, installation labor, } \\
\text { EPC overhead, and developer overhead }\end{array}$ & $\begin{array}{l}\text { Feldman et al. } \\
2021\end{array}$ \\
\hline
\end{tabular}

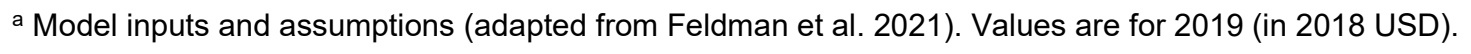


Battery pack prices for stationary storage come from BNEF and are estimated to be $\$ 188 / \mathrm{kWh}$ 2018 USD (BNEF 2019a) in 2019. The price reflects a premium to the price for LIB packs for EVs as discussed previously in the introduction to Section 3. Figure 26 and Figure 27 show the 2019 cost estimate of utility-scale BESS for storage durations of $2-10$ hours in $\$ / \mathrm{kWh}$ and $\$ / \mathrm{kW}$ respectively. The cost estimates assume a stand-alone $60-\mathrm{MW}$ DC BESS system and are made using the NREL bottom-up BESS cost model. The figures include a breakout of costs by component. The figures show how costs in terms of $\$ / \mathrm{kW}$ and $\$ / \mathrm{kWh}$ can vary significantly with storage duration.

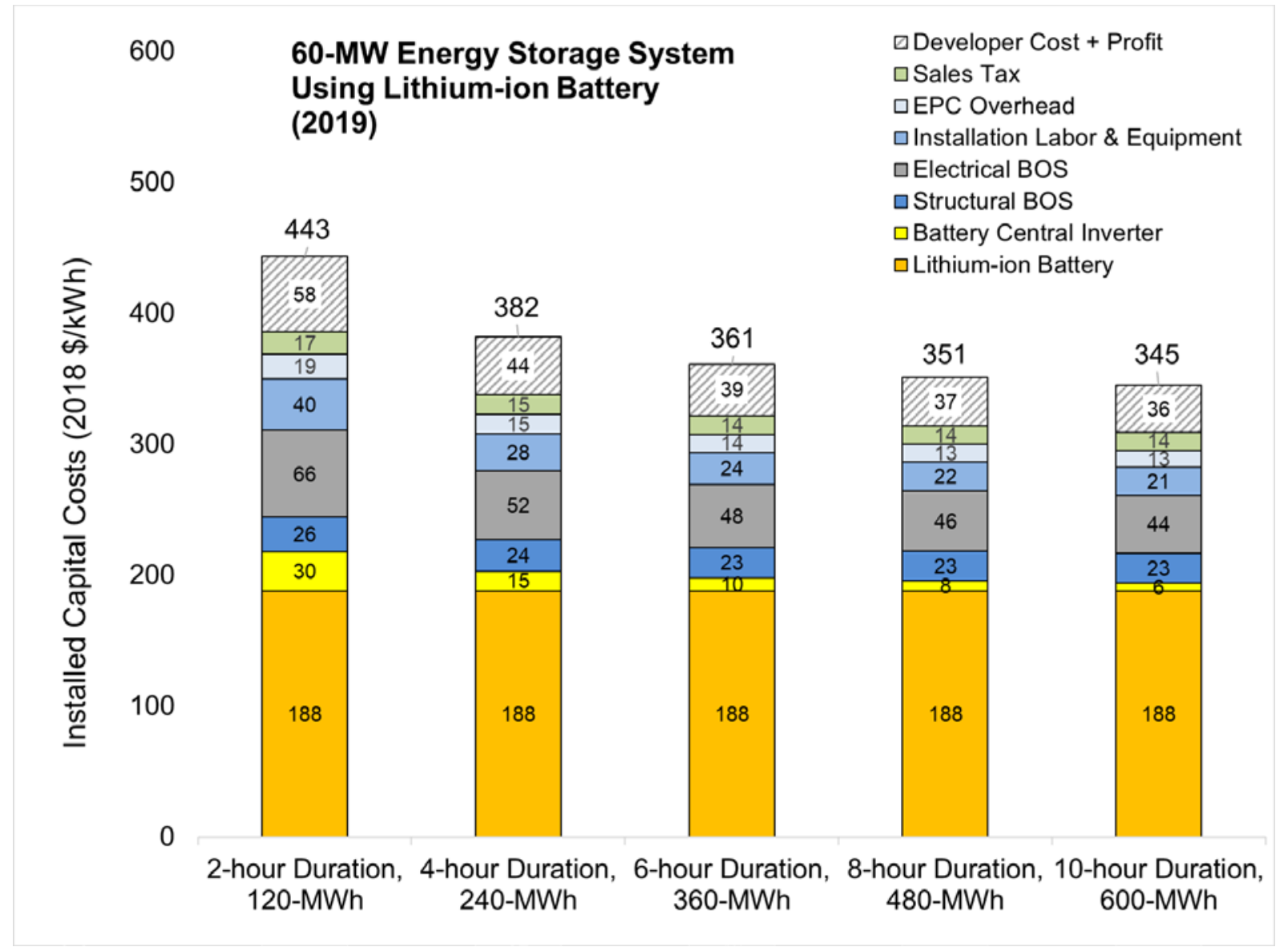

Figure 26. 2019 U.S. utility-scale LIB stand-alone storage costs for durations of 2-10 hours $(60 \mathrm{MW}$ DC) in $\$ / \mathrm{kWh}$ 


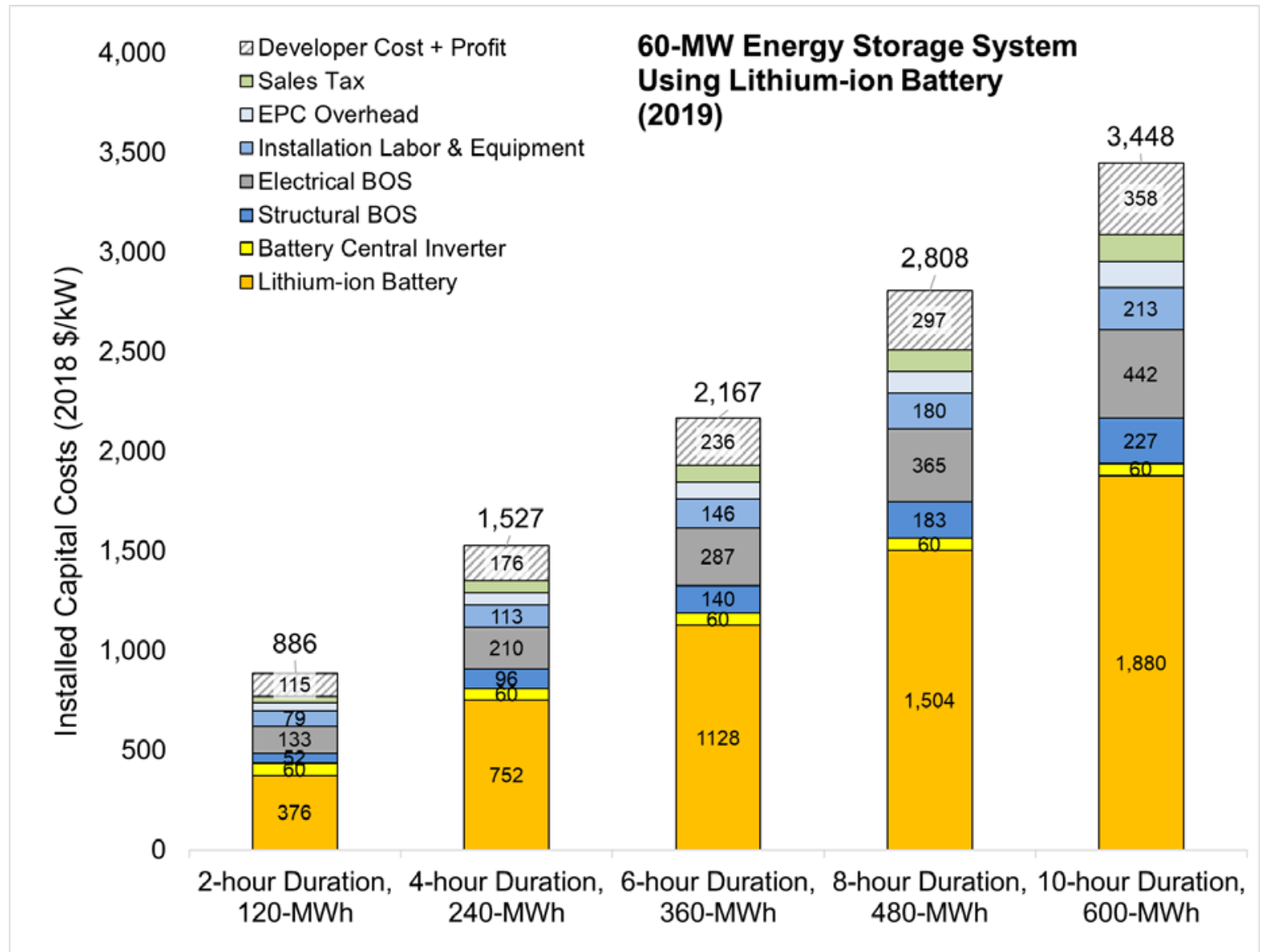

Figure 27. 2019 U.S. utility-scale LIB stand-alone storage costs for durations of 2-10 hours $(60 \mathrm{MW}$ DC) in $\$ / \mathrm{kW}$

\subsubsection{Utility-Scale PV+BESS}

Utility-scale BESS can be built free-standing or can be combined with new or existing electricity generation systems. $\mathrm{PV}$ is the generation technology most commonly paired with BESS (PV+BESS): $9 \%$ of annual front-of-the-meter PV deployments and 55\% of all annual storage deployments in the United States expected to be paired with BESS by 2023 (Gupta 2019). Colocation of PV and BESS allows for sharing of several hardware components by the $\mathrm{PV}$ and energy storage systems as well as also soft costs related to site preparation, land acquisition, installation labor, permitting, interconnection, and EPC/developer overhead and profit, resulting in savings of $5 \%-10 \%$ of total costs compared to installing the PV and BESS separately (Feldman et al. 2021). However, because the ReEDS model is not currently configured to deploy PV+BESS systems, this study considers only stand-alone BESS.

\subsubsection{Future Cost Projections}

Future cost projections for utility-scale BESS are based on cost projections by Cole and Frazier (2020) that are used in the ATB (National Renewable Energy Laboratory (NREL) 2020) with variations for duration described below. The BESS cost projections (Figure 28) are based on a literature review of utility-scale BESS costs. For the SFS, we use the Conservative, Moderate, and Advanced Scenarios. 


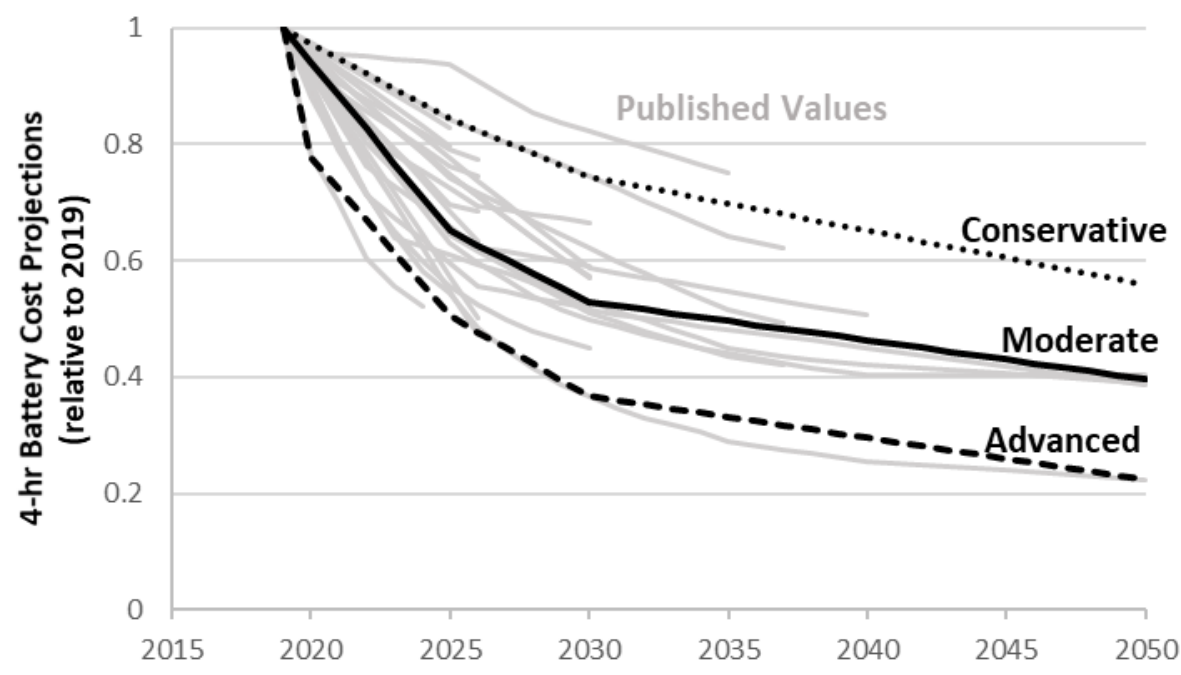

Figure 28. Normalized battery cost projections for 4-hour LIBs, with values relative to 2019 from Cole and Frazier (2020) used in this study

Cost projections are shown relative to published values from a literature review.

The ATB utility-scale BESS cost projections in Figure 28 assume a 4-hour BESS. Applying the same relative trajectory to all BESS regardless of storage duration implies future cost reductions apply equally to all BESS cost components. However, multiple studies (BNEF 2019a; EPRI 2018) predict the majority of cost reductions are from lower battery pack costs in the future. From Figure 27, it is clear that for a given BESS power capacity (power delivery potential to grid), reductions in battery costs will lower the cost of longer duration systems more than shorter-duration systems.

Future cost projections must consider the storage duration when calculating costs. Although we do not have future cost projections from the literature specifically for all storage durations of interest to us, we can estimate future cost projections that consider storage duration using the information we do have. BNEF projects LIB costs out to 2050 (BNEF 2019a; BNEF 2019b). Because BNEF is the only source that gives both cost projections by component and projections out to 2050, the time-frame considered in the capacity-expansion models, we use BNEF data in our component cost analysis. By assuming the BNEF battery cost reduction projections can be applied to the battery component cost term, we can back-calculate the remaining costs (the power component costs) for a 4-hour duration BESS based on utility-scale BESS cost projections from the ATB (National Renewable Energy Laboratory (NREL) 2020) and then use these parameters to adjust the cost for any storage duration we desire. The following methodology (illustrated in Figure 29, page 41) involves the following steps to generate the storage-durationspecific future cost projects for the SFS Moderate Scenario:

1. Use current (2019) 60-MW DC utility-scale BESS costs from NREL bottom-up model for storage durations of 2-10 hours to develop a linear correlation relating BESS costs to duration for the current year. Note that this model is based on a bottom-up model for PV that has been used and refined for years. The BESS cost model is more recent but builds on the PV component cost methodology and has been reviewed by numerous industry experts. 

A. $\operatorname{BESS} \operatorname{cost}(\$ / \mathrm{kW})=\$ 246 / \mathrm{kW}+\$ 320 / \mathrm{kWh} * \mathrm{~d}$
B. $d=$ storage duration (hours)

2. Apply the ATB (National Renewable Energy Laboratory (NREL) 2020) cost projection curve, normalized to 2019, to the current (2019) 4-hour utility-scale BESS cost to determine the cost of a 4-hour BESS in future years.

3. Apply the normalized BNEF LIB cost projections to the energy $(\$ / \mathrm{kWh})$ term in the current (2019) BESS cost correlation from Step 1 to determine the energy term (slope) of the correlation in future years. Multiply the energy component term $(\$ 320 / \mathrm{kWh})$ by future year normalized cost reduction for LIBs from BNEF (e.g., $2030=36 \%$ of 2019 value) for each future year

4. Use the 4-hour BESS cost for each year and the updated energy component term to backcalculate the power $(\$ / \mathrm{kW})$ term (y-intercept) for each future year. Use the updated power and energy component term for each future year to estimate the cost of BESS systems at 6-, 8- and 10-hour storage durations.

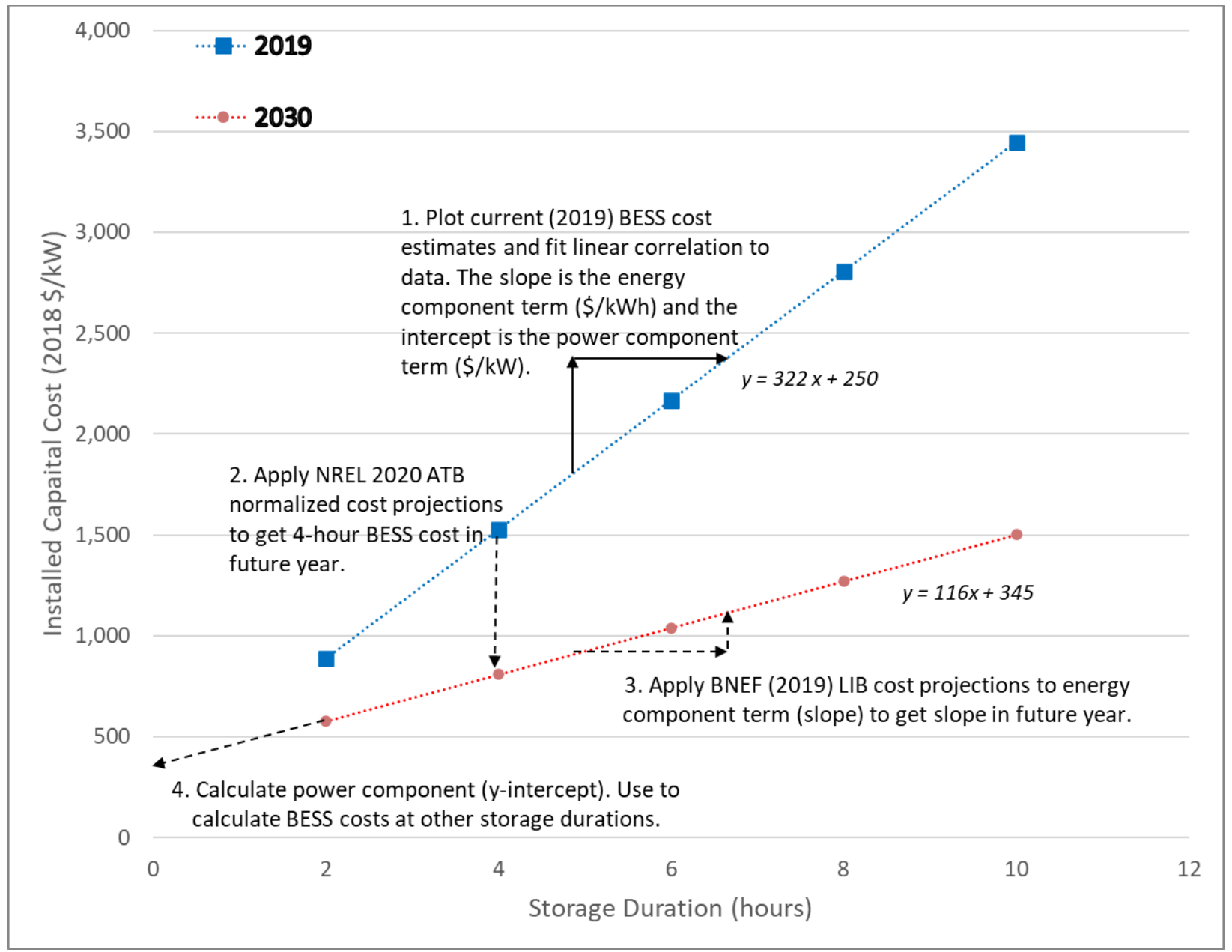

Figure 29. Methodology for projecting utility-scale BESS costs 
The BNEF battery price reduction projections are for the price of the battery pack only, but in the methodology above, we apply it to the whole energy component term, which includes the costs of the LIB packs, the additional hardware for installation (BOS), and their installation. The costs of BOS and installation labor are not expected to drop as quickly as the price of LIB packs. However, the energy density of LIB packs is expected to continue to increase, so future BESS would require fewer LIB packs for a given amount of storage, which would drive down installation and BOS costs. We do not have data to quantify the impact of increasing energy density on BESS costs. The methodology overestimates the decline of the energy component term, but this should be partially offset by declines in installation costs of LIB that we did not capture.

We do not have future LIB cost projections for Advanced or Conservative Scenarios. Instead, we use the Advanced and Conservative normalized cost projections from the 2020 ATB and apply them to all storage durations. The resulting future cost projection curves for the Moderate, Advanced, and Conservative Scenarios are shown in Figure 30, Figure 31, and Figure 32 respectively. Costs are shown for storage durations of 2-10 hours, assuming a $60-\mathrm{MW} \mathrm{DC}_{\mathrm{DC}} \mathrm{BES}$. As expected, costs on a $\$ / \mathrm{kW}$ basis drop more rapidly for longer-duration BESS than shorter duration because battery costs decrease faster than other system costs.

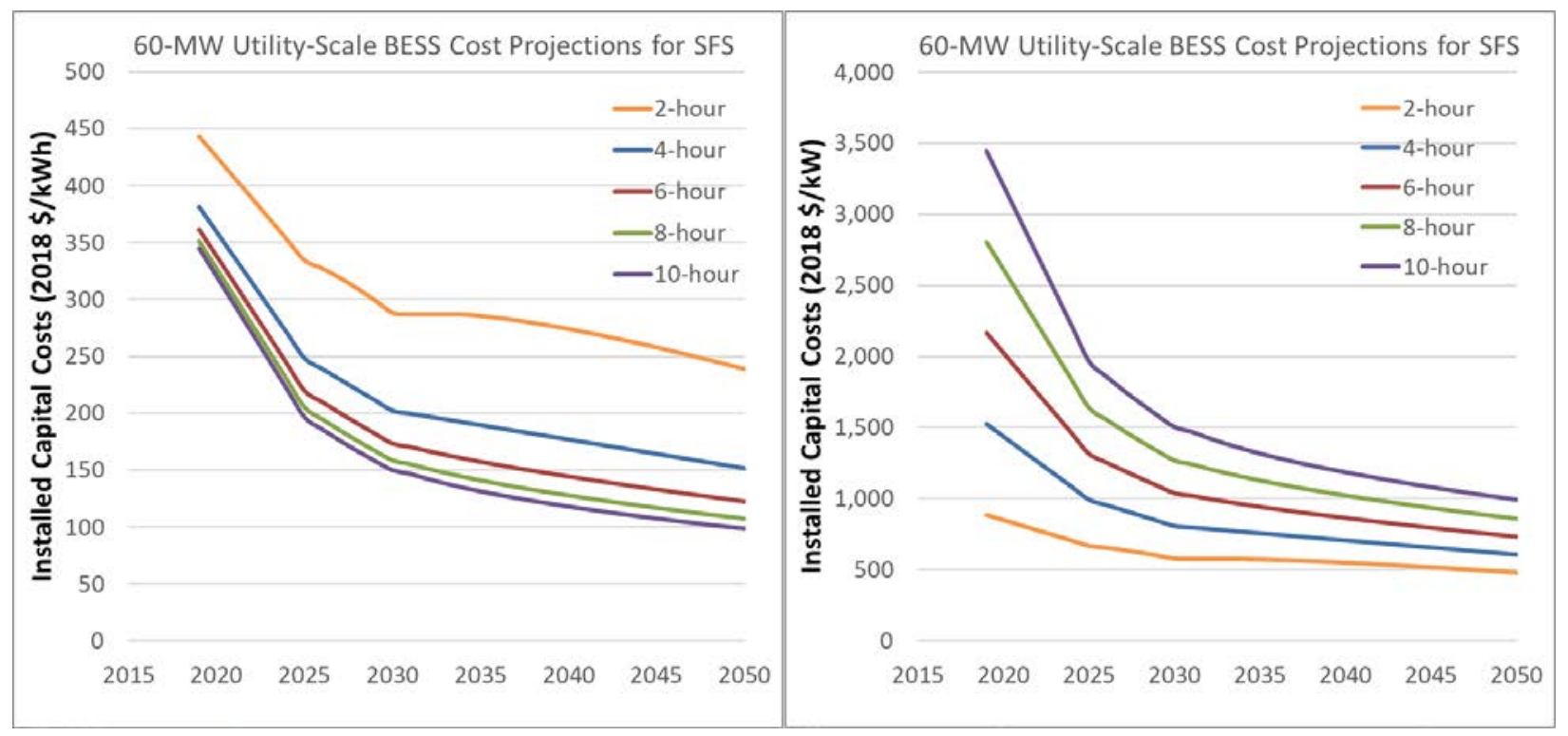

Figure 30. Utility-scale BESS Moderate Scenario cost projections, on a $\$ / \mathrm{kWh}$ basis (left) and a $\$ / k W$ basis (right)

Projections assume a 60-MW $\mathrm{DC}_{\mathrm{DC}}$ project. 


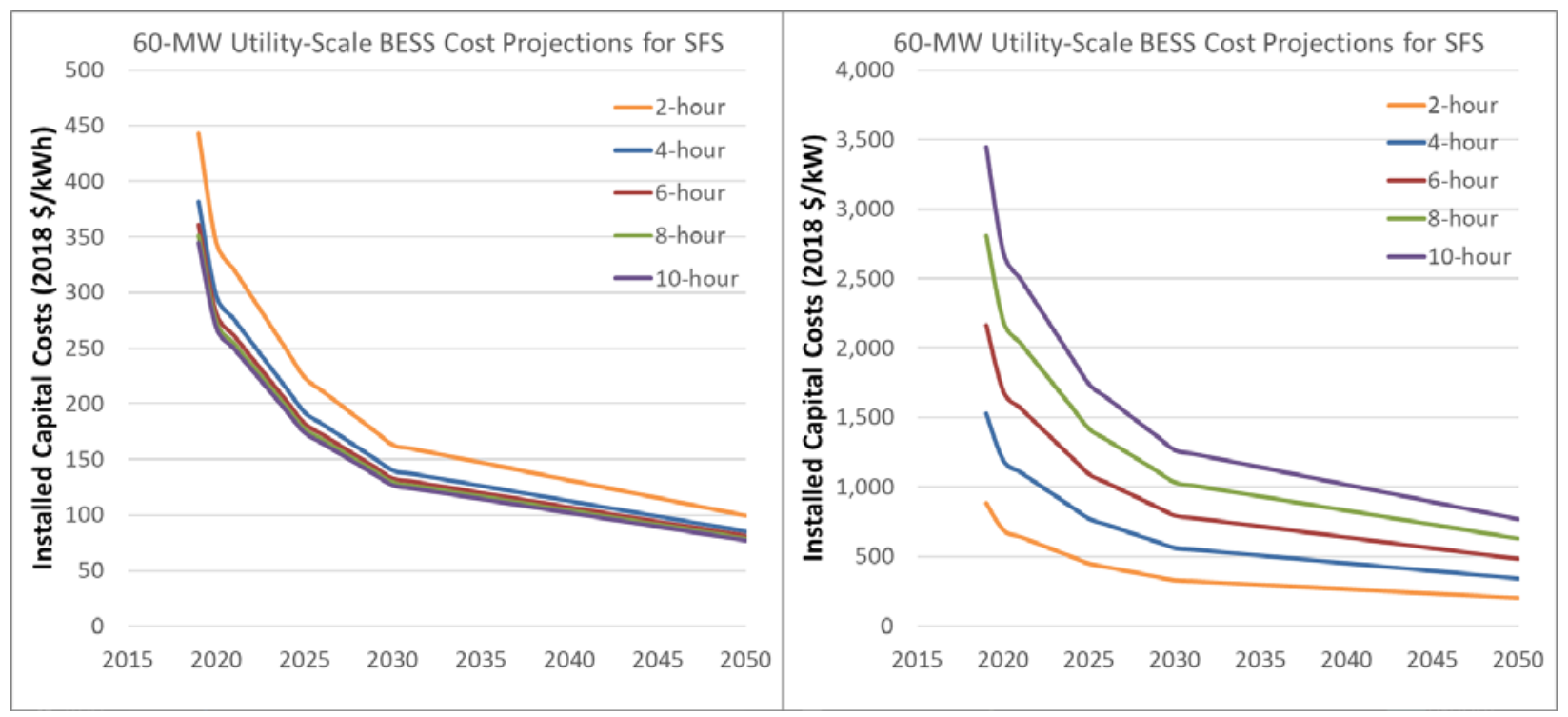

Figure 31. Utility-scale BESS Advanced Scenario cost projections, on a $\$ / \mathrm{kW}$ basis and $\$ / \mathrm{kWh}$ basis

Projections assume a 60-MWDC project

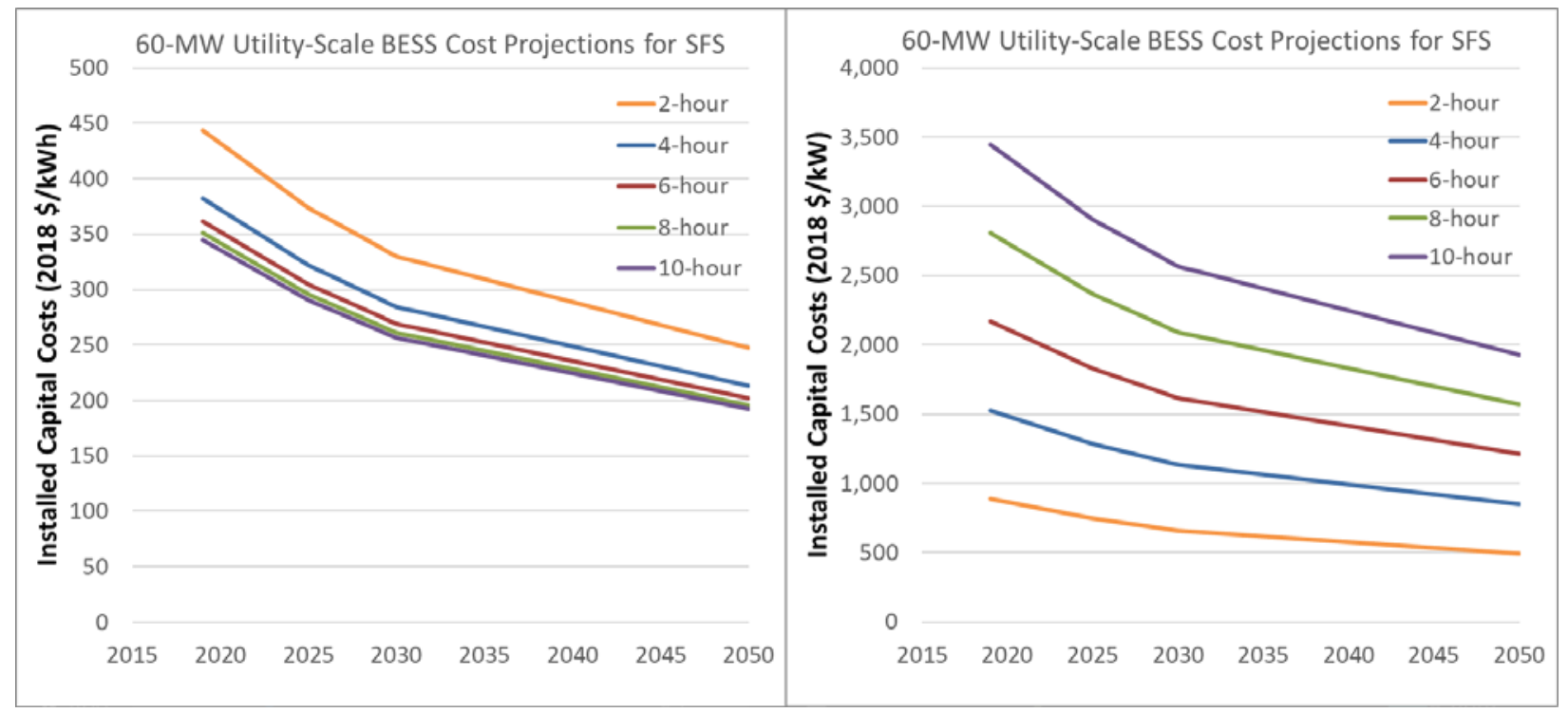

Figure 32. Utility-scale BESS Conservative Scenario cost projections, on a $\$ / \mathbf{k W}$ basis and $\$ / \mathrm{kWh}$ basis

Projections assume a $60-\mathrm{MW}$ DC project. 
We compare our current and future cost projections to values in the literature for reasonableness, paying special attention to the later-year future cost projections to ensure they are realistic. The projected cost of a 4-hour utility-scale BESS in 2050 used in the NREL SFS is $\$ 152 / \mathrm{kWh}$ for the Moderate Scenario, $\$ 85 / \mathrm{kWh}$ for the Advanced Scenario, and $\$ 213 / \mathrm{kWh}$ for the Conservative Scenario. We found two sources in the literature that give BESS cost projections at the component cost level. One is from EPRI's Energy Storage Technology and Cost Assessment (2018) and gives component level costs out to 2030. The other is from BNEF's 2019 Long-Term Energy Storage Outlook (2019a) and gives component level costs out to 2050. ${ }^{19}$

Because of differences in methodology, included costs, and nomenclature, the reported cost components cannot be easily compared between studies. To make a general comparison, we group cost components into three groups: battery, balance of plant, and installation and soft costs. Figure 33 (page 45) compares current cost estimates (in $\$ / \mathrm{kWh}$ ) for 4-hour utility-scale BESS between BNEF, EPRI, and the values used in the SFS Moderate Scenario. The figure also compares EPRI and BNEF future cost projections out to 2030 and shows BNEF's estimates out to 2050. From the figure, we observe that:

- Current cost estimates across studies are consistent in terms of total estimated cost and by component breakout. All studies put current battery costs at around $\$ 200 / \mathrm{kWh}$, and remaining costs are split roughly equally between capital and soft costs.

- BNEF and EPRI cost estimates are comparable through 2030, and the difference in projected cost comes mostly from the assumed cost of batteries. EPRI's battery cost estimate is consistently higher.

- Most BESS cost reductions in the future come from reductions in battery pack costs. By 2040 , the cost of batteries on a $\$ / \mathrm{kWh}$ basis is comparable to capital and soft costs.

\footnotetext{
${ }^{19}$ BNEF gives updated BESS cost estimates in their Energy Storage System Costs Survey 2019 (BNEF 2019b), but
} that source only includes projections out to 2030 . 


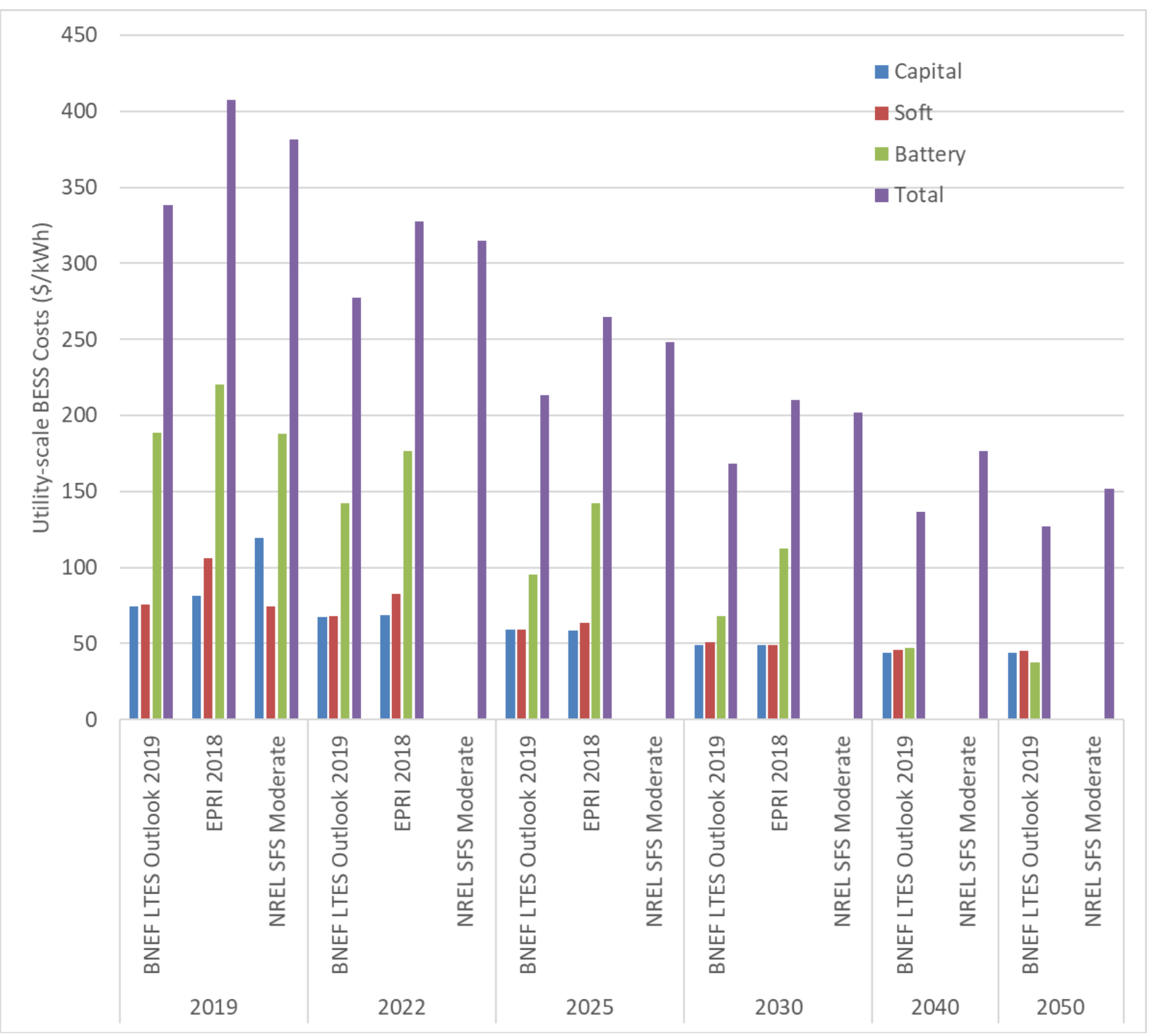

Figure 33. Comparison of current and future utility-scale BESS cost estimates from different sources

Costs are broken out by major components and assume 4-hour storage.

Figure 34 shows the total system cost projections for the SFS through 2050 compared to cost projections from literature. In future years, the SFS Moderate Scenario is nearly identical to the EPRI estimate and, in later years, to projections from Schmidt et al. (2017; 2018), while the SFS Advanced Scenario is similar to the BNEF estimate after 2025. The SFS Conservative Scenario is more costly than any of the literature values after 2030. Taken together, the SFS scenarios have future utility-scale BESS costs that are realistic and span the range of costs projected by literature. 


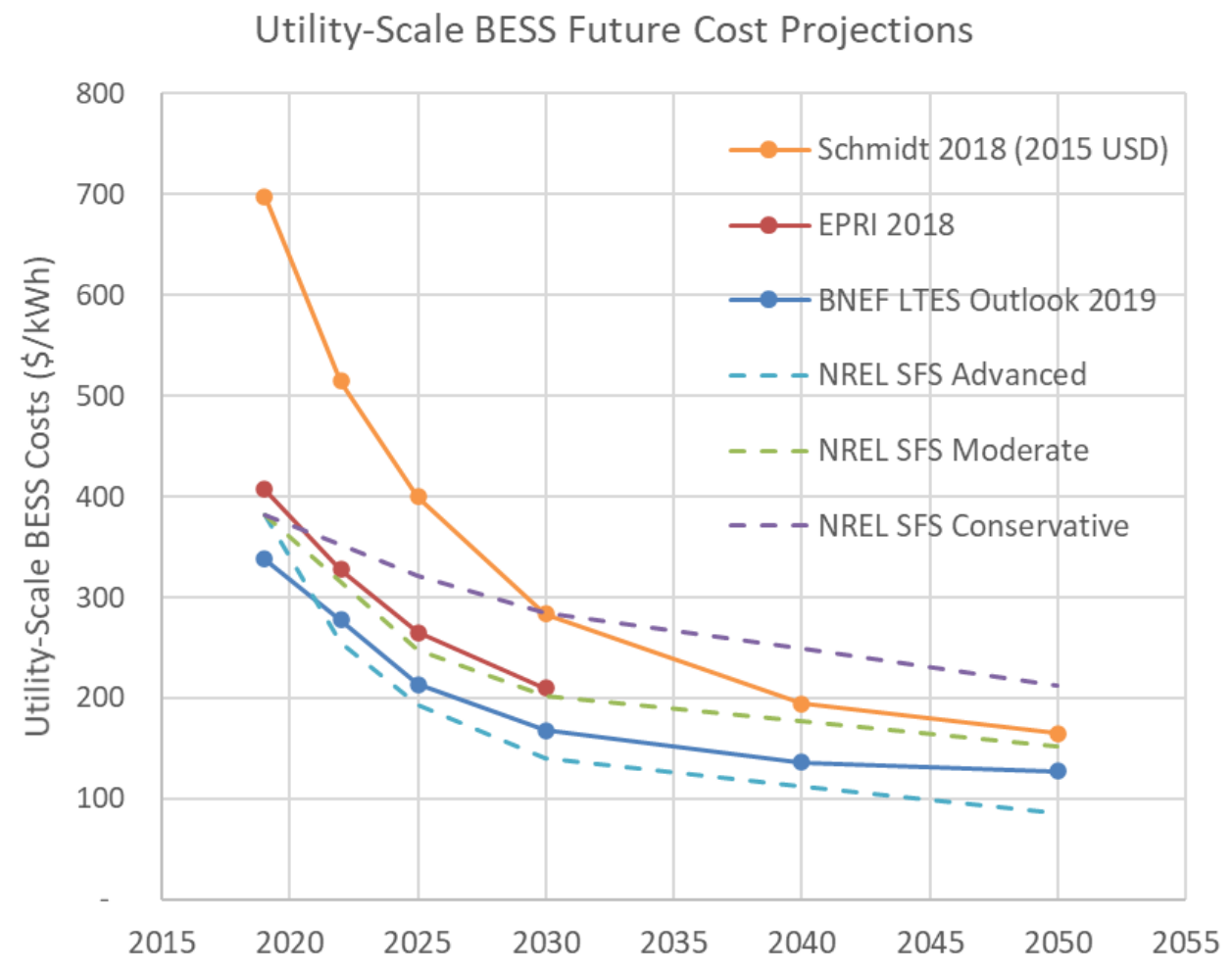

Figure 34. Comparison of utility-scale BESS future cost projections

When using the utility-scale BESS cost projections in analysis, it is important to remember they were developed assuming learning and manufacturing scale will drive down BESS costs. Thus, any modeling that uses the projections should see results where the cost reductions scale with BESS deployment projected by the model. The cost projections from BNEF and Schmidt et al. (2018) are based on observed experience rates $^{20}$ applied to assumptions about future cumulative installed capacity. Data from Schmidt et al. project that in 2030 there will be $238 \mathrm{GWh}$ of cumulative installed manufacturing capacity and it will help drive the cost of utility-scale BESS down to $\$ 283 / \mathrm{kWh}$ (2015 USD). In 2040, there will be 1,000 GWh of cumulative installed capacity and the price of utility-scale BESS will be \$195/kWh (2015 USD). In 2050 there will be roughly 2,000 GWh of installed capacity and the price drops to $\$ 165 / \mathrm{kWh}$ (2015 USD). Note that these deployment projections are for utility-scale BESS only. Demand for LIBs is also driven by their use in electronics and EVs, and this demand contributes to price reductions in LIBs through learning rates tied to deployment. Figure 23 (page 34) shows how BNEF projects the price of LIBs with deployment in different markets through 2030. BNEF projects 9,577 GWh of cumulative demand for LIBs by 2030 (Frith and Goldie-Scot 2019), mostly from EVs. This amount is similar in magnitude to the $5,220 \mathrm{GWh}$ of total LIBs cumulative demand in 2030 project by Schmidt et al. (2018). EPRI projections are based on a compounded annual growth rate and do not appear to take installed capacity into consideration.

\footnotetext{
${ }^{20}$ The experience rate is the decrease in the cost of a technology for every doubling of installed cumulative capacity.
} 


\subsection{Residential BESS}

\subsubsection{Current Costs}

Current (2020) costs for residential BESS are based on NREL's bottom-up BESS cost model using the data and methodology in Feldman et al. (2021). In that study, Feldman et al. estimated costs for both AC- and DC-coupled systems for a less-resilient ( $3 \mathrm{~kW} / 6 \mathrm{kWh})$ installation and a more-resilient $(5 \mathrm{~kW} / 20 \mathrm{kWh})$ installation. We use the same model and methodology but do not restrict the power or energy capacity of the BESS to two options. Key modeling assumptions and inputs are shown in Table 3. We assume 2020 battery pack costs of $\$ 248 / \mathrm{kWh} \mathrm{hC}_{\mathrm{DC}} 2018 \mathrm{USD}$ (BNEF 2019b).

Table 3. Residential Storage-Only Modeling Inputs and Assumptions ${ }^{a}$

\begin{tabular}{|c|c|c|}
\hline Model Component & Modeled Value & Description \\
\hline \multirow[t]{2}{*}{ System size } & 3-8 kW power capacity & Battery capacity is in $\mathrm{kW}$ \\
\hline & 2-5 E/P ratio & $\begin{array}{l}\text { E/P is battery energy to power ratio and is } \\
\text { synonymous with storage duration in hours }\end{array}$ \\
\hline Battery pack cost & $\$ 248 / \mathrm{kWh}$ & Battery pack only (BNEF 2019b) \\
\hline $\begin{array}{l}\text { Battery-based } \\
\text { inverter cost }\end{array}$ & $\$ 479 / \mathrm{kW}$ & $\begin{array}{l}\text { Assumes a bidirectional inverter (BNEF 2019b), } \\
\text { converted from } \$ / \mathrm{kWh} \text { for } 5 \mathrm{~kW} / 14 \mathrm{kWh} \text { system }\end{array}$ \\
\hline Supply-chain costs & $5 \%$ of cost of equipment & $\begin{array}{l}\text { Includes costs of inventory, shipping, and } \\
\text { handling of equipment }\end{array}$ \\
\hline Sales tax & $6.86 \%$ (U.S. average) & U.S. average sales tax on equipment \\
\hline Installation labor cost & $\begin{array}{l}\text { Electrician: } \$ 28.39 / \text { hour } \\
\text { Laborer: } \$ 19.34 / \text { hour }\end{array}$ & Assumes U.S. average pricing \\
\hline Engineering fee & $\$ 100$ & $\begin{array}{l}\text { Engineering design and professional engineer- } \\
\text { stamped calculations and drawings }\end{array}$ \\
\hline $\begin{array}{l}\text { Permitting, inspection, } \\
\text { and interconnection }\end{array}$ & Electrician: $\$ 29.21 /$ hour & $\begin{array}{l}20-32 \text { hours (DC-coupled/AC-coupled) of } \\
\text { commissioning and interconnection labor, and } \\
\text { permit fee }\end{array}$ \\
\hline $\begin{array}{l}\text { Sales and marketing } \\
\text { (customer acquisition) }\end{array}$ & $\$ 0.61 / \mathrm{W}_{\mathrm{DC}}$ & $\begin{array}{l}20 \text { additional hours for DC system, and } 32 \\
\text { additional hours for AC system, per closed sale, } \\
\text { associated with selling a PV system with storage }\end{array}$ \\
\hline $\begin{array}{l}\text { Overhead (general } \\
\text { and administrative) }\end{array}$ & $\$ 0.28 / W_{D C}$ & $\begin{array}{l}\text { Rent, building, equipment, staff expenses not } \\
\text { directly tied to permitting, inspection, and } \\
\text { interconnection; customer acquisition; or direct } \\
\text { installation labor }\end{array}$ \\
\hline Profit (\%) & $17 \%$ & $\begin{array}{l}\text { Fixed percentage margin applied to all direct } \\
\text { costs including hardware, installation labor, direct } \\
\text { sales and marketing, design, installation, and } \\
\text { permitting fees }\end{array}$ \\
\hline
\end{tabular}

a Values are from(based on Feldman et al. 2021). Values are for 2020 (in 2018 USD) 
Residential BESS can be installed separately or can be added to an existing PV system (as an AC-coupled system). We also consider the installation of PV systems combined with BESS (PV+BESS) systems. Costs for residential PV systems come from NREL's bottom-up PV cost model (Feldman et al. 2021). We do include some cost savings for a combined PV and battery storage system. We assume the electrical BOS and installation labor are $90 \%$ of what they would be if the systems were installed separately. We also assume the sales and marketing costs for PV+BESS includes the cost of 20 additional hours for a DC-coupled system and 32 additional hours for an AC-coupled system than they would be for a PV-only system installation (Feldman et al. 2021, Table 10). For the PV systems shown in Figure 35, this adds $20 \%-30 \%$ to customer acquisition costs. The resulting cost estimates are shown in Figure 35.

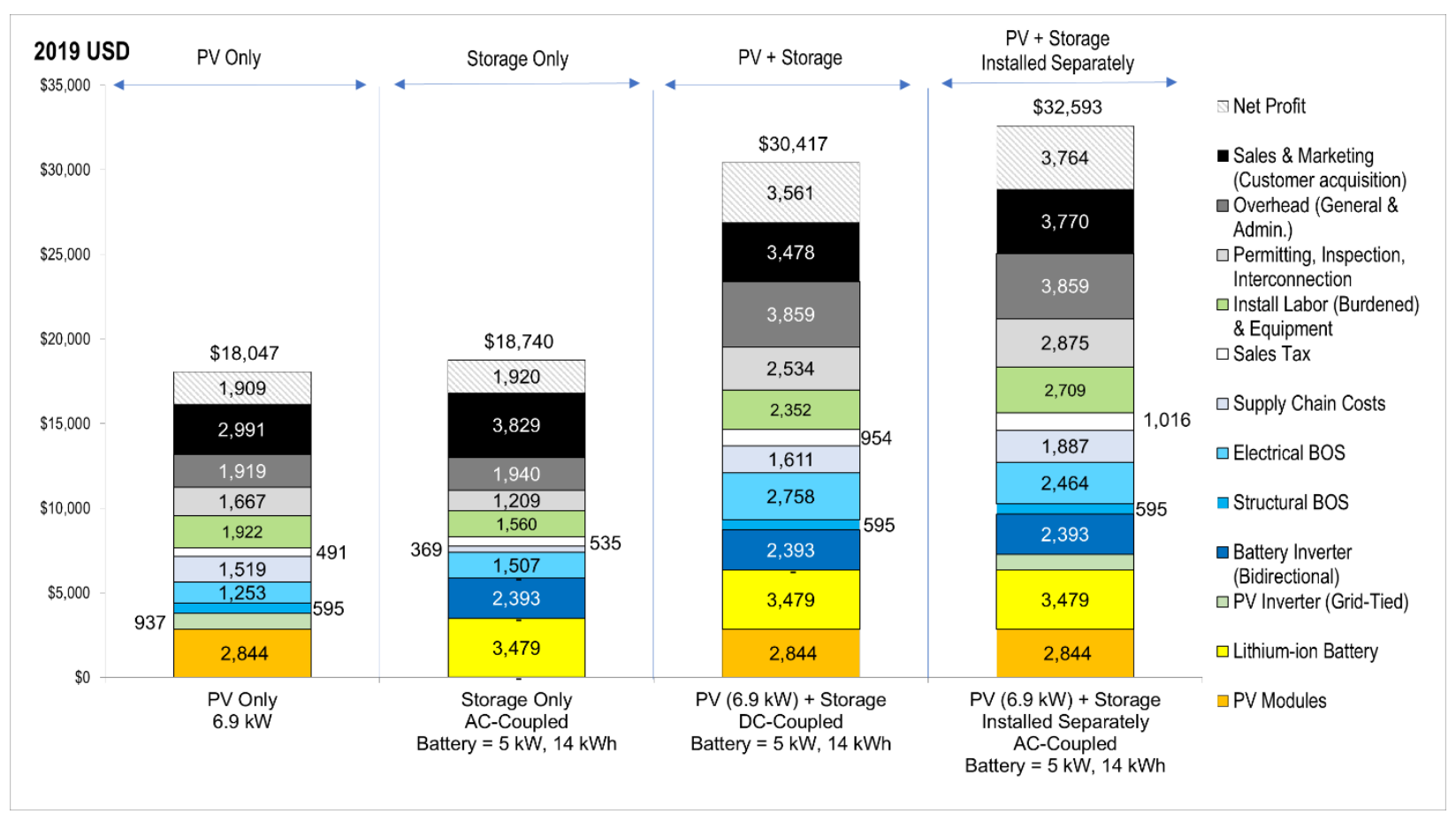

Figure 35. Cost of residential PV-stand-alone, BESS-stand-alone, and PV+BESS systems estimated using NREL bottom-up models

Figure 36 compares NREL's cost estimate for a residential BESS against BNEF's (BNEF 2019b). The power and energy storage capacity in the NREL model are changed to match the BNEF system size of $5 \mathrm{~kW} / 14 \mathrm{kWh}$. The BNEF estimate divides the costs into only four components, and it does not include soft costs (e.g., permitting, sales and marketing costs) as a separate category. Instead, BNEF assumes a flat installation cost of \$2,500 (BNEF 2019b). Despite adopting BNEF's battery and inverter cost estimates, the NREL current cost estimate is more than twice the value reported by BNEF. Most of the difference is due to soft costs, which we have confirmed that BNEF does not include specifically. They note that the United States is an outlier for installation costs which can vary from $\$ 2,000$ to $\$ 8,000$ per project in the United States. 


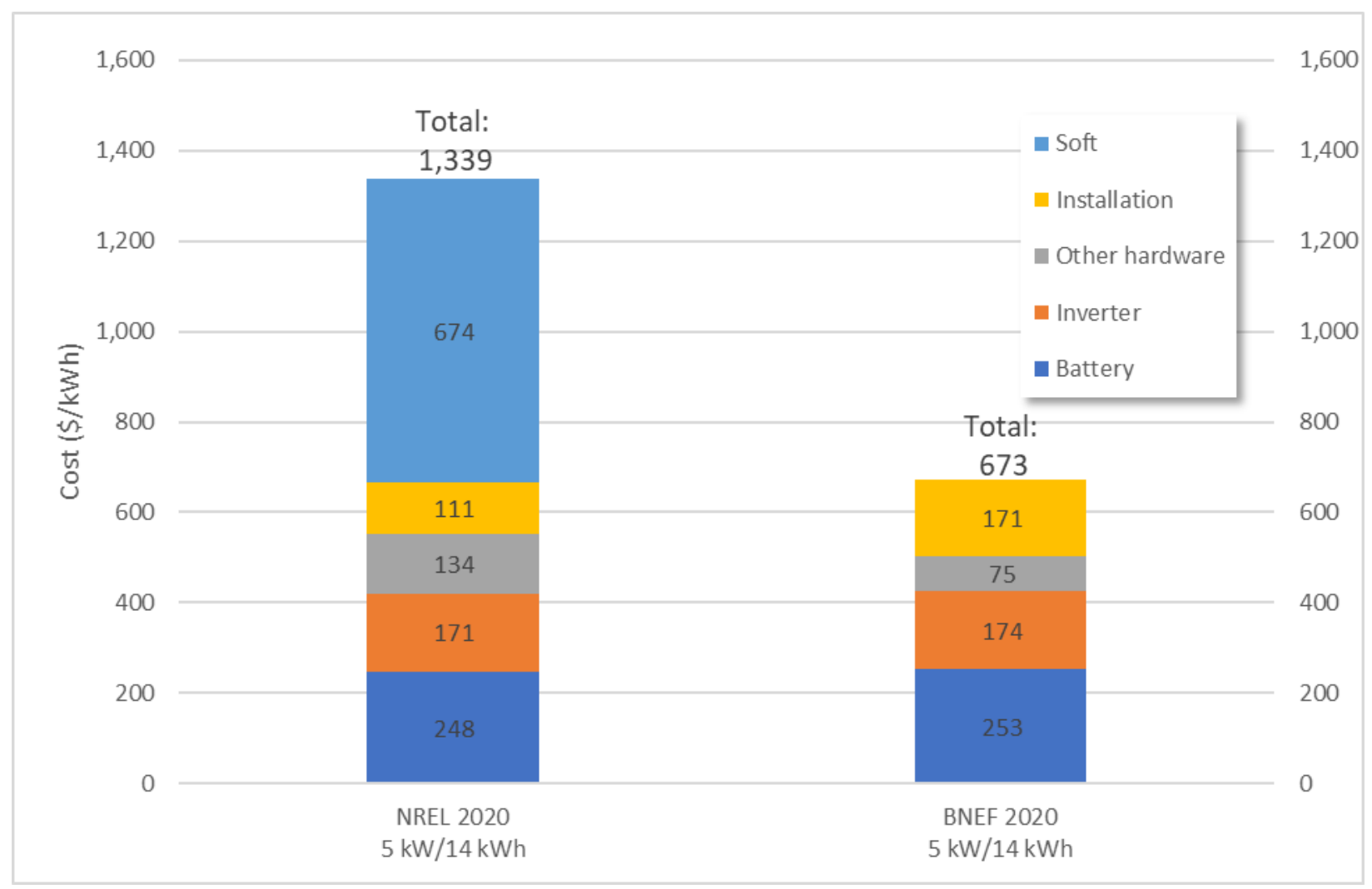

Figure 36. Comparison of current residential BESS total and component costs from NREL and BNEF

As with PV and when looking across both utility-scale and distributed sectors, these soft costs can be significant. The US has experienced higher residential PV costs than other major economies (Figure 37). This historical trend is due to several factors (Feldman 2020), but the soft costs of the system installation is indicated as the biggest and most consistent effect. Our bottomup modeling includes those soft cost effects for distributed storage as well. It may be that for linked PV-battery systems the soft costs are shared or could be attributed to the PV costs but for standalone systems, these costs are relevant and significant. More global focused data from BNEF or Schmidt do not include significant soft cost values leading to the differences noted in Figure 36 and Figure 39. 


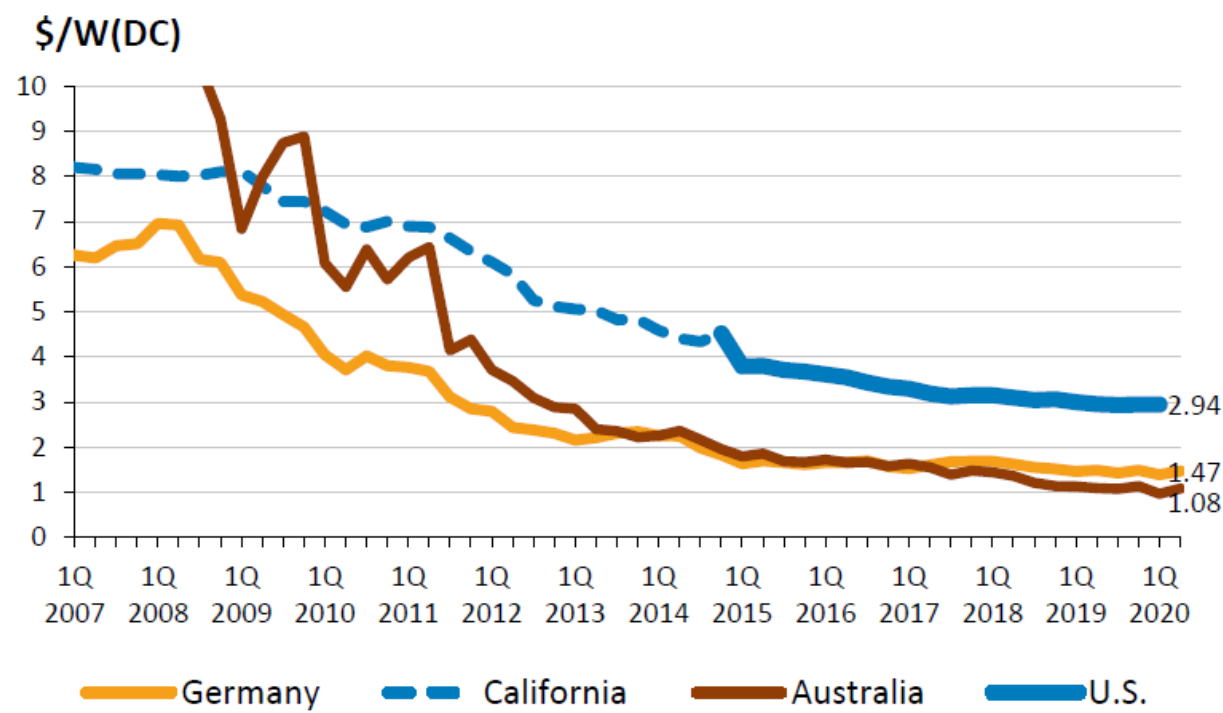

Figure 37. Historical residential PV system costs indicating higher US soft costs Feldman (2020)

As with utility-scale BESS, the cost of a residential BESS is a function of both the power capacity and the energy storage capacity of the system, and both must be considered when estimating system cost. Furthermore, the dGen model does not assume specific BESS system sizes and it needs an algorithm to estimate residential BESS system cost based on the attributes of the residences (agents) it generates.

We develop an algorithm for stand-alone residential BESS cost as a function of power and energy storage capacity using the NREL bottom-up residential BESS cost model (Feldman et al. 2021) with some modifications. The NREL bottom-up model assumes either a 6-kW (lessresilient) or 8-kW (more-resilient) inverter, which introduces a step function to the model and limits system size. We update the model to assume inverter costs of $\$ 0.48 / \mathrm{W}_{\mathrm{DC}}$, which is consistent with BNEF estimates for inverter costs (BNEF 2019b). We then run the model for BESS with $3 \mathrm{~kW}-10 \mathrm{~kW}$ of power capacity and $4 \mathrm{kWh}-50 \mathrm{kWh}$ of energy storage capacity. We achieve a near-perfect fit for all systems by fitting the costs to a linear equation with three constants:

- $\quad$ BESS cost $($ total $\$)=\$ 1,690 / \mathrm{kW} * \mathrm{P}_{\mathrm{B}}+\$ 354 / \mathrm{kWh} * \mathrm{E}_{\mathrm{B}}+\$ 5,982$

- Where $\mathrm{P}_{\mathrm{B}}=$ battery power capacity $(\mathrm{kW})$ and $\mathrm{E}_{\mathrm{B}}=$ battery energy storage capacity ( $\left.\mathrm{kWh}\right)$

We also develop an algorithm for PV+BESS using the same methodology. We assume the $\mathrm{PV}+\mathrm{BESS}$ is DC-coupled, use PV system sizes of $3.5 \mathrm{~kW}-14 \mathrm{~kW}$, and rerun the bottom-up cost model for the same combinations of BESS power and energy storage capacity. We achieve an excellent fit for all systems by fitting the costs to a linear equation with four constants:

- $\quad \mathrm{PV}+\mathrm{BESS}$ cost $($ total $\$)=\$ 2,440 / \mathrm{kW} * \mathrm{P}_{\mathrm{PV}}+\$ 674 / \mathrm{kW} * \mathrm{P}_{\mathrm{B}}+\$ 329 / \mathrm{kWh} * \mathrm{E}_{\mathrm{B}}+\$ 4,561$

- Where $\mathrm{P}_{\mathrm{PV}}=\mathrm{PV}$ power capacity $(\mathrm{kW})$ 


\subsubsection{BESS Future Cost Projections}

NREL has not maintained future cost projections for residential BESS for the ATB as it has for utility-scale systems. In their absence, we base residential BESS cost projections on the NREL bottom-up cost model for residential systems combined with component cost projections from BNEF. BNEF has published cost projections for a 5-kW/14-kWh BESS system through 2030 (BNEF 2019b), with the projections being based on learning rates and future capacity projections.

The NREL bottom-up model reports component costs at a more detailed level than reported by BNEF. To allow a comparison, the component costs from the NREL model are assigned to the categories used by BNEF (2019b) as shown in Table 4. As mentioned previously, BNEF assumes a flat installation cost of $\$ 2,500$ (BNEF 2019b) and does not include a soft cost categories, so we add that category. Table 4 also shows the learning rates assumed for each category. The learning rates, when combined with installed capacity projections, give the future cost projections by year (BNEF 2019b). We assume a 10\% learning rate for soft costs, which is the same as what is assumed for other hardware and installation costs. Figure 38 (page 52) shows the relative change in costs of the different component categories over time through 2030. Note how the battery component costs decrease more quickly than other components.

Table 4. Assignment of Component Cost Categories from NREL Model to BNEF Component Cost Categories, and Learning Rates Assumed for the Moderate Scenario

\begin{tabular}{|c|c|c|}
\hline $\begin{array}{l}\text { NREL Residential BESS Bottom-Up } \\
\text { Cost Model Component Cost Category }\end{array}$ & $\begin{array}{l}\text { BNEF Residential BESS } \\
\text { Component Cost Category }\end{array}$ & $\begin{array}{l}\text { Learning } \\
\text { Rate }^{\mathrm{a}}\end{array}$ \\
\hline Battery pack & Battery & $18 \%$ \\
\hline Inverter & Inverter & $15 \%$ \\
\hline BOS, supply chain costs & Other hardware & $10 \%$ \\
\hline $\begin{array}{l}\text { Installation labor and equipment } \\
\text { Engineering fee }\end{array}$ & Installation & $10 \%$ \\
\hline $\begin{array}{l}\text { Sales tax } \\
\text { Permitting, inspection, and interconnection } \\
\text { Overhead } \\
\text { Sales and customer acquisition } \\
\text { Profit }\end{array}$ & Soft ${ }^{\mathrm{b}}$ & $10 \%{ }^{b}$ \\
\hline
\end{tabular}




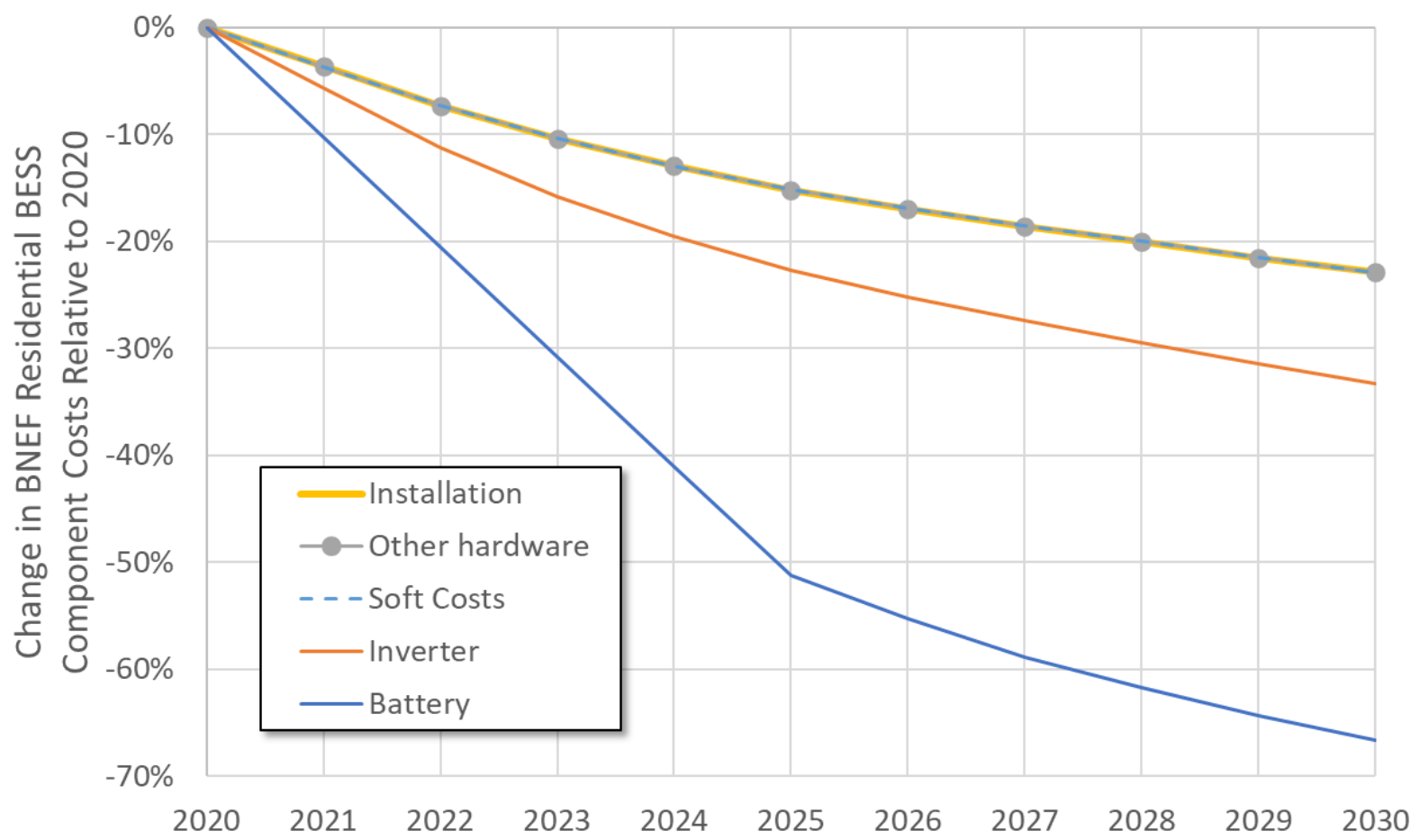

Figure 38. Relative changes in projected component costs for residential BESS

Data Source: (BNEF 2019b)

The following methodology involves the following the steps to generate the Moderate Scenario future cost projections in detail:

1. Estimate current costs for a range of BESS power and energy capacity combinations using the NREL bottom-up residential BESS cost model.

A. Total and component cost results are recorded.

B. Component costs are assigned to categories according to Table 4 .

2. Moderate Scenario: For each future year, apply cost reductions.

A. Apply cost reductions from the BNEF projections (Figure 38) to the corresponding component cost category for each BESS considered.

B. BNEF projections only go to 2030 . We assume residential BESS component costs decline by an additional $25 \%$ from 2030 to 2050 , similar to the assumption used in the ATB utility-scale BESS cost projections (Cole and Frazier 2020).

3. Advanced and Conservative Scenarios: Apply cost projections from the corresponding ATB utility-scale BESS scenario to all component costs.

4. Sum the component costs to get the total BESS cost in future years. For each future year, develop a linear correlation relating BESS costs to power and energy capacity:

A. BESS cost (total $\$)=\mathrm{c}_{\mathrm{a}} * \mathrm{P}_{\mathrm{B}}+\mathrm{c}_{2} * \mathrm{E}_{\mathrm{B}}+\mathrm{c}_{3}$

B. Where $P_{B}=$ battery power capacity $(\mathrm{kW})$ and $\mathrm{E}_{\mathrm{B}}=$ battery energy storage capacity $(\$ / \mathrm{kWh})$, and $\mathrm{c}_{\mathrm{i}}=$ constants specific to each future year 
Figure 39 show BESS cost projections from BNEF (2019b) and Schmidt et al. (2018) compared to the SFS scenarios. As indicated above, note the significant disparity due to the inclusion of soft costs by NREL and the exclusion by the other organizations. The BNEF and SFS curves assume a 5-kW/14-kWh BESS; Schmidt et al. do not identify the size of the system. BESS costs depend on both system power and energy capacity, so comparisons of studies should be made using the same system size. The Schmidt et al. costs are higher than BNEF cost projections initially, but they converge around 2030. Schmidt et al. report both learning rates and installed capacity assumptions. For example, Schmidt et al. project residential BESS costs of $\$ 401 / \mathrm{kWh}$ assuming $285 \mathrm{GWh}$ installed worldwide capacity in 2030 and $\$ 251 / \mathrm{kWh}$ in 2050 assuming $2+$ GWh installed capacity (Schmidt et al. 2018). Both SFS scenarios are higher in costs than the literature data. This is due to the inclusion of larger soft costs in the NREL model when compared to BNEF data. Further inquiries to Schmidt et al. indicate that they do include soft costs in their BESS costs. However, as discussed above, US soft costs are typically much larger than either global or European soft costs and that translates into these values. As discussed in Section 2.4, the definition of what is included in the overall system cost is critical and currently is not handled consistently across the globe nor are specific US prices always defined (which should be higher with soft costs included). Note that many analyses might use any of these current and future costs for analyses and come back with significantly different results.

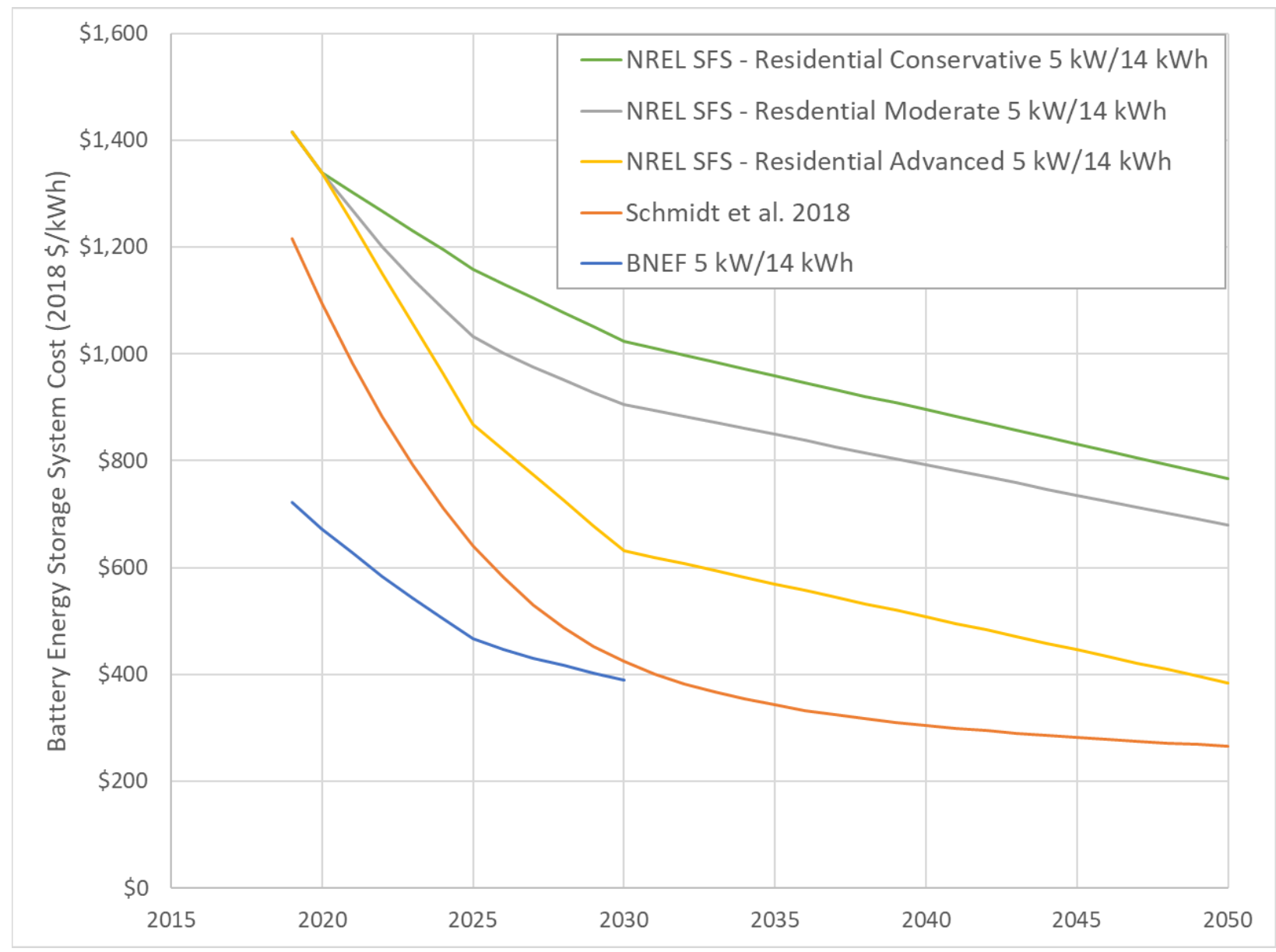

Figure 39. Comparison of BNEF and Schmidt et al. (2018) residential BESS installed costs Storage Futures Study scenarios with time on a $\$ / \mathbf{k W h}$ basis 
BNEF and NREL curves assume a 5-kW/14-kWh BESS. Schmidt et al. does not specify a system size.

\subsubsection{PV+BESS Future Costs}

Future costs for DC-coupled PV+BESS are developed using the same methodology as for standalone systems and including the costs for PV from the NREL bottom-up model (Feldman et al. 2021) as described in the section on PV+BESS current costs (Section 3.3.1), including cost savings from combining systems. Future cost projections for the PV portion of the system costs are calculated using the cost projections for residential PV in the 2020 ATB (National Renewable Energy Laboratory (NREL) 2020). The ATB Moderate and Advanced cost projections are applied to the PV cost component in future years in the SFS Moderate and Advanced Scenarios, respectively.

\subsection{Commercial and Industrial BESS}

Commercial and industrial BESS range in power capacity from tens of kilowatts to more than a megawatt. We estimate commercial and industrial BESS costs in the same way we estimate residential BESS: using an NREL bottom-up BESS cost model to estimate current costs and using projections from NREL (the ATB) and BNEF to make future cost projections.

\subsubsection{Current Costs}

Current costs for commercial and industrial BESS are based on NREL's bottom-up BESS cost model using the data and methodology in Feldman et al. (2021). That study estimated costs for a $600-\mathrm{kW}_{\text {DC }}$ stand-alone BESS with $0.5-4.0$ hours of storage. We use the same model and methodology but do not restrict the power and energy capacity of the BESS. Feldman et al. assumed an inverter/storage ratio of 1.67 based on guidance from Denholm, Eichman, and Margolis (2017). We adopt this assumption, too. Key modeling assumptions and inputs are shown in Table 5. Because we do not have battery costs that are specific to commercial and industrial BESS, we use the battery pack costs from Feldman et al. (2021), which vary depending on the battery duration. These battery costs are close to our assumptions for battery pack costs for residential BESS at low storage duration and for utility-scale battery costs for utility-scale BESS at long durations. The underlying battery costs in Feldman et al. come from BNEF (2019b) and should be consistent with battery cost assumptions for the residential and utilityscale markets.

Table 5. Commercial and Industrial LIB Energy Storage Systems: 2019 Model Inputs and Assumptions (in 2018 USD)

\begin{tabular}{lll}
\hline Model Component & Modeled Value & Description \\
\hline System size & $\begin{array}{l}60-1,200 \mathrm{kWDC} \\
\text { power capacity } \\
0.5-4 \text { E/P ratio }\end{array}$ & $\begin{array}{l}\text { Battery capacity is in } \mathrm{kWDC} \\
\text { E/P is battery energy to power ratio and is synonymous } \\
\text { with storage duration in hours }\end{array}$ \\
\hline LIB price & $\begin{array}{l}0.5-\mathrm{hr}: \$ 242 / \mathrm{kWh} \\
1-\mathrm{hr}: \$ 223 / \mathrm{kWh}\end{array}$ & Ex-factory gate (first buyer) prices (Feldman et al. 2021) \\
& $\begin{array}{l}2-\mathrm{hr}: \$ 198 / \mathrm{kWh} \\
4-\mathrm{hr}: \$ 194 / \mathrm{kWh}\end{array}$ & \\
\hline Inverter/storage ratio & 1.67 & $\begin{array}{l}\text { Ratio of inverter power capacity to storage battery } \\
\text { capacity (Denholm, Eichman, and Margolis 2017) }\end{array}$ \\
& &
\end{tabular}




\begin{tabular}{lll}
\hline Model Component & Modeled Value & Description \\
\hline $\begin{array}{l}\text { Battery central } \\
\text { inverter price }\end{array}$ & $\$ 60 / \mathrm{kW}$ & Ex-factory gate (first buyer) prices \\
\hline
\end{tabular}

We also consider the installation of commercial and industrial PV systems combined with BESS (PV+BESS) systems (Figure 40). Costs for commercial and industrial PV systems come from NREL's bottom-up PV cost model (Feldman et al. 2021). We assume an inverter/load ratio of 1.3 , which when combined with an inverter/storage ratio of 1.67 sets the BESS power capacity at $60 \%$ of the installed PV capacity. As with residential PV+BESS, we include cost savings for a combined PV and battery storage system. We assume the electrical BOS and installation labor are $90 \%$ of what they would be if the systems were installed separately. We also assume the sales and marketing costs for PV+BESS include 20 additional hours for a DC-coupled system and 32 additional hours for an AC-coupled system than they would be for a PV-only system installation.

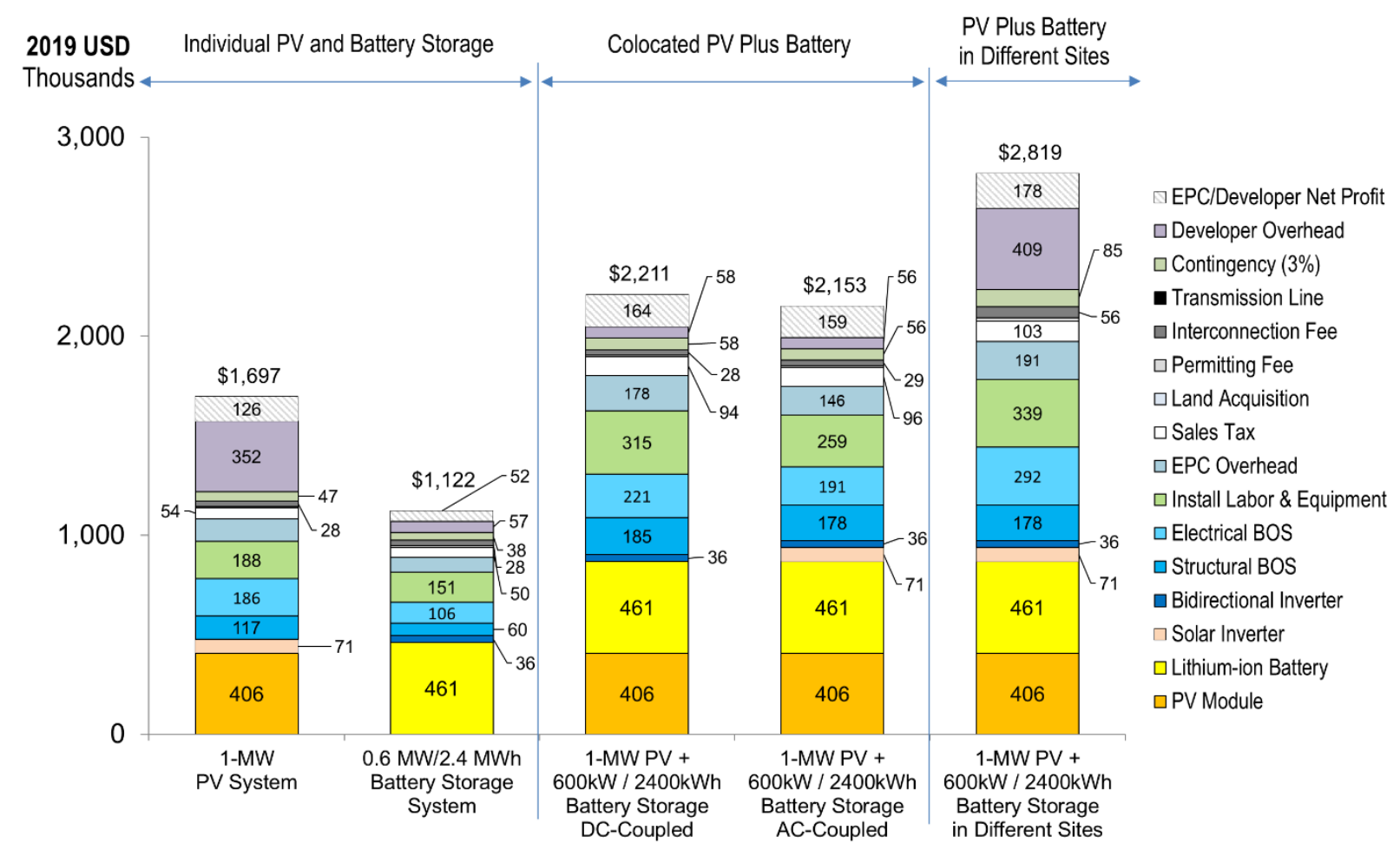

Figure 40. Estimated costs of commercial and industrial stand-alone PV, stand-alone BESS, and PV+BESS using NREL bottom-up model

\subsubsection{Future Cost Projections}

Future cost projections for commercial and industrial BESS and PV+BESS are made using the same methodology as is used for residential BESS and PV+BESS. The normalized cost reduction projections for LIB packs used in residential BESS by BNEF (2019b) are applied to future battery costs, while cost reductions for other BESS components use the same cost reduction potentials in Figure 38 (page 52). Costs for commercial and industrial PV systems come from the 2020 ATB Moderate and Advanced Scenarios (National Renewable Energy Laboratory (NREL) 2020). We could not find projected costs for commercial and industrial BESS in the literature for comparison. 


\section{Pumped-Storage Hydropower Inputs to ReEDS}

In this section, we estimate the resource potential and current and projected cost for pumpedstorage hydropower (PSH). As noted in Section 2.4.2 (page 14), PSH currently has far more installed capacity in the United States and worldwide than any other energy storage technology. Existing PSH deployments in the United States total 22.2 GW. However, most PSH plants in the United States were constructed from the 1960s to the 1980s and deployments have slowed dramatically in recent decades (DOE 2016). The decline in new PSH projects in recent years has produced a dearth of data on PSH costs, making estimates of current and future costs uncertain.

PSH is location-restricted due to hydrology and topography. Therefore, the resource potential analysis from the DOE HydroVision study (DOE 2016) is used; that study considered two types of PSH resource: natural and artificial. The natural resource consists of existing, identified resources and is derived from all PSH projects proposed to the Federal Energy Regulatory Commission (FERC) since 1980. In total, there is 108.7 GW FERC-based PSH resource (Figure 41, page 57). This is a lower bound, as it does not include potential sites that have not submitted applications to FERC or sites that do not need FERC authorization. In theory, a closed-loop PSH configuration (using two human-made reservoirs unconnected to existing bodies of water) can be built anywhere there is sufficient elevation change. A study of PSH potential based on physical geography found over 1,000 GW of resource (U.S. Army Corps of Engineers 1981). To recognize this unknown resource potential and prevent over-constraining PSH expansion in regions without FERC applications, the HydroVision study (DOE 2016) assumed there is an "artificial" PSH resource potential. The HydroVision study also used the ReEDS model and implemented their assumption by including $750 \mathrm{MW}$ of artificial closed-loop PSH resource potential in every ReEDS balancing area. This resulted in $100.5 \mathrm{GW}$ of artificial PSH resource in ReEDS. $^{21}$

The cost of developing PSH projects is site-specific. Each project has unique topography and site development challenges to consider. Capital costs for natural PSH resources identified through FERC applications are based on O'Connor et al. (2015) and include site-specific estimates. The artificial PSH resource is assumed to have a capital cost of $\$ 3,500 / \mathrm{kW}$, following the assumption used in the HydroVision report (DOE 2016) and is near the upper bound of greenfield PSH resource, which is sized at $750 \mathrm{MW}$ (Figure 42, page 57). For the Moderate Scenario, we assume smaller cost reductions of 5\% by 2035 and $9 \%$ by 2050. For the Advanced Scenario, cost reductions of $12 \%$ by 2035 and $15 \%$ by 2050 are assumed. These assumptions are consistent with those used in the DOE HydroVision study.

PSH fixed O\&M costs of 2\%/year of the initial capital cost are also based on O'Connor et al. (2015), and RTE is assumed to be $80 \%$ for all existing and new capacity. In ReEDS, PSH is assumed to have sufficient storage to operate as needed within the diurnal variations represented in the model. ReEDS assumes of 12 hours for PSH duration for existing storage capacity.

\footnotetext{
${ }^{21}$ Detailed geographic information system-based assessment to refine the resource estimates is ongoing at NREL and is expected to be available for future analyses in 2022 .
} 


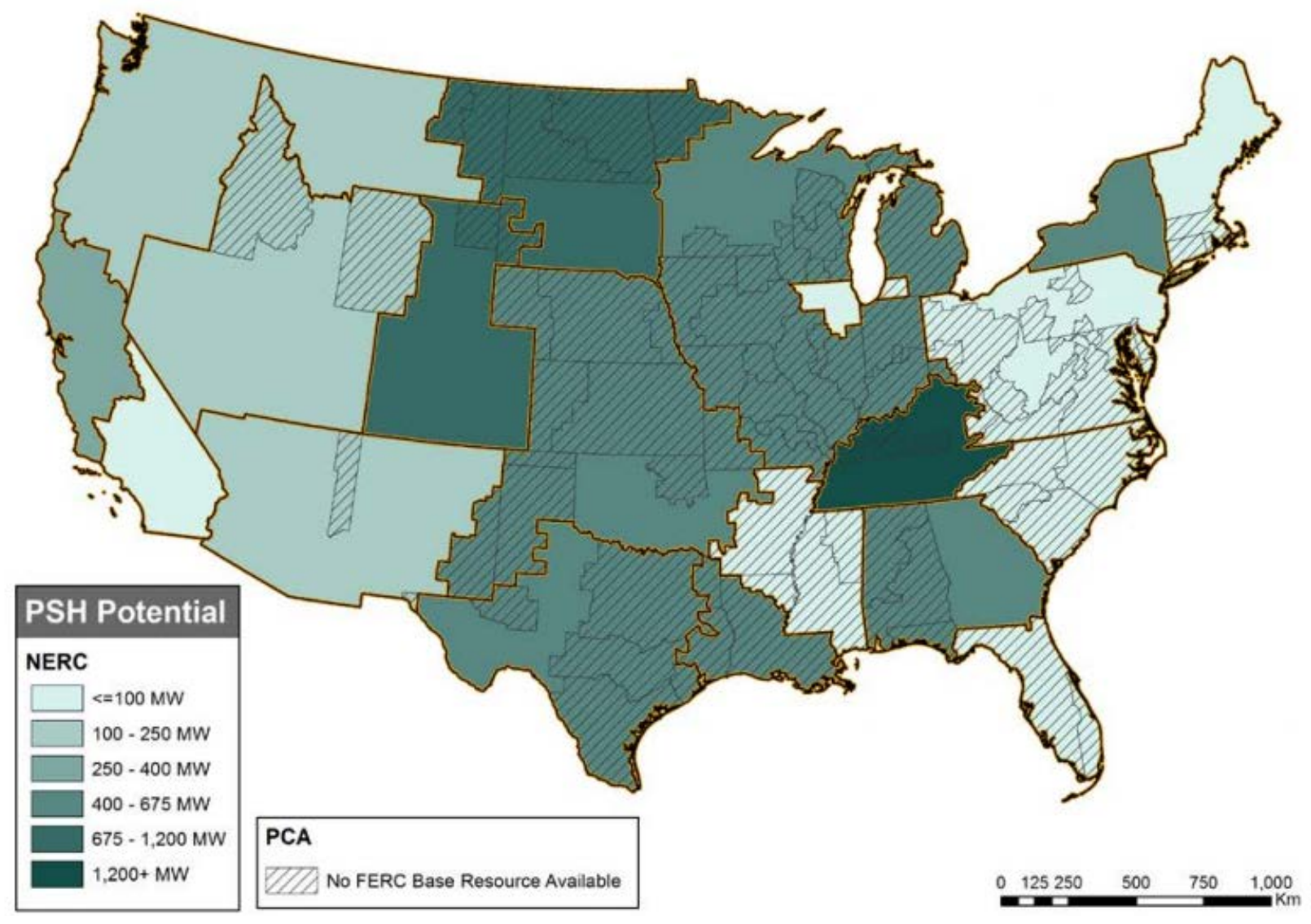

Figure 41. Modeled new PSH resource potential

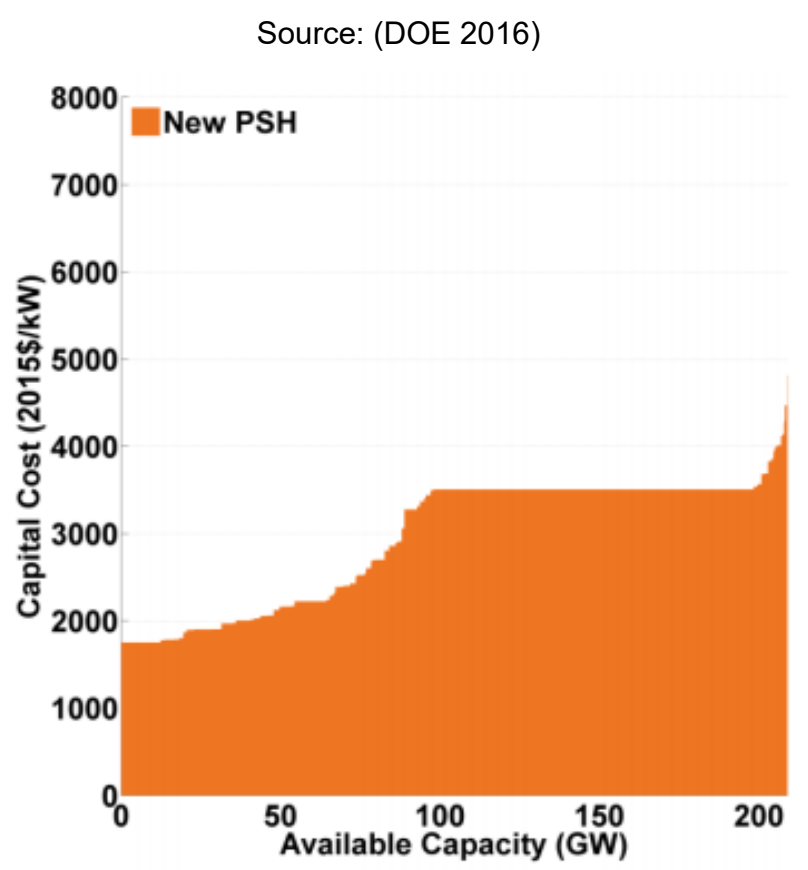

Figure 42. National PSH supply curve of capital cost versus cumulative capacity potential Source: (DOE 2016) 


\section{Conclusions}

The demand for energy storage is growing. This can be seen not only in the increasing number of utility-scale and behind-the-meter energy storage installations, but also in the increasing interest in new and existing energy storage technologies. This study summarized a variety of mature and emerging energy storage technologies with storage durations ranging from minutes to months. It quantified the current or anticipated costs of those technologies, recognizing that energy storage technologies must be described in terms of both their power capacity $(\mathrm{kW})$ and energy capacity $(\mathrm{kWh})$ to assess their costs and potential use cases.

We observed that energy storage systems whose total costs are dominated by power component costs $(\$ / \mathrm{kW})$ are better suited for longer-term energy storage and those dominated by energy (storage) component costs $(\$ / \mathrm{kWh})$ should be used for shorter-term energy storage. We illustrated this by comparing total system costs as a function of storage duration and storage power. From this comparison, we observe the points where high energy component costs increase with storage duration to drive the cost of technologies like batteries beyond the cost of technologies with high power component costs but little duration costs (like PSH, hydrogen storage or PTES). We also noted how cost alone does not determine the market for energy storage technologies; historical or low levels of PV on the grid result in a smaller grid storage market while high levels of variable renewables and specifically solar are anticipated to create a market for 4-hour and even longer-duration energy storage.

The second part of this report describes the current and future cost projections for energy storage technologies used in the modeling done in the broader Storage Futures Study. The modeling uses LIBs and PSH to fill any energy storage demand. These are commercially available technologies that are low-cost options both now and, in the future, based on projections.

Because the energy models consider only a few parameters such as cost, storage duration, and capacity factor, the inputs can function as a proxy for any technology with similar performance. Current costs for LIB were estimated from NREL bottom-up models, and future costs were derived from ATB projections and data from BNEF. Those projections rely on learning rates to estimate costs as a function of installed capacity. The same underlying battery pack cost data are used for utility-scale, commercial/industrial, and residential BESS cost projections so that the projections across markets are internally consistent. Our analysis projects that LIB will continue to be the low-cost leader among diurnal energy storage technologies. However, with many entrants and innovative ideas being researched daily, one or more breakthroughs or steady incremental improvements could lead to technologies other than LIBs capturing a share of the market. Finally, energy storage technologies (LIB in particular) have costs and performance that are rapidly changing, so this report may not reflect current values. The reader is encouraged to check for updated information before using the values and conclusions in this report. 


\section{References}

Bloomberg New Energy Finance (BNEF). 2019a. "2019 Long-Term Energy Storage Outlook.” https://www.bnef.com/core/insights/21113. . 2019b. "Energy Storage System Costs Survey 2019."

Cole, Wesley, and Will Frazier. 2020. "Cost Projections for Utility-Scale Battery Storage: 2020 Update.” NREL/TP-6A20-75385. Golden, CO: National Renewable Energy Laboratory. https://www.nrel.gov/docs/fy20osti/75385.pdf.

Denholm, Paul, Wesley Cole, A. Will Frazier, Kara Podkaminer, and Nate Blair. 2021. "The Four Phases of Storage Deployment: A Framework for the Expanding Role of Storage in the U.S. Power System." NREL/TP-6A20-77480. Golden, CO: National Renewable Energy Laboratory. https://www.nrel.gov/docs/fy21osti/77480.pdf.

Denholm, Paul, Josh Eichman, and Robert Margolis. 2017. "Evaluating the Technical and Economic Performance of PV Plus Storage Power Plants." NREL/TP-6A20-68737. https://www.nrel.gov/docs/fy17osti/68737.pdf.

Desrues, T., J. Ruer, P. Marty, and J.F. Fourmigué. 2010. "A Thermal Energy Storage Process for Large Scale Electric Applications." Applied Thermal Engineering 30 (5): 425-32. https://doi.org/10.1016/j.applthermaleng.2009.10.002.

DOE. 2011. "Technology Readiness Assessment Guide." DOE G 413.3-4A. Washington, D.C.: U.S. Department of Energy. https://www.directives.doe.gov/directives-documents/400series/0413.3-EGuide-04a.

—. 2016. "Hydropower Vision: Full Report." DOE/GO-102016-4869. U.S. Department of Energy. https://doi.org/10.2172/1330494.

Electric Power Research Institute (EPRI). 2018. "Energy Storage Technology and Cost Assessment: Executive Summary.” 3002013958. http://membercenter.epri.com/abstracts/Pages/ProductAbstract.aspx?ProductId=0000000 03002013958.

Energy Sector Management Assistance Program (ESMAP). 2019. "Mini Grids for Half a Billion People : Market Outlook and Handbook for Decision Makers." ESMAP Technical Report 014/19. Washington, D.C.: World Bank. http://hdl.handle.net/10986/31926.

Feldman, David, Vignesh Ramasamy, Ran Fu, Ashwin Ramdas, Jal Desai, and Robert Margolis. 2021. "U.S. Solar Photovoltaic System and Energy Storage Cost Benchmark: Q1 2020." NREL/TP-6A20-77324. Golden, CO: National Renewable Energy Laboratory. https://www.nrel.gov/docs/fy21osti/77324.pdf.

Frith, James, and Logan Goldie-Scot. 2019. "2019 Lithium-Ion Battery Price Survey." Bloomberg New Energy Finance.

Gupta, Mitalee. 2019. "Solar-Plus-Stoarge System Architectures Design, Pricing and Economics in U.S." Wood Mackenzie Power \& Renewables.

Hunter, Chad, Michael Penev, Evan P. Reznicek, Joshua Eichman, Neha Rustagi, and Samuel F. Baldwin. 2020. "Techno-Economic Analysis of Long-Duration Energy Storage and Flexible Power Generation Technologies to Support High Variable Renewable Energy Grids." SSRN Electronic Journal. https://doi.org/10.2139/ssrn.3720769.

Igogo, Tsisilile, Debra Sandor, Ahmad Mayyas, and Jill Engel-Cox. 2019. "Supply Chain of Raw Materials Used in the Manufacturing of Light-Duty Vehicle Lithium-Ion Batteries." NREL/TP-6A20-73374. Golden, CO: Clean Energy Manufacturing Analysis Center, National Renewable Energy Laboratory. https://www.nrel.gov/docs/fy19osti/73374.pdf. 
Laughlin, Robert B. 2017. "Pumped Thermal Grid Storage with Heat Exchange." Journal of Renewable and Sustainable Energy 9 (4): 044103. https://doi.org/10.1063/1.4994054.

McTigue, Joshua D., P. Farres-Antunez, K. Ayyanathan, C. Markides, and A. White. In Press. "Techno-Economic Analysis of Recuperated Joule-Brayton Pumped Thermal Energy Storage (PTES)." Applied Energy.

McTigue, Joshua D., Alexander J. White, and Christos N. Markides. 2015. "Parametric Studies and Optimisation of Pumped Thermal Electricity Storage." Applied Energy 137 (January): 800-811. https://doi.org/10.1016/j.apenergy.2014.08.039.

Mongird, Kendall, Vilayanur V. Viswanathan, Jan Alam, Charlie Vartanian, Vincent Sprenkle, and Richard Baxter. 2020. "2020 Grid Energy Storage Technology and Cost Performance Assessment.” DOE/PA-0204.

https://www.pnnl.gov/sites/default/files/media/file/Final\%20\%20ESGC\%20Cost\%20Performance\%20Report\%2012-11-2020.pdf.

Mongird, Kendall, Vilayanur V. Viswanathan, Patrick J. Balducci, Md Jan E. Alam, Vanshika Fotedar, V. S. Koritarov, and Boualem Hadjerioua. 2019. "Energy Storage Technology and Cost Characterization Report." PNNL-28866. Pacific Northwest National Lab. (PNNL), Richland, WA (United States). https://doi.org/10.2172/1573487.

Morandin, Matteo, Mehmet Mercangöz, Jaroslav Hemrle, François Maréchal, and Daniel Favrat. 2013. "Thermoeconomic Design Optimization of a Thermo-Electric Energy Storage System Based on Transcritical CO2 Cycles." Energy 58 (September): 571-87. https://doi.org/10.1016/j.energy.2013.05.038.

National Renewable Energy Laboratory (NREL). 2020. "2020 Annual Technology Baseline." Golden, CO: National Renewable Energy Laboratory. https://atb.nrel.gov/.

O'Connor, Patrick W., Qin Fen Zhang, Scott T. DeNeale, Dol Raj Chalise, and Emma E. Centurion. 2015. "Hydropower Baseline Cost Modeling." ORNL/TM--2015/14, 1185882. Oak Ridge National Laboratory. https://doi.org/10.2172/1185882.

Pesaran, A. A., G. H. Kim, and M. Keyser. 2009. "Integration Issues of Cells into Battery Packs for Plug-in and Hybrid Electric Vehicles: Preprint." NREL/CP-540-45779. National Renewable Energy Lab. (NREL), Golden, CO (United States). https://www.osti.gov/biblio/953833-integration-issues-cells-battery-packs-plug-hybridelectric-vehicles-preprint.

Schmidt, Oliver. 2018. "Levelized Cost of Storage: Gravity Storage.” Imperial College London Consultants. https://heindl-energy.com/wpcontent/uploads/2018/10/LCOS_GravityStorage-II-Okt-2018.pdf.

Schmidt, Oliver, A. Hawkes, A. Gambhir, and I. Staffell. 2017. "The Future Cost of Electrical Energy Storage Based on Experience Rates.” Nature Energy 2 (8): 17110. https://doi.org/10.1038/nenergy.2017.110.

Schmidt, Oliver, Sylvain Melchior, Adam Hawkes, and Iain Staffell. 2018. "Update 2018 - The Future Cost of Electrical Energy Storage Based on Experience Rates." Figshare. https://doi.org/10.6084/M9.FIGSHARE.7012202. . 2019. "Projecting the Future Levelized Cost of Electricity Storage Technologies." Joule 3 (January). https://doi.org/10.1016/j.joule.2018.12.008.

Steinmann, W.D. 2014. "The CHEST (Compressed Heat Energy STorage) Concept for Facility Scale Thermo Mechanical Energy Storage.” Energy 69 (May): 543-52. https://doi.org/10.1016/j.energy.2014.03.049. 
U.S. Army Corps of Engineers. 1981. "National Hydroelectric Power Resources Study Vol X: An Assessment of Hydroelectric Pumped Storage.” IWR-82-H-10. Washington, D.C.: Department of the Army Corps of Engineers Institute for Water Resources. https://www.iwr.usace.army.mil/Portals/70/docs/iwrreports/IWR019-000001-000517.pdf. U.S. Energy Information Administration (EIA). 2019. "Most Pumped Storage Electricity Generators in the U.S. Were Built in the 1970s." Today in Energy (blog). October 31, 2019. https://www.eia.gov/todayinenergy/detail.php?id=41833\#.

Wood Mackenzie P\&R/ESA. 2020. "U.S. Energy Storage Monitor 2019 Year in Review.” Wood Mackenzie Power \& Renewables/ESA U.S. Energy Storage Monitor. https://www.woodmac.com/reports/power-markets-us-energy-storage-monitor-2019year-in-review-393355/. 


\section{Appendix A. Energy Storage Technology Data}

Table 6. Energy Storage Technology Data

\begin{tabular}{|c|c|c|c|c|c|c|c|c|c|c|c|}
\hline Technology Abbrev. & $\begin{array}{l}\text { Capital } \\
\text { Costs } \\
\text { (Energy) } \\
\text { (\$/kWh) }\end{array}$ & $\begin{array}{l}\text { Capital } \\
\text { Costs } \\
\text { (Power) } \\
\text { (\$/kw) }\end{array}$ & $\begin{array}{l}\text { Variable } \\
\text { O\&M } \\
\text { (\$/MWh) }\end{array}$ & $\begin{array}{l}\text { Fixed } \\
\text { O\&M } \\
(\$ / k W-y r)\end{array}$ & $\begin{array}{l}\text { Round-trip } \\
\text { Efficiency } \\
\text { (DOD) }\end{array}$ & $\begin{array}{l}\text { Cycles } \\
\text { (at 80\% } \\
\text { DOD) }\end{array}$ & $\begin{array}{l}\text { \# of } \\
\text { cycles } \\
\text { per year }\end{array}$ & $\begin{array}{l}\text { Depth of } \\
\text { discharge } \\
\text { (DOD) }\end{array}$ & $\begin{array}{l}\text { Project } \\
\text { lifetime } \\
\text { (years) }\end{array}$ & $\begin{array}{l}\text { WACC } \\
\text { used for } \\
\text { LCOS }\end{array}$ & $\begin{array}{l}\text { Approx. } \\
\text { LCOS }\end{array}$ \\
\hline
\end{tabular}

\begin{tabular}{|c|c|c|c|c|c|c|c|c|c|c|c|}
\hline Flywheel (2018) & 11520 & 0 & 30 & 5.60 & 0.86 & 200000 & 660 & 1 & 20 & 0.065 & 1.832 \\
\hline Ultracapacitors (2018) & 74480 & 0 & 30 & 1.00 & 0.92 & 1000000 & 660 & 1 & 16 & 0.065 & 12.578 \\
\hline LEAD (2018) & 352 & 137 & 0.5125 & 5.11 & 0.72 & 900 & 660 & 1 & 3 & 0.065 & 0.707 \\
\hline LIB -4 hour (2020) & 320 & 246 & 0.5125 & 10 & 0.86 & 3500 & 330 & 0.8 & 10 & 0.065 & 0.254 \\
\hline FLOW (2018) & 483 & 137 & 0.5125 & 5.89 & 0.68 & 10000 & 330 & 1 & 15 & 0.065 & 0.277 \\
\hline Sodium Sulfur (2018) & 794 & 450 & 0.3 & 10.00 & 0.75 & 4000 & 330 & 0.8 & 13.5 & 0.065 & 0.543 \\
\hline $\begin{array}{l}\text { Sodium Metal Halide } \\
\text { (2018) }\end{array}$ & 815 & 450 & 0.3 & 10.00 & 0.83 & 3500 & 330 & 1 & 12.5 & 0.065 & 0.425 \\
\hline $\begin{array}{l}\text { Zinc-Hybrid Cathode } \\
(2018)\end{array}$ & 438 & 450 & 0.3 & 10.00 & 0.72 & 3500 & 330 & 1 & 10 & 0.065 & 0.346 \\
\hline CAES (2020) & 3.66 & 1153 & 0.5125 & 16.12 & 0.52 & 1 & 330 & 1 & 25 & 0.065 & 0.096 \\
\hline LAES (anticipated) & 450 & 3500 & 3.3 & 48.70 & 0.60 & 10000 & 330 & 1 & 25 & 0.065 & 0.348 \\
\hline PTES (anticipated) & 37 & 1836 & 3.3 & 48.70 & 0.56 & 10000 & 330 & 1 & 25 & 0.065 & 0.116 \\
\hline PSH (2020) & 72.4 & 1150.8 & 0.5125 & 26.62 & 0.80 & 15000 & 52 & 1 & 40 & 0.065 & 0.237 \\
\hline Gravity (anticipated) & 337.00 & 692 & 0 & 6.12 & 0.80 & 200000 & 52 & 1 & 25 & 0.065 & 0.771 \\
\hline $\begin{array}{l}\text { H2 elec-cavern- CC } \\
(2020)\end{array}$ & 3.8 & 7350.59 & 9.4 & 29.7 & 0.27 & 10000 & 52 & 1 & 30 & 0.065 & 2.486 \\
\hline $\begin{array}{l}\mathrm{H} 2 \text { elec-cavern- FC } \\
\text { (Future) }\end{array}$ & 3.8 & 1675.31 & 4.9 & 27.0 & 0.37 & 10000 & 52 & 1 & 30 & 0.065 & 0.410 \\
\hline
\end{tabular}




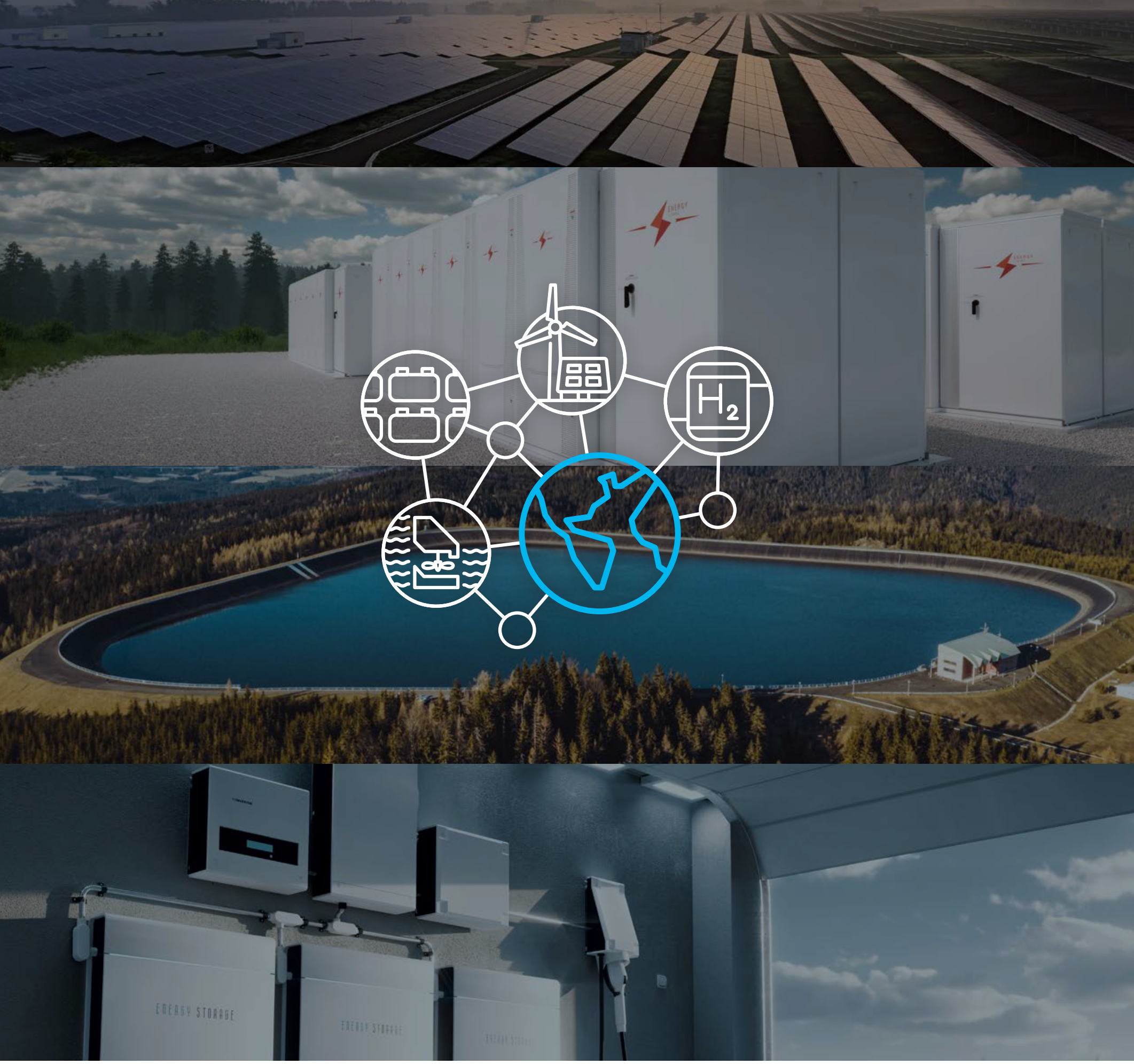

National Renewable Energy Laboratory

15013 Denver West Parkway, Golden, CO 80401 303-275-3000 • www.nrel.gov

NREL prints on paper that contains recycled content.
NREL is a national laboratory of the U.S. Department of Energy Office of Energy Efficiency and Renewable Energy Operated by the Alliance for Sustainable Energy, LLC NREL/TP-5700-78694 • May 2021 